\title{
The Nature of Enticement
}

Biophilic Design in the Urban Setting

Molly Williams 
The Nature of Enticement

Biophilic Design in the Urban Setting

Molly Emily Hamilton Williams

A 120 point thesis submitted to the School of Architecture \& Design, Victoria University of Wellington, in fulfiliment of the requirements for the degree of Masters in Architecture (Prof)
Victoria University of Wellington 2017 
Thank you;

To my exceptional parents for your unyielding love and support; you will never know the lengths that your love has propelled met

To my big brother, always setting the bar high and encouraging me to strive for greatness.

Mum, Dad, Thomas and Anne, you are my four pillars, without whom I could not stand. I hope I have made you all as proud as I am to have you in my life.

To the family of classmates that have endured alongside me since year one. Thank you for reminding me I am young.

Finally, Maibritt, for your patience and time in my education.

Your guidance, knowledge and passion are to be admired and have been invaluable throughout this journey. 
"... the enjoyment of scenery employs the mind without fatigue and yet exercises it, tranquilize it and yet enlivens it; and thus, through the

influence of the mind over the body, gives the effect of refreshing rest and reinvigoration to the whole system.

(Olmested, 1865) 
My two preoccupations in life, well-being and

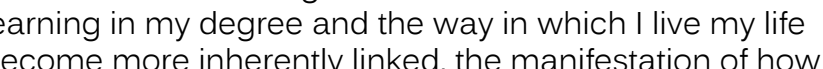
articulate treatment of the mind, body and soul comes from the designed built environment. My motivation then is derived from function and harmony, both of which can wersonal ell-being and architecture.

Our habitual connection to nature and natural concepts ensure an unse the built environment. With the process of densification and urbanisation in the past, society has successfully protected itself from harsh natural elements and has conveniently positioned cities to aid urban dwelling, but what they have also succeeded at doing is constructing a barrier between people and the neurologically

Due to this separation from and exclusion of simple necessities such as sunlight and direct contact with other living organisms, illnesses and diseases of the body have increasingly become commonplace, such as experiencing headaches whilst working in the office and leaving work at $5 \mathrm{pm}$ feeling fatigued and nauseous.

The proposal is to investigate how biophilic design can contribute to a healthy lifestyle through the strategic
design of common workspaces that a majority of the population will come in contact with. Utilising design as a mechanism for preventative medical assistance should be implicated in our everyday environment, not just in our health facilities where the negalive effects of disconnected living has already taken its tol.
As the world's population rapidly becomes significantly adapted living can also become a barier betwe un humans and the living ecosystems they are a part of and that urbanisation in its current form, which tends to entail a disconnection with nature is having negative impacts on the minds and bodies of residents (such as excessive stress, headaches and fatigue).

This thesis explores the theories of biophilia and how architects can respond to the adverse effects of The research investigates how to invite people into designed spaces that connect them with the immediate ecosystem, the outcomes that are felt on the mind and body. Specifically, biophilic principles and the articulatio of the nature of a space is explored regarding their

and restoring cognitive functions, to potentially ignite ripple effect that can change the way in which we live our daily lives in urban settings.

Wellington, New Zealand has been identified as a global biophilic city and is the chosen site for this designled thesis, which tests how an area largely devoid of nature can be redesigned and used in a positive way to to further enhance the connections made between the existing biophilic interventions and ultimately improve the holistic health of those who experience the urban setting.

A set of biophilic criteria are developed and used in he design, with the outcome of this design exploration being a collaborative Ecologies Design Lab where can come together for the collective goal of forwarding urban biophilic practice research In addition to this, the intervention is designed to encourage the public to interact with the building, widening the scope of the building and targeted demographic. The investigation of aspects in biophilic design and how this can draw people through and beyond the immediate site to existing biophilically alive spots in other parts of the city theories such as narrative design, interior architecture principles, landscape architecure and founding

journey throughout the city intent on initiating the healing process that occurs as people experience a connection with nature, either literally or metaphorically. 


\section{Table Of Contents}

Molly Williams

The Nature of Enticement

Acknowledgements

Preface

Abstract

Introduction

1.1 - Human psychological well-being and the living world (biophilia)

1.2 - Research Question

1.3 - Scope

1.4 - Aims and Objectives

1.5 - Methodology

2.0

Biophilia in time:

from marco to micro

\section{1 - International Network}

2.2 - Wellington Network

2.3 - Biophilic Map of Wellington

2.4 - Local Transect

2.5 - Site Situation

2.6- Taranaki Street Transect

A shift in relating to nature

3.1 - Theorists Overview

3.2 - 14 Patterns of Biophilic Design

Design led research;

process \& reflections

4.1- Establsihment + Quickstart

4.2- Urban Acupuncture

4.4- Critical Reflection
2 6
8
Experimentation

5.1- Expresion of Enticemen

5.2- Spatial Characteristics of Enticement

5.3- Programatic Plan; An Ecologies Design Lab

49

6.0

6.1- Design Iteration One

6.2 - Design Iteration Two

6.3 - Design Iteration Three

7.0

Refinement + Reflection

7.1 - Ripples of Well-Being

7.2 - Relating to climate and ecology

7.3 - Structural Integrity

8.0

Resolved Design

8.1 - Experiential Journey $\quad 82$

8.2 - Critical Reflection $\quad 110$

9.0

Findings

9.1 Discussion $\quad 114$

9.2 Conclusion $\quad 116$

10.0

Bibliography

10.1 - Works Cited 120

10.2 - Sources of Firgures 124
50
52

56

61

62

64

73

74

76
78

82
10

116 
1.0

Introduction 
As much as urbanisation illustrates how varying more condensed urban lifestyle (for example being able to live 20 minutes from work via walking driving or catching a train). its synthetic make-up and densification has had an adverse effect on residents' holistic health. The number of people living in urban settings has increased from 756 million in 1950 to nearly 4 billion in 2014. The percentage of the worlds $70 \%$ by 2050 (United Nations, 2015) This then poses great reliance on and opportunity for urban planners, designers and architects to create urban settings to not only create a convenient way of living, but also a nourishing one.

At present the prevailing approach to constructing he modern urban built environment has encourage natural ecosystems and increasing separation

between people and the natural world they evolved in. A growing body of evidence supports the notion that alienation from natural biological systems is having adverse effects on humans' holistic health The grounds of this evidence is based on the fact hat humanity's dependence on nature reflects their being created and conditioned in a sensory ich ws where the connection with critical environmental features such as light, sound, odour wind, weather water, vegetation, colour, animals and landscapes is a biological norm (Heerwagen, Kellert, Mador, 2008). Unfortunately, many of these features are overlooked in the majority of urban structures (Pedersen Zari

Humans need nature. This has been made clear through the teachings of such authors like Park (et be triggered by connections with nature that relax muscles, lower blood pressure and reduce stress hormones in the blood stream. This is called biophilia Defined by O.E. Wilson, it is .... the innately emotional affiliation of human beings to oher living organisms, ultimate human nature" (as quoted in Browning 2014)
It addresses the conscious and subconscious addressing work place stress, student performancly and creativity, patient recovery, community cohesiveness, cognitive functions and other challenges that arise from the separation of humans to nature.

Biophilic design is when natural concepts are applied to the built environment in order to create more to cognitive psychological and physiological performance, biophilia is not a single instinct, but "... a complex set of learning rules that can be teased apart and analysed individually. The feelings moulded by the learning rules fall along several emotional spectra from attraction to aversion, from awe to indifference, from peacefulness to fear-driven anxiety" (Kaplan, architects to replicate designed situations that inst the same responses in the built environment that work towards healing people, preventing such a high occurrence of diseases of the mind and body. Although technical and engineering accomplishments have fostered a belief that humans can transcend their natural and genetic heritage, connections

function stimuli hey are essential to a human's
"The best doctors anywhere and no one can deny it are sunshine, water, rest, and air exercise and diet

These six will gladly you attend if only you are willing. Your mind they'll ease. Your will they'll mend.

And charge you not a shilling."

What the River Knows, Wayne Fields 1990 


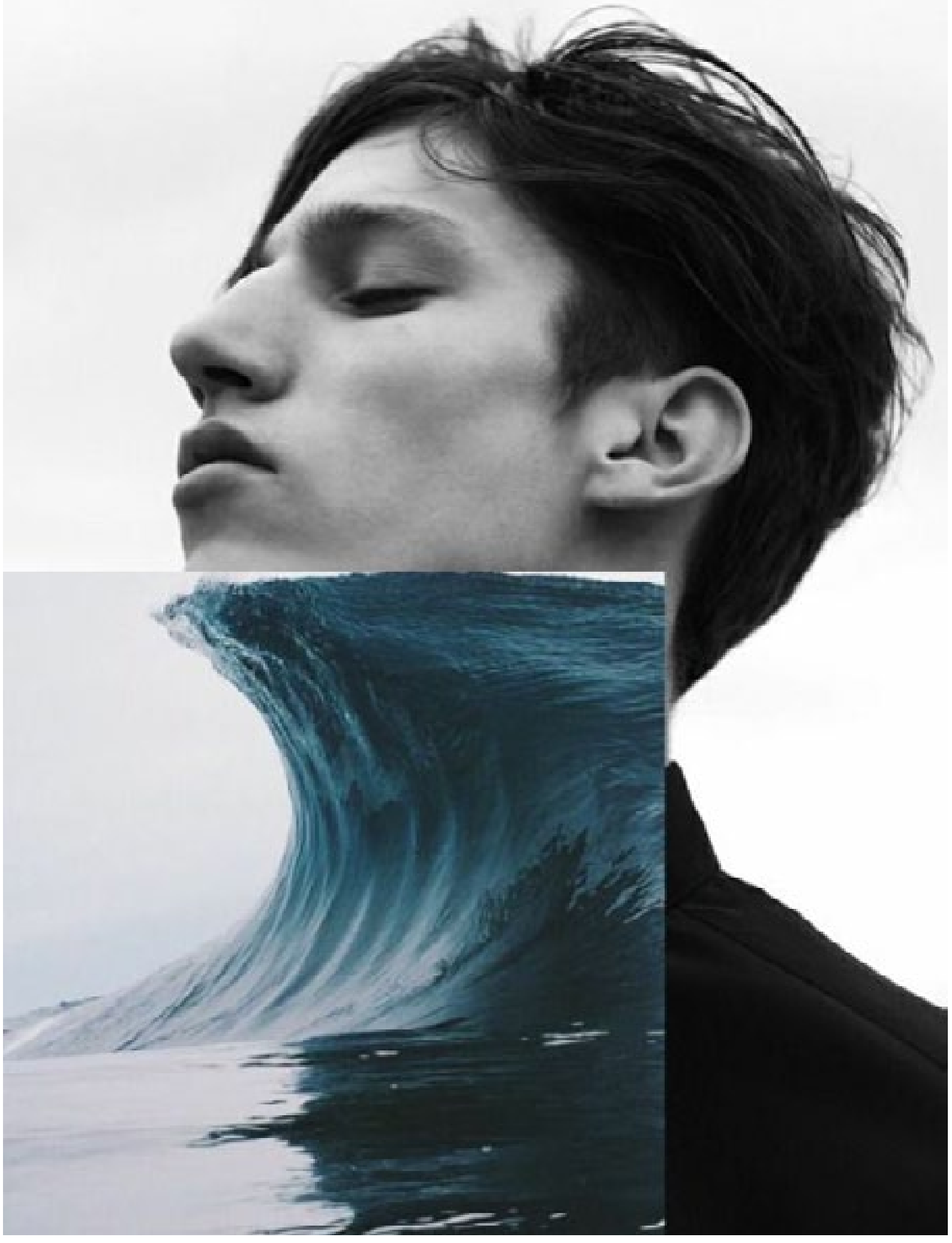

oster and celebrate connections between

people and their surrounding ecosystems

through biophilic design?

Fig 1.01. Abstraction of relationship between humans and nature 
1.3 - Scope

This thesis works as a design-led research project within the scope of the theory of biophilia and biophilic design (as it is an architectural thesis), is based in Wellington

New Zealand (as it is a recognised biophilic city),

includes linkages with Victoria University Te Aro Faulty

of Architecture and Design (due to its location within the ehicle for movement, and is expressed in the design of one Ecologies Design Lab.

Designing a biophilic Ecologies Design Lab is the goal of this design-led research that will ultimately address
and improve the holistic health of people who reside in Wellington.

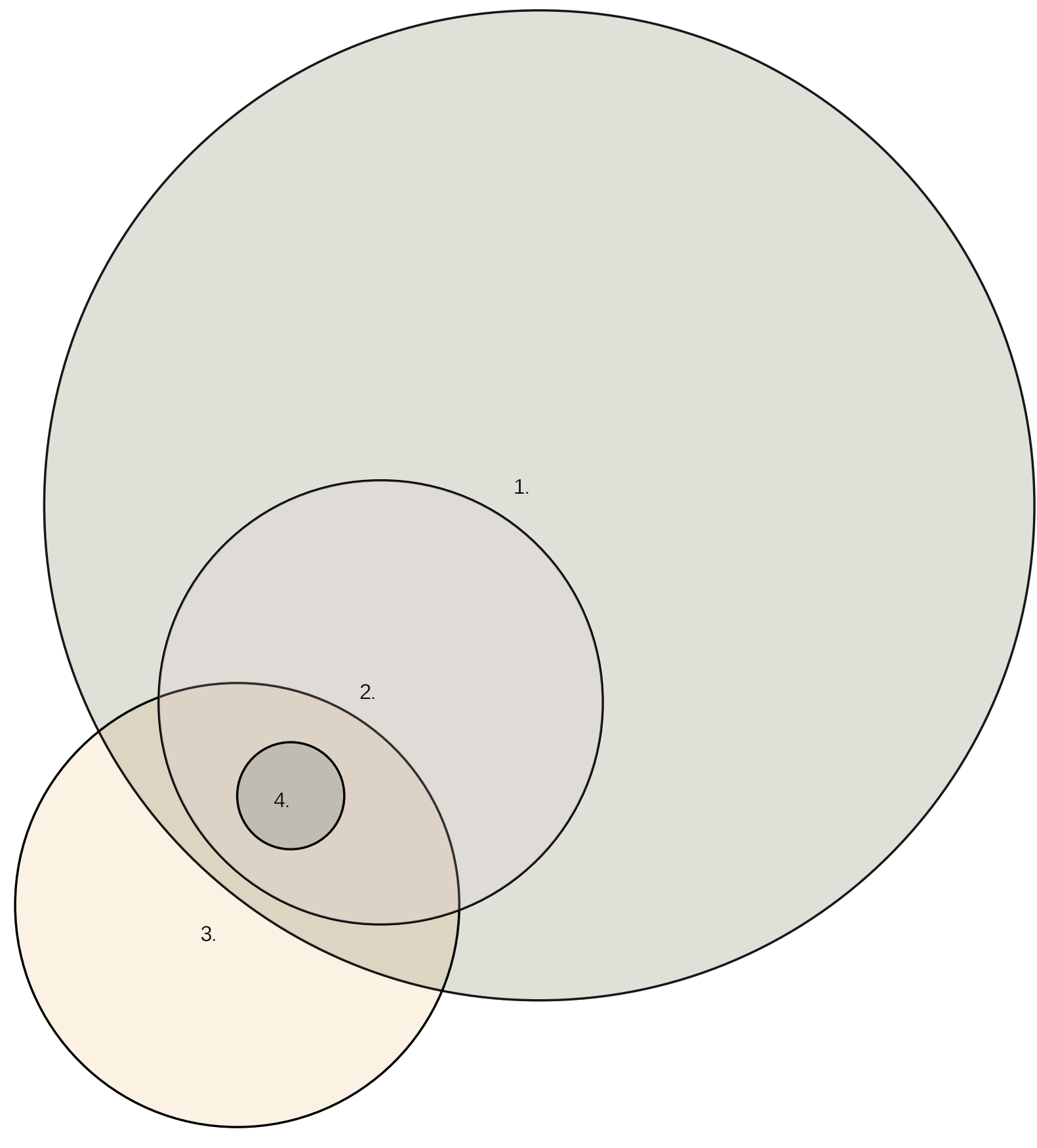

Fig 1.02. Diagram of scope within this thesis. Representing. 1. Biophilia. 2. Biophilic Design. 3. Enticement. 4. Ecologies Design Lab. 
1.5 - Methodology

This thesis uses design-led research and is utilised as the primary research methodology. Iterative critically analysed and either developed or left as influential milestones on the thesis journey. Differing mediums, tools and theories are compared, utilised and evaluated in order to present, at the conclusion of this thesis, a design outcome that is the accumulative result of many trials and experiments. Specifically the

1 / A three week 'quick start methodology' was utilised to explore and present initial 'hunches', or assumptions about the design situation. Research then critiqued by fellow students and superviso of the Ecologies Design Lab at Victoria University of Wellington Faculty of Architecture and Design. feasibility were discussed.

$2 /$ Further investigation was carried out into the quick start design, critical assessment regarding whether dispersed spatial project.

3 / A 'Transect Walk' was conducted with locals the igh Wellington in order to call to attention to time and space, and determine suitable areas for intervention.

4/ Extensive field observation and investigation of present biophilic sites around Wellington.

$5 /$ Utilising the concept of urban acupuncture (refer to chapter 42) to choose points in which to formalise designs.

6 / Presentation (May) of analysed findings and concept designs on chosen sites around Wellington and the planning of the next strategic phases.
$7 /$ Revisiting of concept designs and develop through 作 as the vehicle of investigation into the overreaching research question.

$8 /$ Presentation (August) of developed design to external eviewers followed by critical feedback and the planning of the next strategic phases

9 / Feedback applied to final developed designs.

10 / Designs utilised to formulate conclusions and answers to thesis questions articulated in examination presentation (November) to a panel of internal and external examiners and reviewers. 


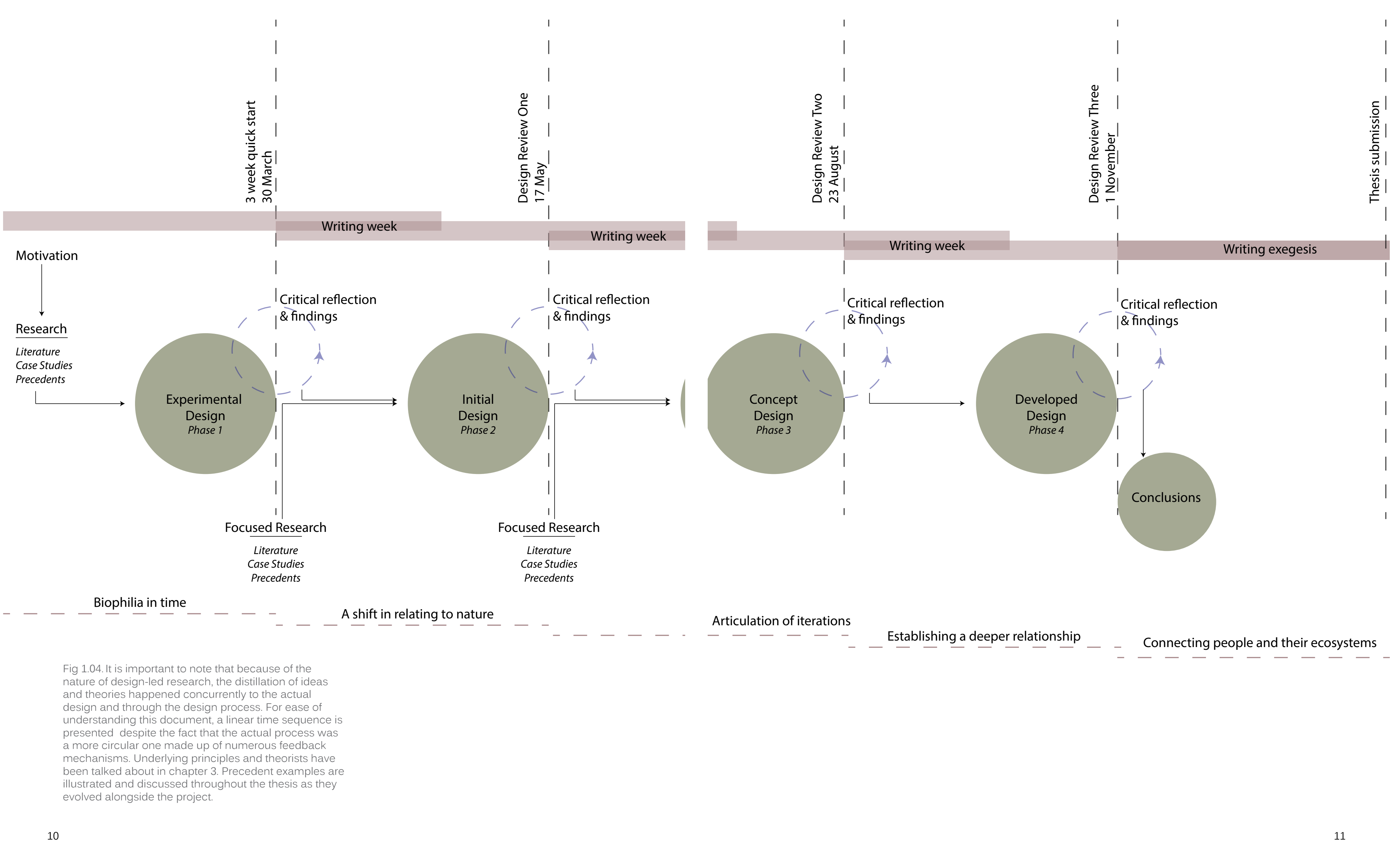


2.0

Biophilia in time; from marco to micro 
2.1 - International Network

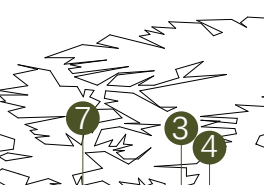

Notwork $5=]_{2}=3_{4}$

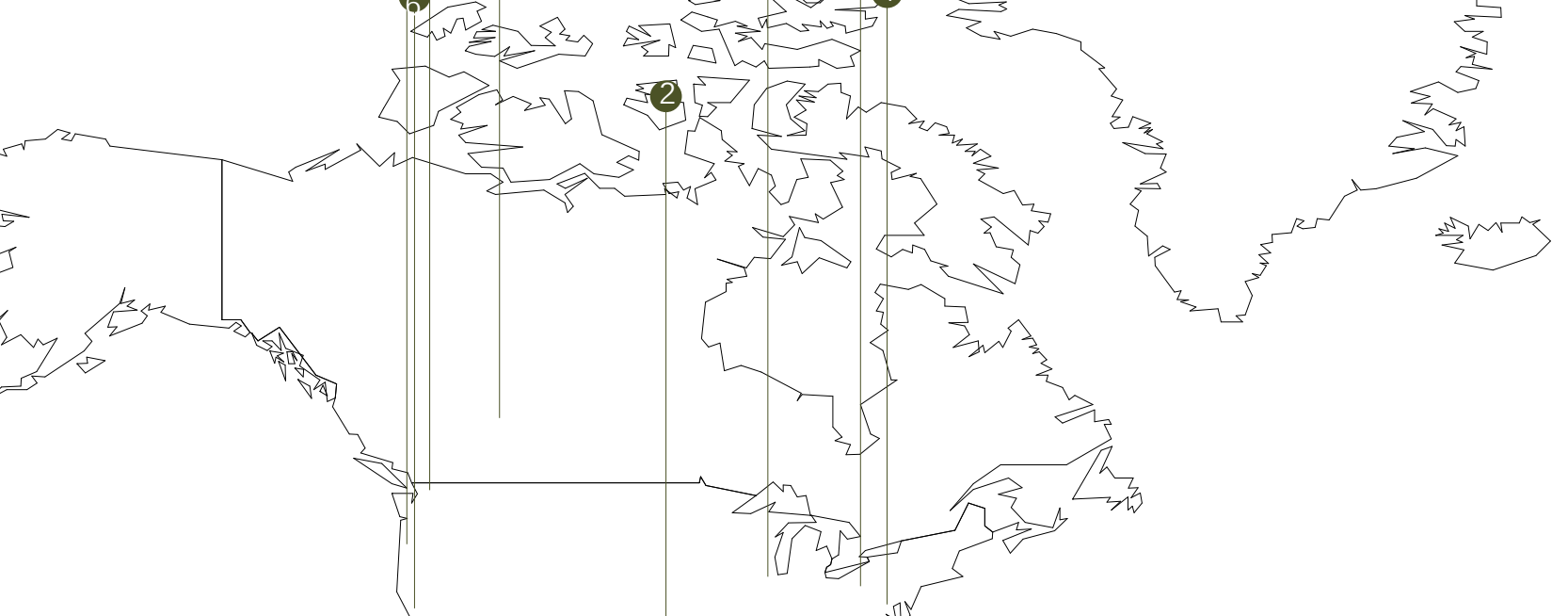

Biophilic Cities is an organisation, providing a common ground that brings like-minded cities from around the world together, working towards the goal of reconnecting activities. Founded by Professor Timothy Beatley of Virginia University, the idea is to further enhance biophilic research and implement interventions and principles

Singapore Pittsburgh San Francisco and Austin in the

Singapore, Pittsburgh, San Francisco and Austin in the

USA and Wellington in New Zealand are all biophilic
cities. Each urban setting is unique and demonstrate how

they practice maintaining a healthy biophilic approach to

city planning and living. Singapore has been referred to

as the "city in a garden" and Wellington as a "city in the

forest" due to their biophilic efforts (Beatley, 2017).

Fig 2.01. Biophilic Cities Map (Beatley 2017)

1. Edmonton, Canada

2. Austin, Texas
3. Milwaukee, W

3. Milwaukee, Wisconsin 4. Pittsburgh, Pennsylvania 6. Sortland, Oregon Francisco, California
7. StLovis, Missoui 7. St Louis, Missouri
8. Washington, DC

9. Birmingham, United Kingdom

10. Victoria- Gasteiz, Spain

11. Singapore

12. Wellington, New Zealand 


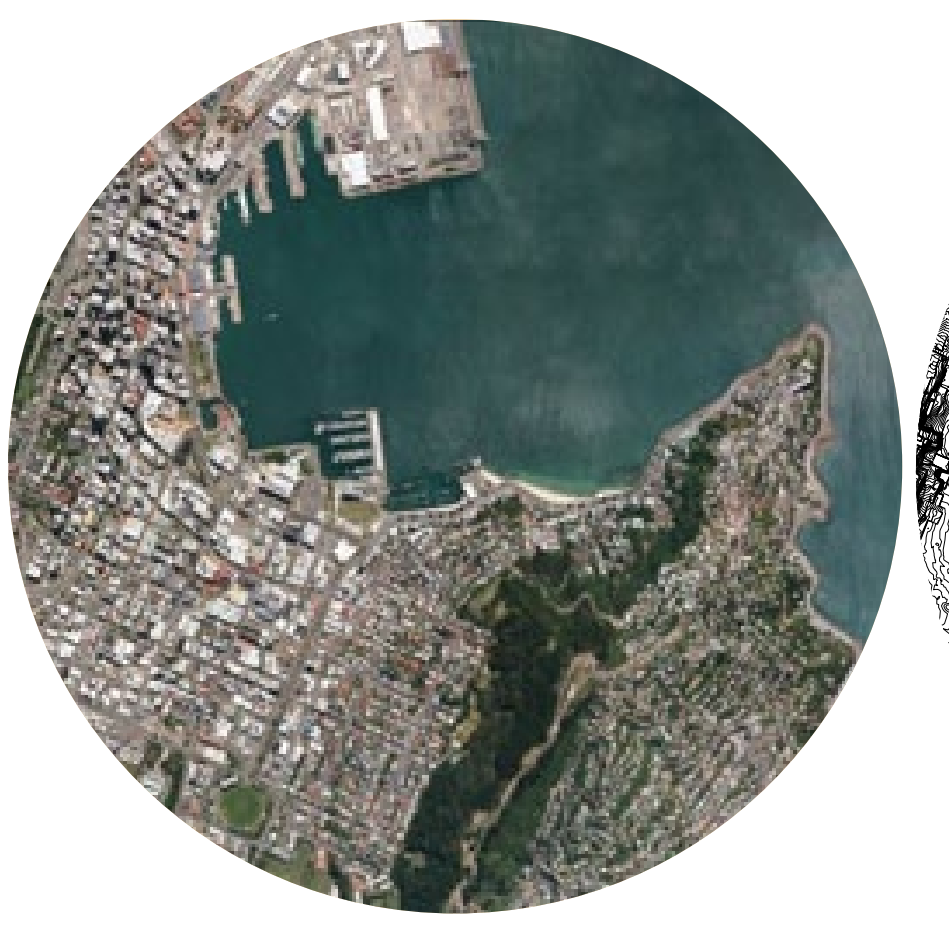

Wellington, New Zealand is made up of windswep beaches, arcane valleys, contrasted with rugged mountain features and luscious town belts that enclose the city in a remarkable shade of green. Overall, extensive green bells, blue belts, a harbour and ocean setting. to dwell within. Wellingtons' natural environment is protected by environmental plans, policies and initiatives For architects and urban designers, is there more to be done within Wellington to exploit the natural delight we have been gifted? Further architectural assessment and comparison to other biophilic cities is useful to consider improvements in the spatial conditions and connections and intertwining parks in Wellington.
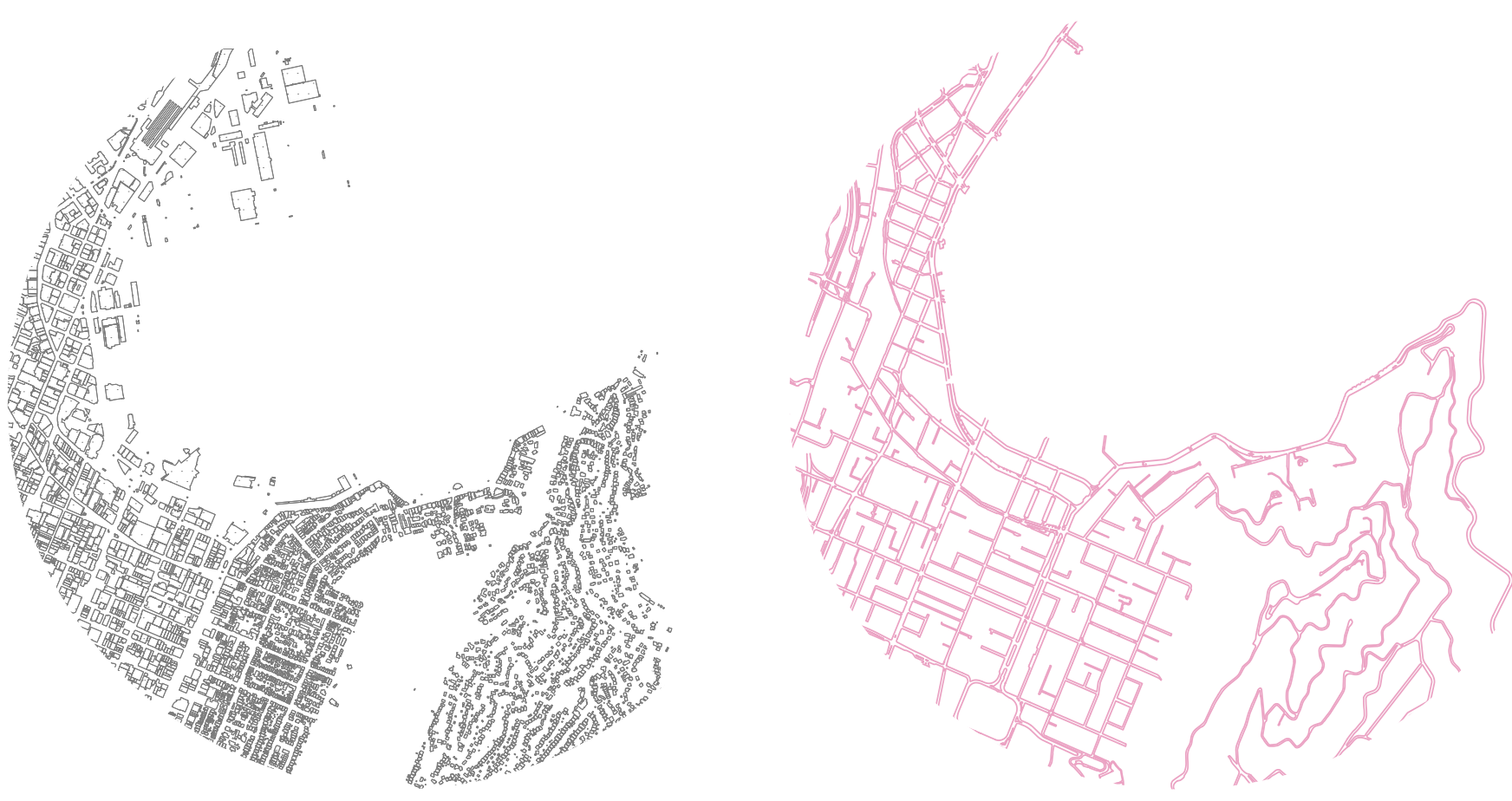

Fig 2.02. Wellington, New Zealand, satellite, $5 \mathrm{~m}$ contour (opposite page), urban development and connecting route

One of the selling points of Wellington is that if you

come here you can get to the

in bush, you can mountain bike and you can enjoy the

Sirpaut Casthecome a sense of whowe are." 


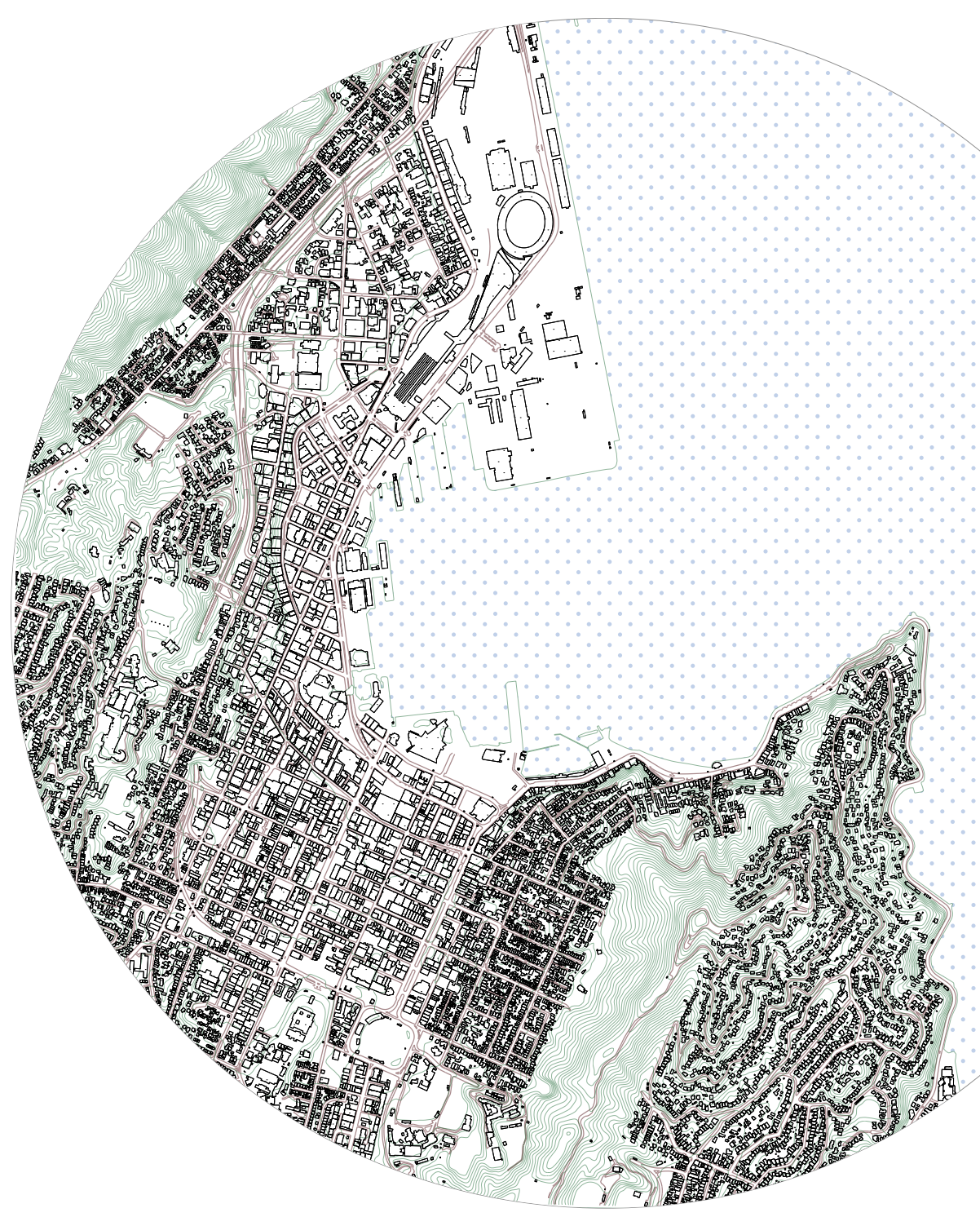


Taranaki Street, running south-southwest through Te Wellington central business district conngh wider amenities and suburbs such as the Wellington Hospital and Newtown area. It has been identified as a road that is devoid of natural elements hence creating negative psychological effects on many of its users. The stretch of road maintains no human scale or natural features that encourages connection when and priority given to the motor vehicle and industrial processes. A large stretch of the road consists of four lanes with the wide footpaths utilised as car parks and loading bays for the production warehouses along the route. Amongst the industrial warehouses sit two of Wellington's main education facilities (Massey University and Wellington High School) where little urban consideration is given to the students as they
move through the city before, during and after classes.

To propose positive biophilic development along this transect of Wellington's vernacular would be to connect people to nature, improve the fluidity
of movement for pedestrians, making it a more enjoyable stretch of journey, further connecting the southern based population to the central business district and the wider nature reserves in a more greenery, weather proction and dyamic lighting has the potential to instil excitement hence a preference of waking and interacting with these spaces.

\begin{abstract}
Opportunity arises when assessing the area surrounding the Taranaki Street transect, especially the sites of Architecture and Design. Many empty lots and earthquake prone buildings are positioned within close proximity to both Taranaki Street and the Faculty of Architecture and Design, allowing for the combined extension of facilities for the University whilst also Improving the connectivity through space and the city Eurher analysis will be undertaken to test initial development in regards to effects on the surrounding urban environment and answering the research question "How can architectural and urban design foster and celebrate connections between people and their surrounding ecosystems through biophilic design?
\end{abstract}

Fig 2.07. Positioning of proposed site in relation to Victoria University Faculty of Architecture and Design, and
Taranaki Street with potential new pedestrian routes

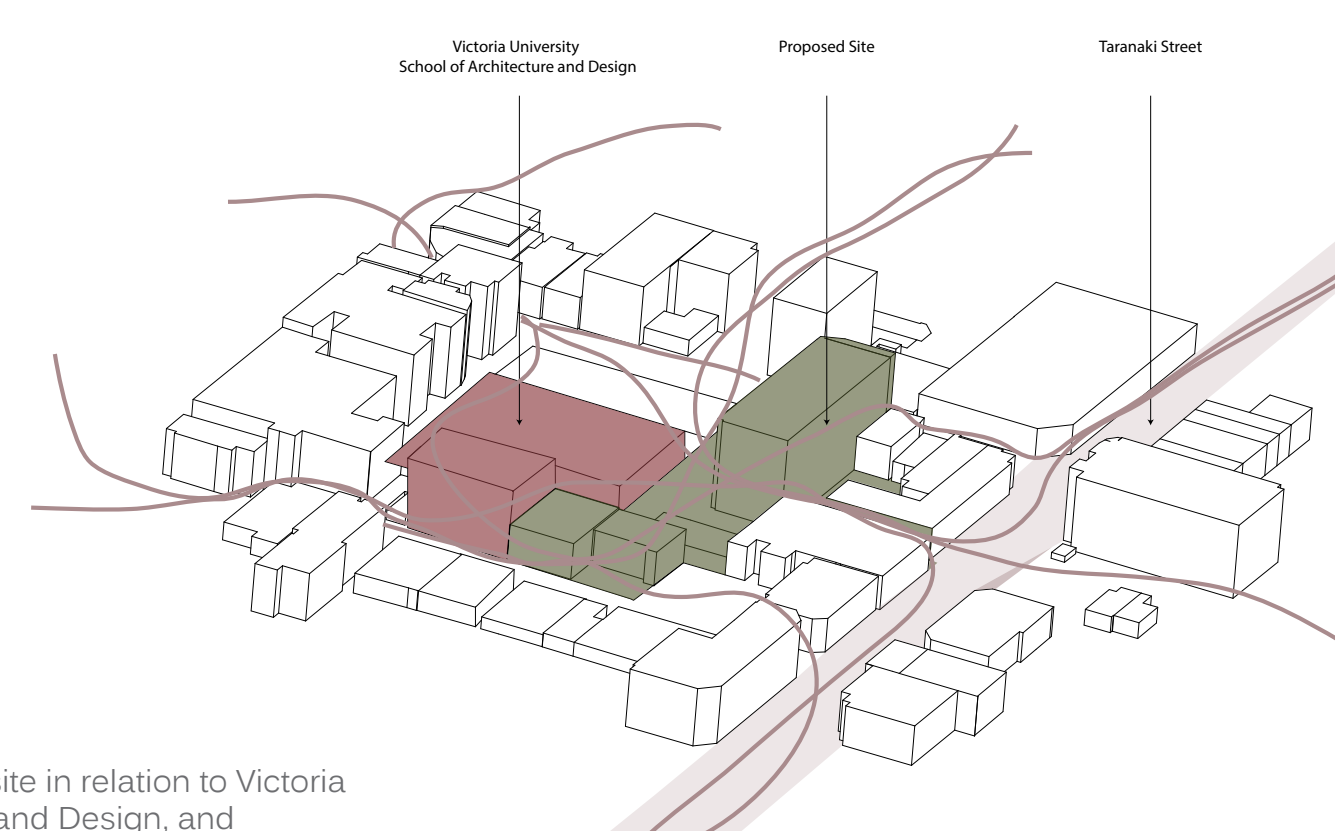


3.0

A shift in relating to nature 
The amalgamation of ideas from many theorists has led to the centralisation of the design iterative process to be moulded by influential ideas being
derived from a number of different backgrounds and mediums. As the overall aim of this design-led research is to investigate how to connect people to immediate ecosystems and environments to ultimately improve well-being through design, theories and design approaches were drawn from biophilic theorists, urban planners, interior architects, landscape architects and narrative designers. The goal when combining aspects from each discipline is to establish a positive relationship between experiencing considering how the user is experiencing the space at eye level. Biophilic interventions are the tools which this thesis uses to promote a sense of wellbeing. however the additional theories and approaches are the vehicles that encourages visitors and residents of Wellington to interact with and explore the design interventions.

When formulating a position on biophilia and gathering knowledge on the area of biophilic design, three key authors helped the critical analysis on Ordway Professor of Social Ecology and Co-Director of the Hixon Centre for Urban Ecology at Yale University, and his book 'Biophilic Design, The theory, Science and Practice of Bringing Buildings to Life' established a solid foundation of overall meaning, reasoning and application of biophilic design, to be applied in architectural settings. This book represents a wide range and diverse spectra of disciplines, including architects, natural scientists, social scientists, health professionals, developers, practitioners and others that offer a vision of collaborative remedial design, aspiring to heal the prevaling breach existing between the modern urban environment Mador 2008). As a general understanding of biophilia was established by this book on a macro scale, it was then valuable to add context to these ideas when then evaluating Dr Timothy Beatleys 'Handbook of Biophilic City Planning \& Design'.

Beatley is chair of the Department of Urban and Environmental Planning and Teresa Heinz Professor of Sustainable Communities at the school of Architecture at the University of Virginia and also the founder of the Bioph biophilic urbanism and urban practice with added emphasis on specific studies from around the world and how they have/ can integrate nature into their planning and design processes. This handbook further influenced this thesis as it has identified Wellington, New Zealand as a case study, which was not only a concise informative chapter on the biophilic efforts as a city, (

biophilic performance.
To further extend this critical analysis, Browning's et al. "14 Patterns of Biophilic Design" was utilised to a micro scale and look at the site conditions existing in Wellington, and to compare Beatley's writings about Wellington in relation to how everyday residents experience the space. Browning et
al. articulates the relationship between nature, human biology and the design of the built environment in a categorised manner, making a more formal and structured criteria on how to analyse and critically assess biophilic principles in Wellington. Overall the 14 Patterns of Biophilic Design (illustrated further in chapter 3.2) are grouped into 3 categories; Nature In Space, Natural Analogues and Nature Of Space (illustrated in context articulation of these catagories in Wellington itself by illustrating a Biophilic Map of Wellington, accounting for all urban and natural features that fit into the above categories (Pedersen Zari, 2017).

As all three of these readings intersect, on both a theoretical and practical large, medium and small scale. They not only add to the background knowledge this thesis is based upon, but they also in combination, set up and a framework that design iterations can be critically assessed agared In correlation with how to implement design iterations, it was also crucial to consider where to implement them for the greatest urban effect and chain reaction. As much as Beatley's writings solidified hunches to select Wellington, New Zealand, as the appropriate location for this thesis to be tested, Jaime Lerner's writings on Urban Acupuncture provided additional substance and methodological reasoning as to where biophilic intervention is best placed. Jaime Lerner is a Brazilian politician, governor of the state of Accompanied by conference papers from Cheng Shidan \& Nui Xile, and journals such as 'Narrating Urban Acupuncture[s]' by Barbel Muller, the practice of urban acupuncture was introduced to this thesis. This concept derives from Chinese acupuncture; a healing methodology applying minimal force at a critical point has maximum impact. When adapted for architectural practice and planning, these notions become progressive type of small-scale, urban renewal (Xile, 4-10 Dec 2010). These theories were used in this thesis to identify 'ailing spots' within Wellington where minor

A synergy is created in this thesis as the approach of urban acupuncture and biophilic interventions are combined. Restoring and nurturing residents' well-being is not so much about fixing a problem once the negative effects have already been felt, but implementing small and meaningful modifications in the urban spots most in need of intervention and located in 


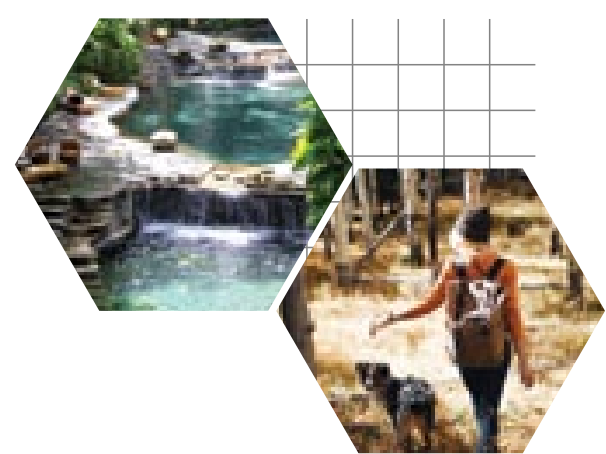

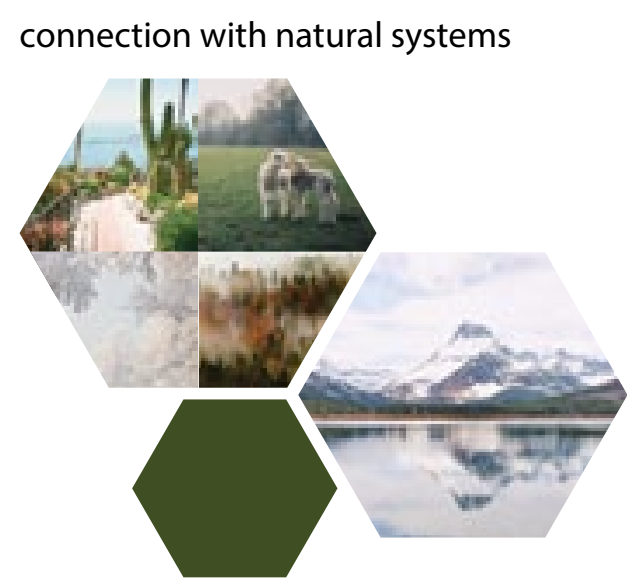

Experiencing natural processes, i.e. seasonal and temporal changes characteristic of a healthy ecosystem

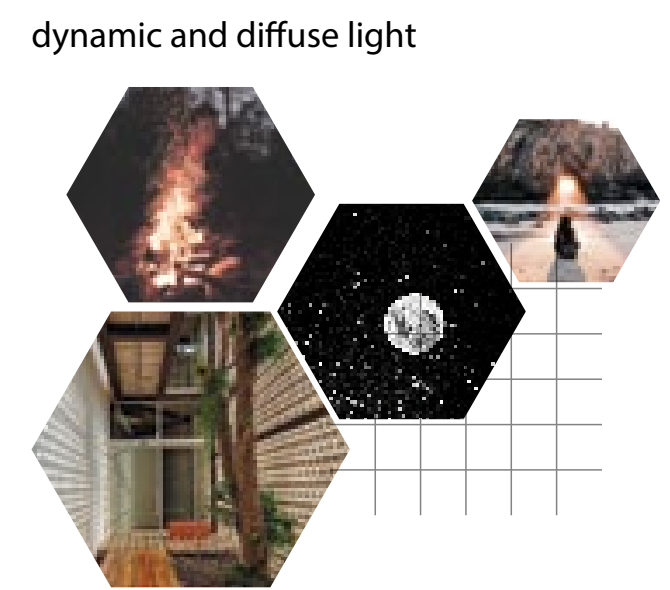

Settings of light and shadow that vary over time to replicate scenes that occur naturally in the wilderness

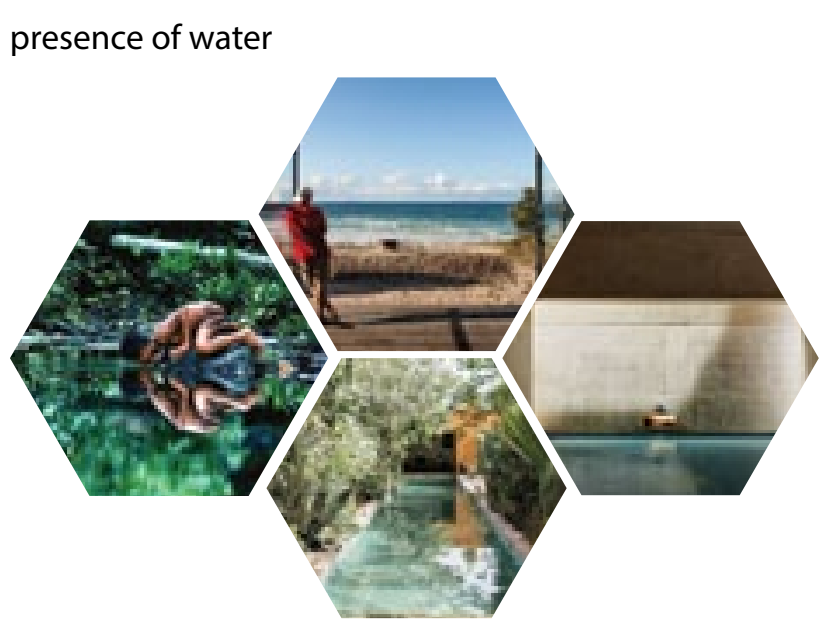

Seeing, hearing or touching of water
Stochastic and ephemeral

connections with nature and living organisms. Usually unpredictable and those that vary in intensity and tone

\section{thermal + airflow variability}

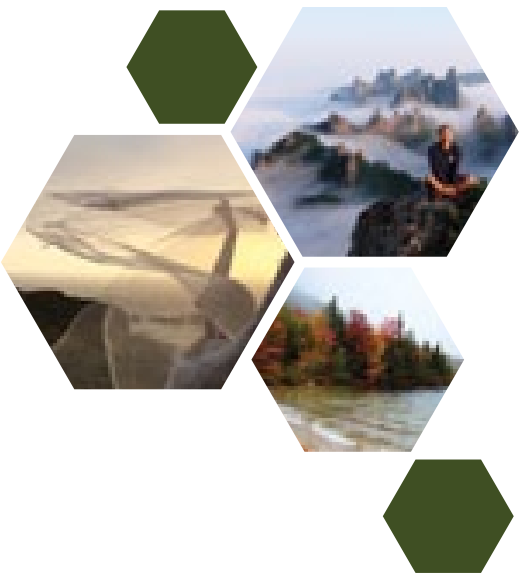

visual connection with nature

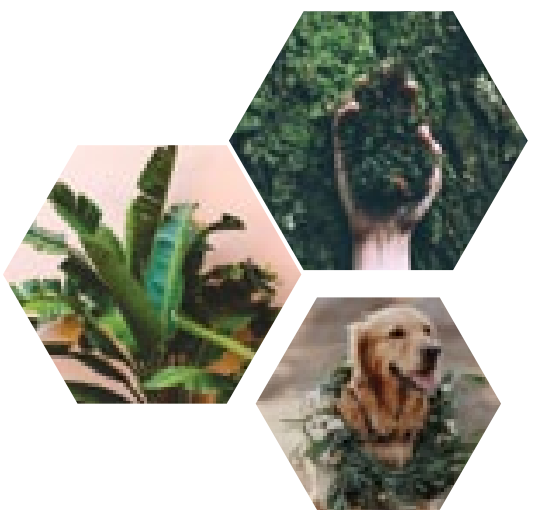

Views or inter
organism non-visual connection with nature

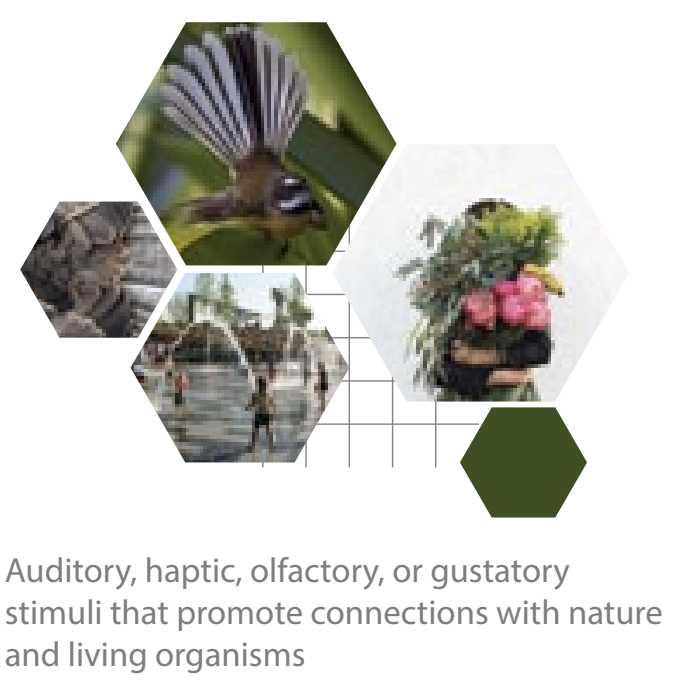

Changes in air temperature, relative humidity,

airflow across the skin, and surface tempera- 

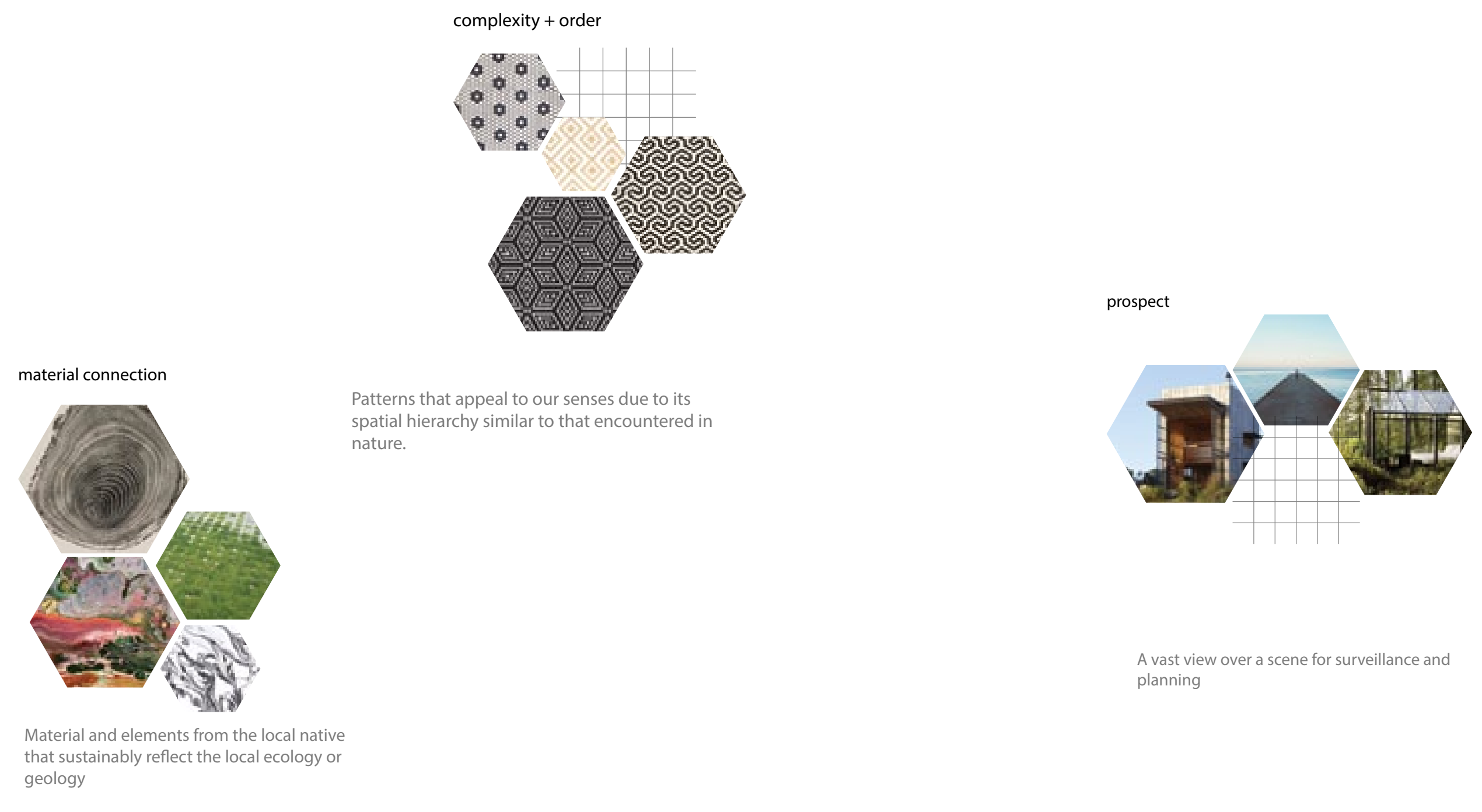
A vast view over a scene for surveillance and
planning

biomorphic forms + patterns

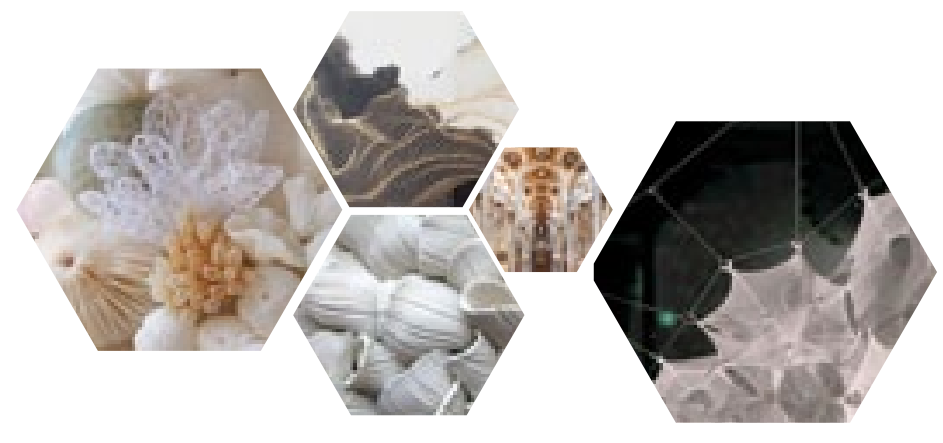

Symbolic references to arrangements that

exist in nature.

(patterned, textured or numerical)

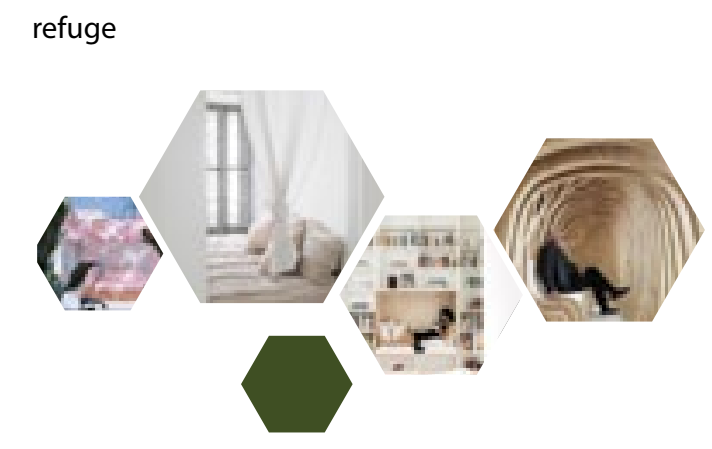

A place for withdrawal, from environment conditions or the main hub of a space, in overhead

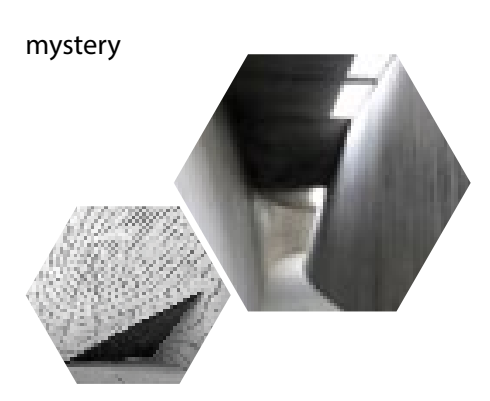

risk / peril

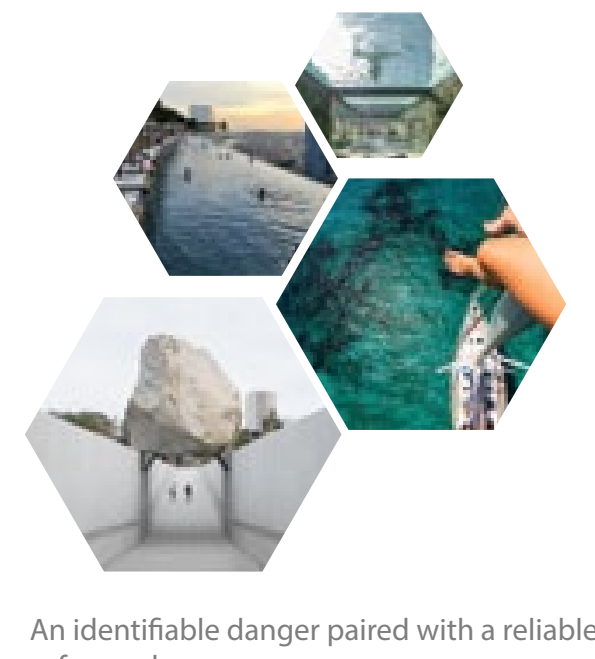

An identifiable danger paired with a reliable safeguard 
Illustrations of the 14 Patterns of Biophilic Design (1) manner within the urban fabric. They are a list of either angible traits or conditions that elicit feelings, usually relating to how humans evolved in nature. These can be directly translated into spatial design. These patterns are expressed in the general sense for the purpose of addressing universal issues of human health and wellbeing (for example stress, visual aculty, hormone balance, creativity) within he bult environment

be linked to research in at least one or more of three

overarching mind-body systems; cognitive, psychological and physiological. These have been explored to varying degrees in laboratory or field studies, to help explain how people's health and well-being are impacted by their

1 for a tont (Browning et al., 2014). Refer to appendix patterns and mind-body impacts.
Cognitive Functionality and Performance "Encompasses our mental agility and memory, and our
ability to think, learn and output either logically or creatively (Browning et al., 2014)."

ittention needed to complete calculations). Over time the directed attention peop

give to such tasks can fatigue the mind due to it being

energy intensive. Strong con hections with nature can

functions take a break from working. The result is being able to complete these repetitive and focused tasks better than someone with a fatigued cognitive state.

Psychological Health and Well-being

"Psychological responses encompass our adaptability,

n and mood and stress management (Browning et al, 2014)."

For example studies have supported the notion that natural environments lower tension in the body, as well as anxiety the mind (Alcock et al. 2013.).

Physiological Health and Well-being

"Physiological responses encompass our aural

musculoskeletal respitaton, circadian systems and overall physical comfort (Browning et al., 2014)."

Physiological responses that can be triggered by

lowering of blood

levels in the blood stream. In saying this, short term stress

increasing heart rate (e.g. looking over a banister 8 stories above ground) can be beneficial to regulating physiological 
4.0

Design led research; process \& reflections 
The quick start was an essential 3 week thesis process designed to the task was to ha of work over the 3 week period, giving a strong basis of product to be critically assessed, that would be the foundation for the next stages of the thesis process.

It begun with looking at and testing existing 'good' and bad' biophilic experiences around Wellington, with particular empxasis on their cond we was discovered from the field work was that biophilic interventions within the urban fabric are not mutually exclusive. Although they are represented on maps as points of position, in reality how people move through, between, arrive at and how they leave is just as crucial to user experience as the geographic positioning of these interventions (Pederser

The project became about a journey. The synergy between bio + people + their link to nature and the
documentation of personal feelings became a pivota point in design considerations. It was obvious for this architectural thesis to maintain depth, that an interior architecture, urban and experiential positioning on designing would need to be included. After extensive esearch into the theory of the 'derive' *it became

apparent that a transect walk (refer to chapter 2.08) with people perceive their environments and what it is that they notice about these places (positive or negative).

After the transect exercise biophilic solutions were proposed to be implemented into Taranakis sreet as a series of small scale proposed interventions (Refer to figure 4.01 and 4.02 ,

* "One of the basic situationist practices is the dérive [literally. "drifting", a technique of rapid passage through varied ambiances. Dérives involve playful-constructive behaviour and awareness of psychogeographical effects, and are thus quite

In a derive one or more persons during a certain period thoir thetr relations, their work and leisure activities, and all themselves be drawn by the attractions of the terrain and the a dérive point of view cities have psychogeographical contours, with constant currents, fixed points and vortexes that strongly discourage entry into or exit
from certain zones." (Debord, 1958)

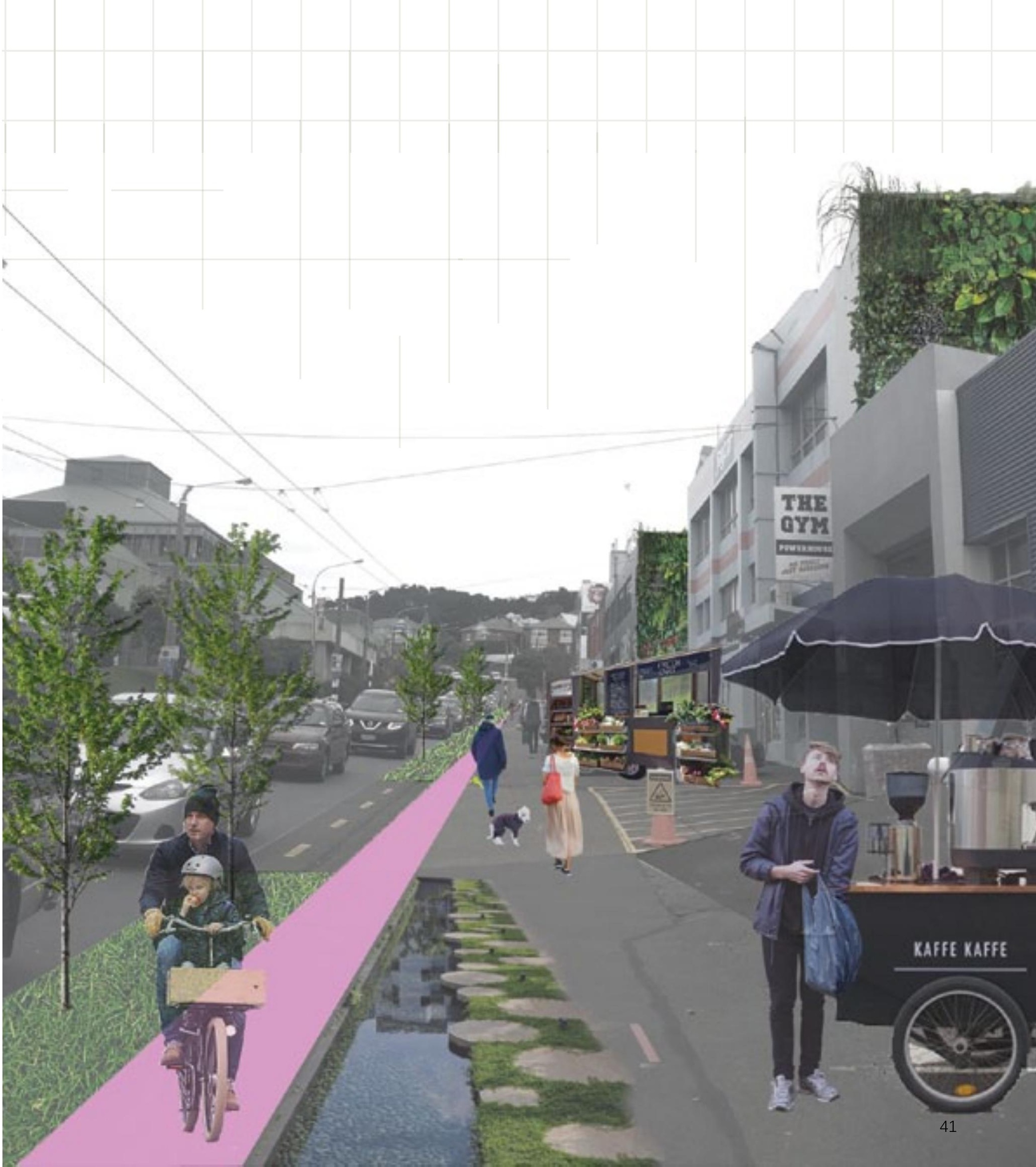


The design outcomes for the 3 week quick start drew upon Wellington's urban fabric that was devoid of biophilic experiences. Many locals populate Taranaki Street, such as students from Massey University, Wellington High School and the many dance, fitness and church groups that are situated along the transect. Currently students and locals crowd the footpath, unprotected from weathe waiting for the bus throughout the day, or waiting to get picked up after dark from various extra-curricular

activities, the vehicle prioritised road and footpath is not an enjoyable space to occupy. These amenities and facilities make Taranaki Street a main throughfare for pedestrians and in order to improve their user experience and well-being it is important to introduce biophilic

Curved grass strips and day lit streams that run the length of Taranaki Street were introduced in this initial and pedestrians, and the abundance of vehicles that use the road. Empty car lots were proposed as sites for bespoke food and coffee stalls to add intrigue and interest along the stretch of road and are designed to be places to wait, linger and enjoy the environment.

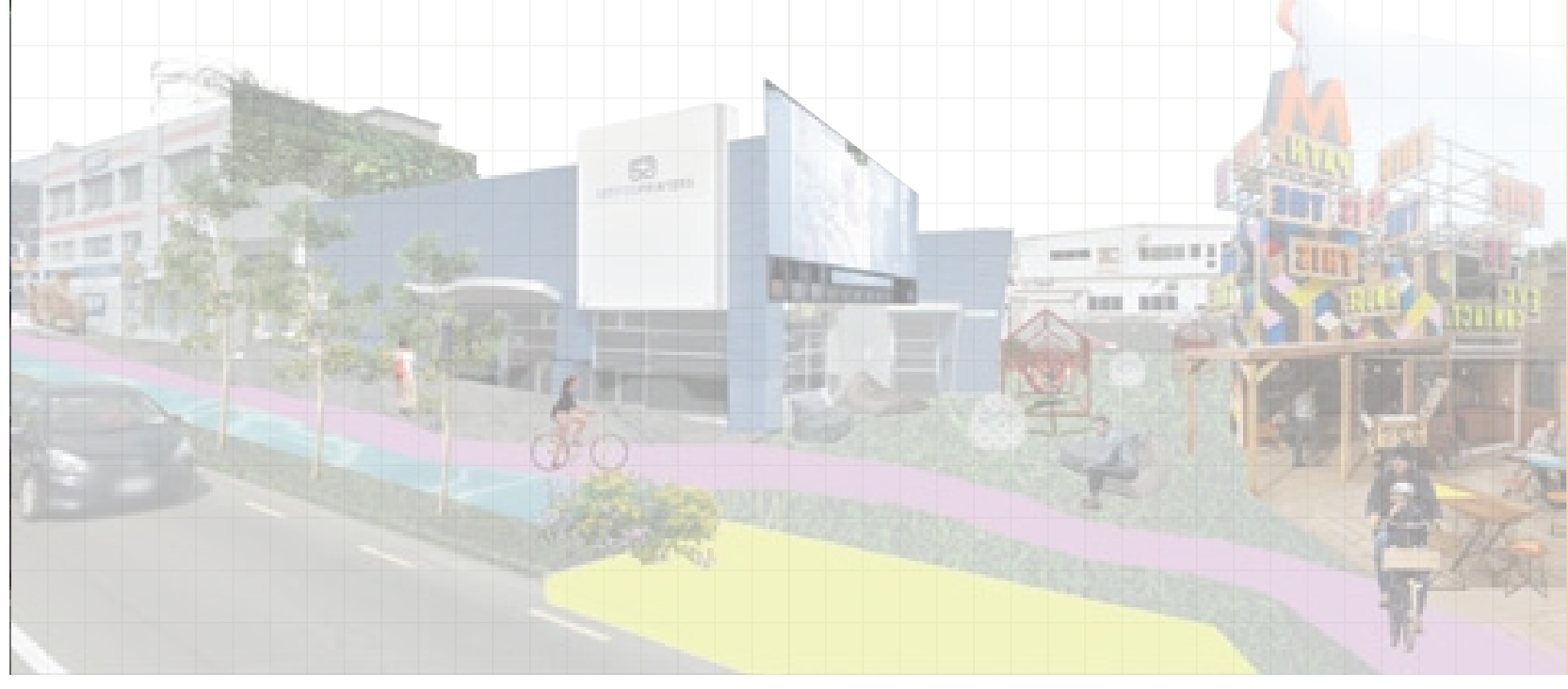

Fig 4.02. Taranaki Street perspective. Spaces created for Massey University and Wellington High Schoo classes.
Based upon the ideas of acupuncture that consider win the body to be responsible for the overall success of well-being (Madsen, 2009), urban acupuncture theory prompts that cities are built atop the underlying systems of flows which are directly linked to the built structure of the urban fabric. Perceived as various social, economic, political and physical forces; to influence the behaviour of residents as well as the development of the city (Cupers, Miessen \& James 2002). Utilising urban acupuncture as the methodology in which to identify points within and physical sweetspots in Wellington's urban fabric that are in need of

improvement relates to the synergy between wellness promoted and found in an urban context. Similar to the human body, these components of the city have linkages with each other (Shidan \& Qian, 2011), allowing wide Incremental change contrasting to complete renewal is principle to the acupuncture theory in order to achieve revitalisation of the urban setting, seeking maximum effect through minimal intervention. This is achieved through the manipulation of channels of energy, utilising lows to initiate a ripple reaction throughout the city (Sola-Morales, 2008) for example the Royal Melbourne Australia They have implemented small architectural changes on the threshold of the university and the city that manipulate how students interact with the city and their campus.

Urban acupuncture is adapted in this thesis to promote the notion of a journey, improving alling spots around the city, enabling a new experience to be felt as people travel, arrive, participate in, linger and leave spaces. beacons along a pathway, constantly reinforcing

biophilic principles that have positive effects on people's well-being.

The theory perceives urban space as dynamic in nature, hence requiring constant negotiation and redefinition, as tis is conaminaled, hybridised and transformed in lime and space (Muller, 2009). 


$$
H=
$$


4.3- Critical Reflection

May marked the first milestone for this thesis review as ideas discussed previously were presented to a pane of architects, urban designers, landscape and interior architects. Design outcomes were discussed, alternate to further research in an effective manner. Discussions concluded that good biophilic de

Dlways make people want to divert stop interign should linger in its presence. It was agreed that the research

conducted in the field for this thesis set up solid grounds for this to happen, given that this research considers human experience, at a personal and local scale. Due to the preoccupation of experiential journeys from a human dynamic but should not be temporary and static. To be dynamic is to relate to nature, directing to the specific effects, feelings and experiences that architectural interventions can produce. Emphasis needs to be on how the structure operates within the urban fabric, changing over time, detailing how people get to it and how they leave. Specifically, architectural spaces are often curently thought of as units of space that are to portray a fluid notion of expression in regards to peoples senses and their ultimate well-being

A focus for the next phase of this thesis was to

implement more impressionable interventions that can be experienced at a prolonged time scale. At present, architectural theories are strong however architectural expression in the urban environment has an ephemeral into the answering the question: how do you retain's the focus of and turn a building into a journey? Why is it important to connect positive things and create a somewhat "accidental" biophilic pathway? In its first stages, pedestrian linkages over the road were displayed beginning to respond to the notion of and the importance of an uninterrupted low for people on foot through the urban fabric. Later this idea was pushed further.

A rigorous two-week experimental phase followed this first review to define a programme more carefully and shifted to how spaces within the urban fabric are not static, but dynamic, changing continuously over time, experienced differently as each person arrives and then leaves. Abstract models (refer to chapter 5.2) were the vehicle for this learning as the current designs presented fluidity that biophilia calls for and that the urban fabric is 


\section{0}

Experimentation 
Throughout the discussion revolving around this thesis what was made apparent was the importance of drawing people though spaces, into naturally rich spaces of residents and visitors. As the intervention was placed within an biophilically underperforming urban spot, the challenge shifted regarding how architecture can be experienced, and going deeper, how can the experience of the buildings and surrounding become a journey in

The concept of enticement then became increasingly important in exploring the movement of people and design outcomes 'Enticement', in this sense means the manner of being attractive, tempting and unexpected encouraging the interaction of people within hidden

The spirit sees, language sees, the body visits. It always transcends its location by virtue of its movement. Movement made in order to see, make use of roads, crossroads, interchanges, so that examination will either become more detalled or will become a general synopsis, change of dimension, of sense and direction Theling.

The body does not act as a simple, passive receiver... It exercises it, trains it, almost as its own accord, loves spring into action, jumps, runs, or dances, is only aware of itself, instantly or without speech, in and through its involvement, discovers tis existence in the burning of its (Von Mies 2013)

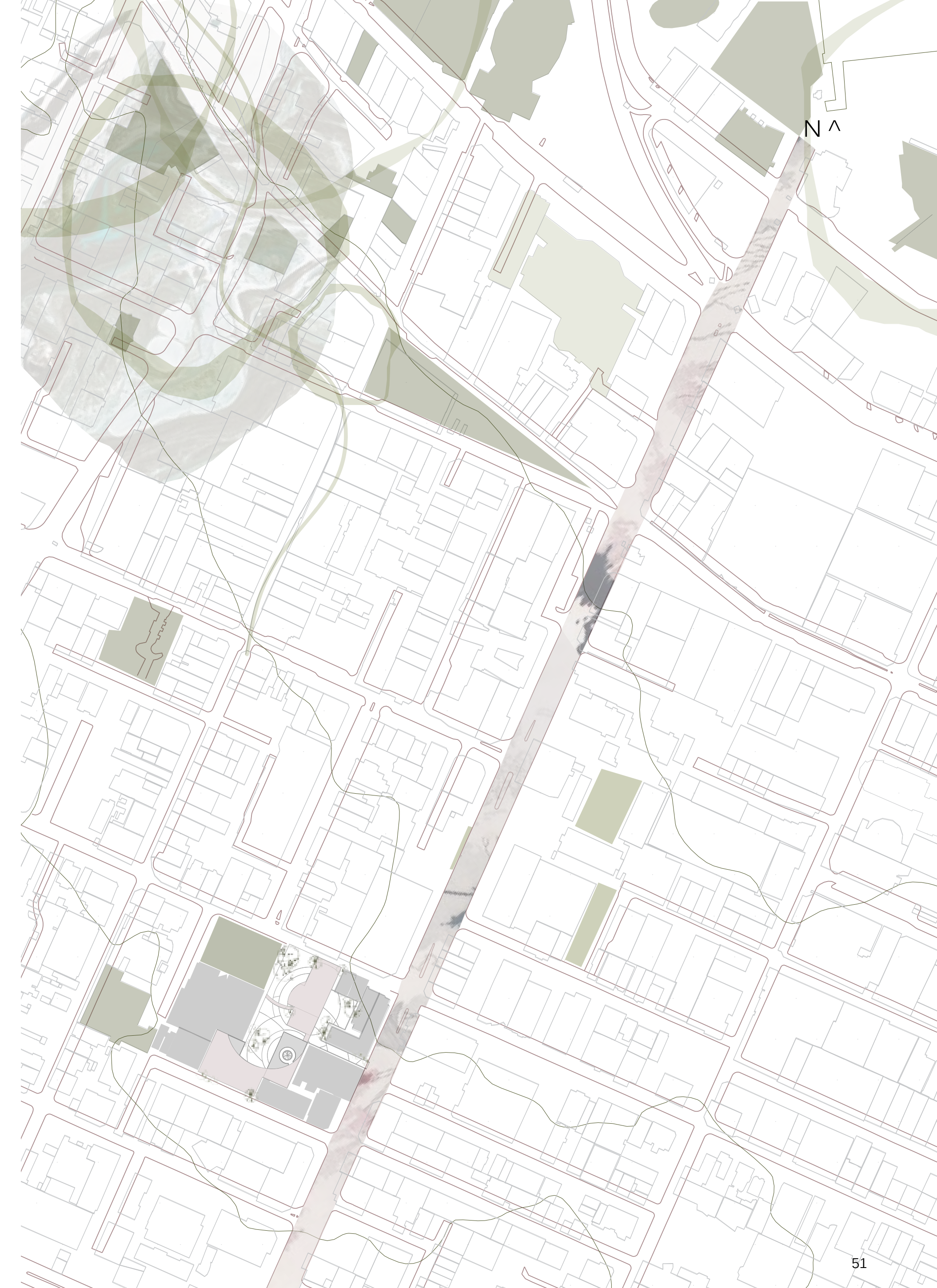


What was done within this thesis that is unique was that are derived from and are the of enticement of principles from biophilic, narrative, architectural, and interior architectural theory. They represent, in a simple format, a complex manifestation of people's movements, conscious and subconscious, and how they change through space and how designers could

Originally there were 10 characteristics that were utilised as a set of characteristics that each of the design iterations are critiqued against, providing a upon and that drives the next phase of investigation. As thought processes progressed however, these spatial qualities were at risk of being viewed as a mere checklist of characteristics to be incorporated so list of 10 , see appendix 2 .

\section{Curved Walls. (Biophilia) Relating to humans'} subconscious appeal towards curiosity, and the
need to uncover mystery. The promise of more

\section{information is achieved through the gradual curvature}

of walls through space satisfies the need to reveal undiscovered territory and travel deeper. (Browing et al. 2014)

2. Platforms and Heights. (Biophilia) Relating to the concepts of prospect and risk/ peril. 'Prospec' safety (when ancestors were nast spaces to ensure predators by urbanisation) and evoking the feeling of freedom. This also relates to the thrill experienced from perceiving 'danger' (e.g. being up high and the risk of falling) paired with the logical understanding that one is actually safe (e.g. being behind a secure railing). (Browning et al. 2014)

3. Viewing spaces through glass (Narrative). Being able to view spaces that are exciting through the enticement people feel and the anticipation of wanting to get to the other side and experience what other people are encountering. (Muller 2009)

"Arrangement of spaces, social relationships and cultural content is fundamental to how buildings are shaped, used and percened. Narrative enters arohteoture through the Ways in perception. The arch of perceivieve speched ethets on our Puffling of information as our bodies pass through spuce:

(Psarra, 2008)

Curved walls

Heights/ platforms

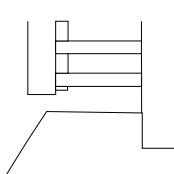

Views through glazed interior
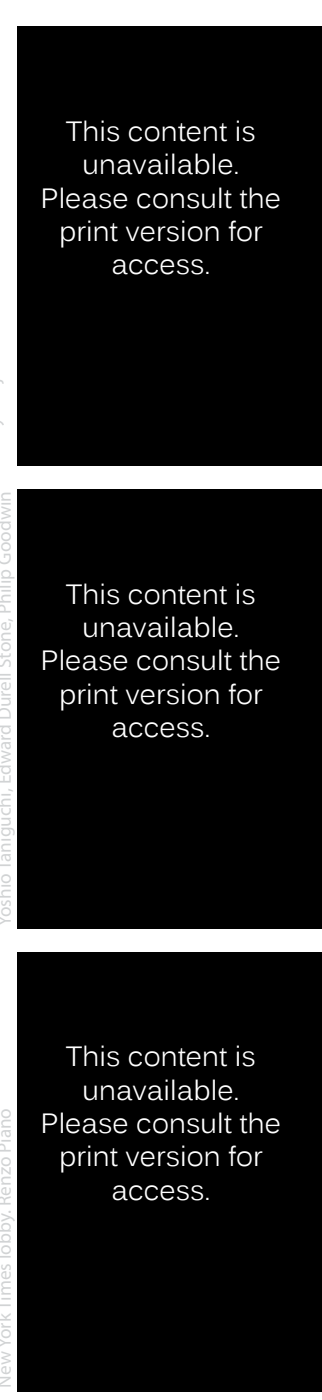
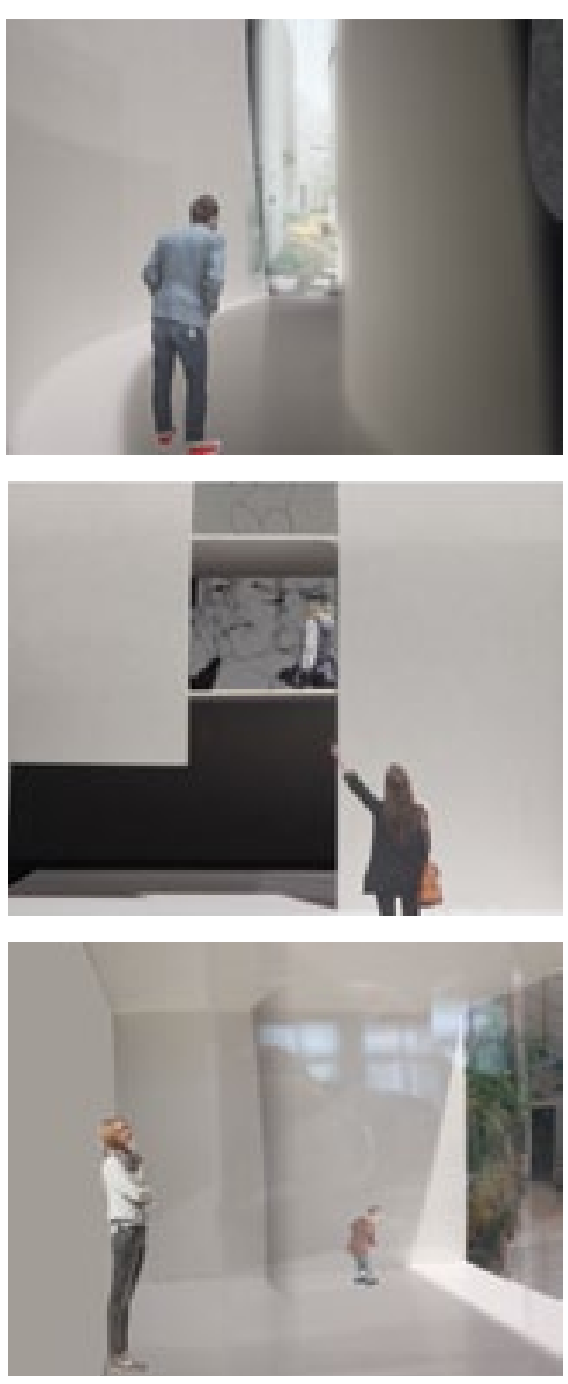
4. Perforated Walls (Biophilia). Replicating dynamic

and dramatic lighting qualities experienced in nature

intensity, colour and movement expresses the passing

of time with drama and intrigue, buffered by a sense of calm. (Browning et al. 2014)

5. Controlled Confusion (Biophilia). Architectura spaces that are well configured with the intention

anticipation, and offer the senses a form of denial and

(curiosity). (Browning et al. 2014)

6. Focal Points (Architecture). Shifting the focal

point in space off the central point of vision in turn shifts

the eye and hence the body, encouraging movement

owaced in. (Sola-Morales 2008)

\section{Perforated walls}

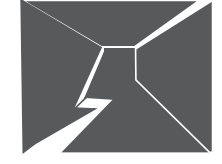

Controlled confusion

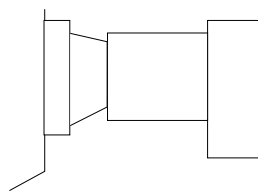

Focal point
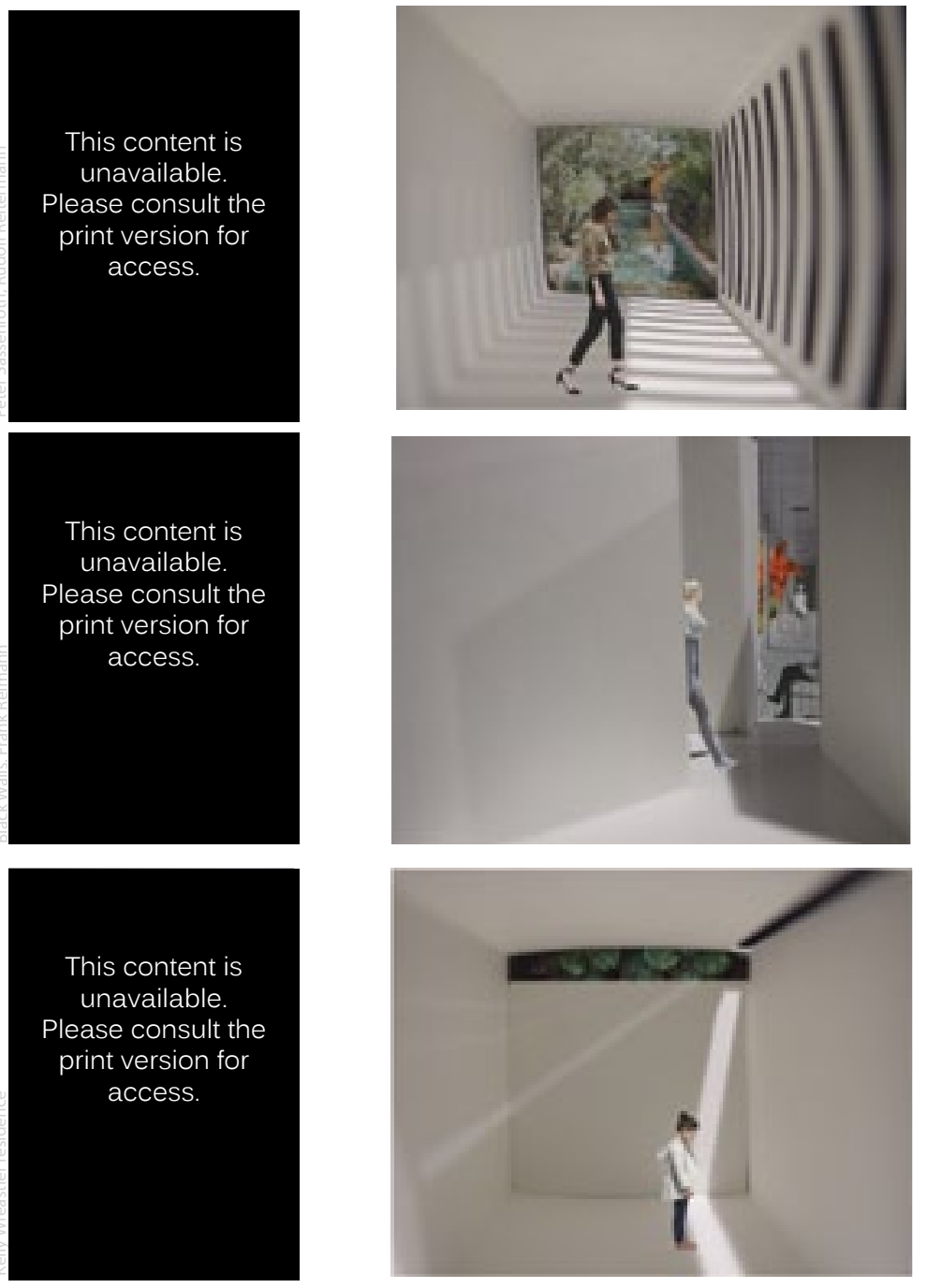
The characteristics listed in section 5.2 have been incorporated in the design of an Ecologies Design Lab where professionals from all disciplines involved with furthering the concept of biophilic urbanism can collaborate, test, enquire, learn and teach about architectursion of the subject. Professionals from planning developing and practitioner backgrounds will be able to come together, as well as the students of Victoria University of Wellingtons Faculty of Architecture and Design, to share ideas and work towards a common goal of bridging the gap between nature and humans hat evolved in and are a part of it.

The public will be invited to engage with the complex so it becones a ling building that not only connects put also so it acts as a point in a journey, connecting people to the rest of Wellington's urban setting throug an alternative biophilic experience to Taranaki Street itself. This is important because the site is on the corner of Taranaki and Vivian Streets.
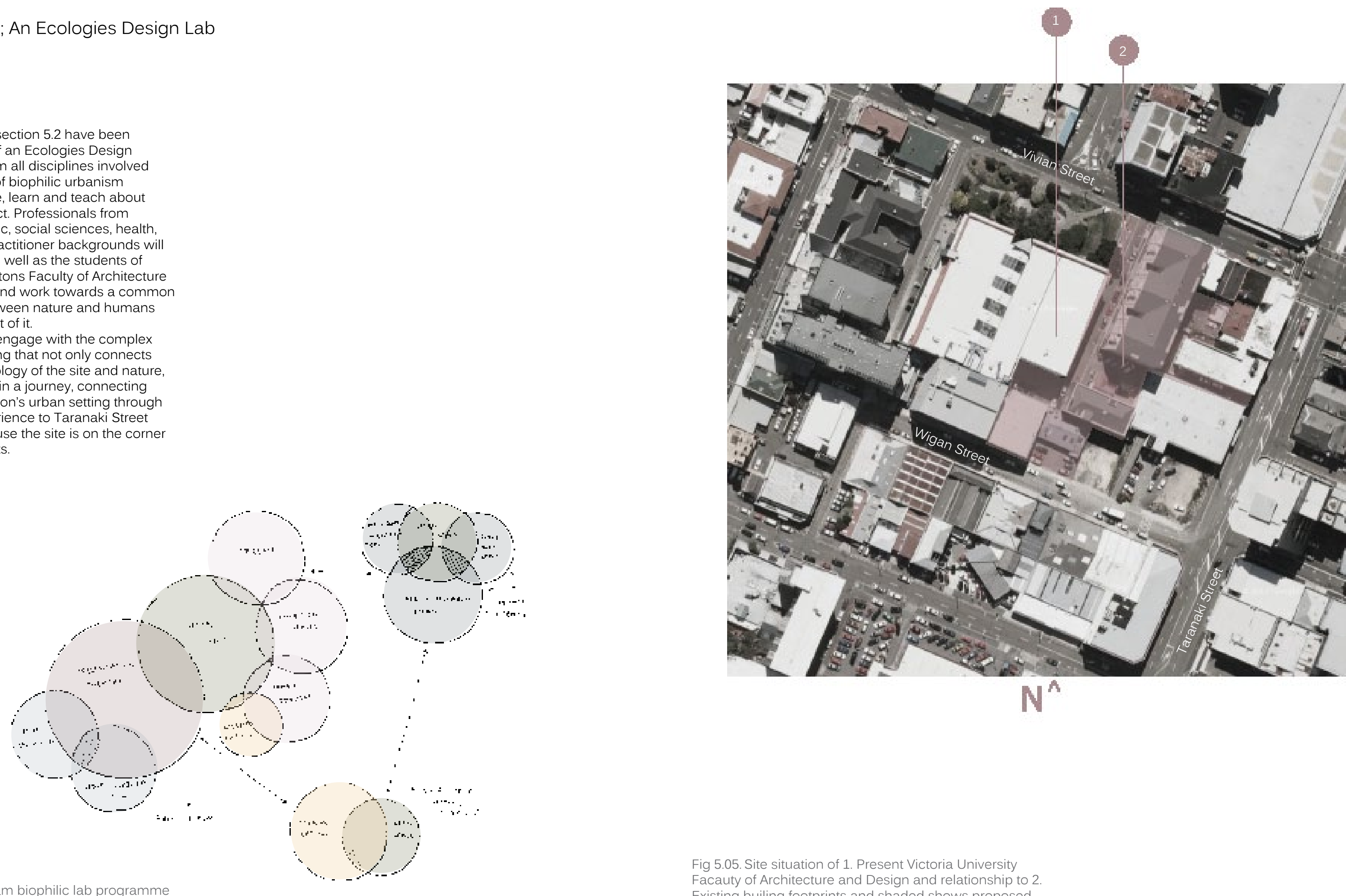

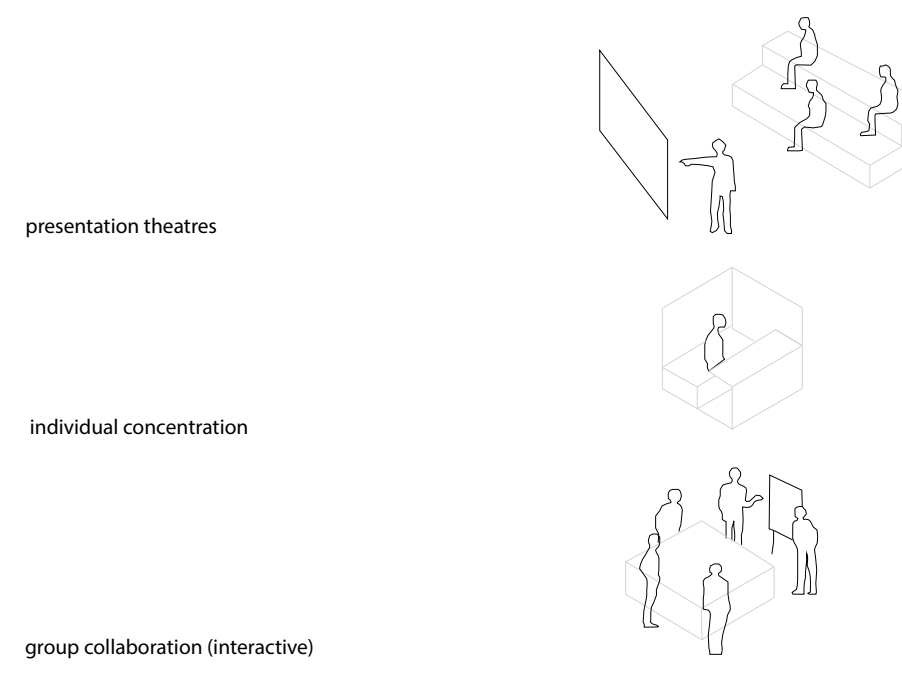

exhibition spaces

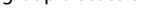

library/ bookstore
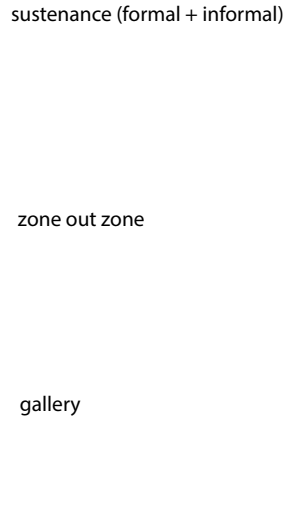

labs r research precincts 
6.0

Iterations 
Design iteration one assumed an organically curved and light façade that was intended to contrast the

sharp angles and heavy materiality of the existing
Te Aro Faculty of Architecture and Design. With the

curvature expressing direction into Knigges Ave, a sense

of curiosity and enticement is achieved as the lines of

perspective draw one down the laneway and into the

unlikely, newly created vibrancy of Knigges Ave and

Wigan Street. This experiment also relates to the first

(his

(hapter 5.2)

What worked well for this iteration was the gentle

curvature and formulation of gestures and shapes of

the façade, however at this point it was a struggle to

articulate interior space that complement the fluidity of

movement from the exterior. The current composition of

space divorces further the exterior natural elements and

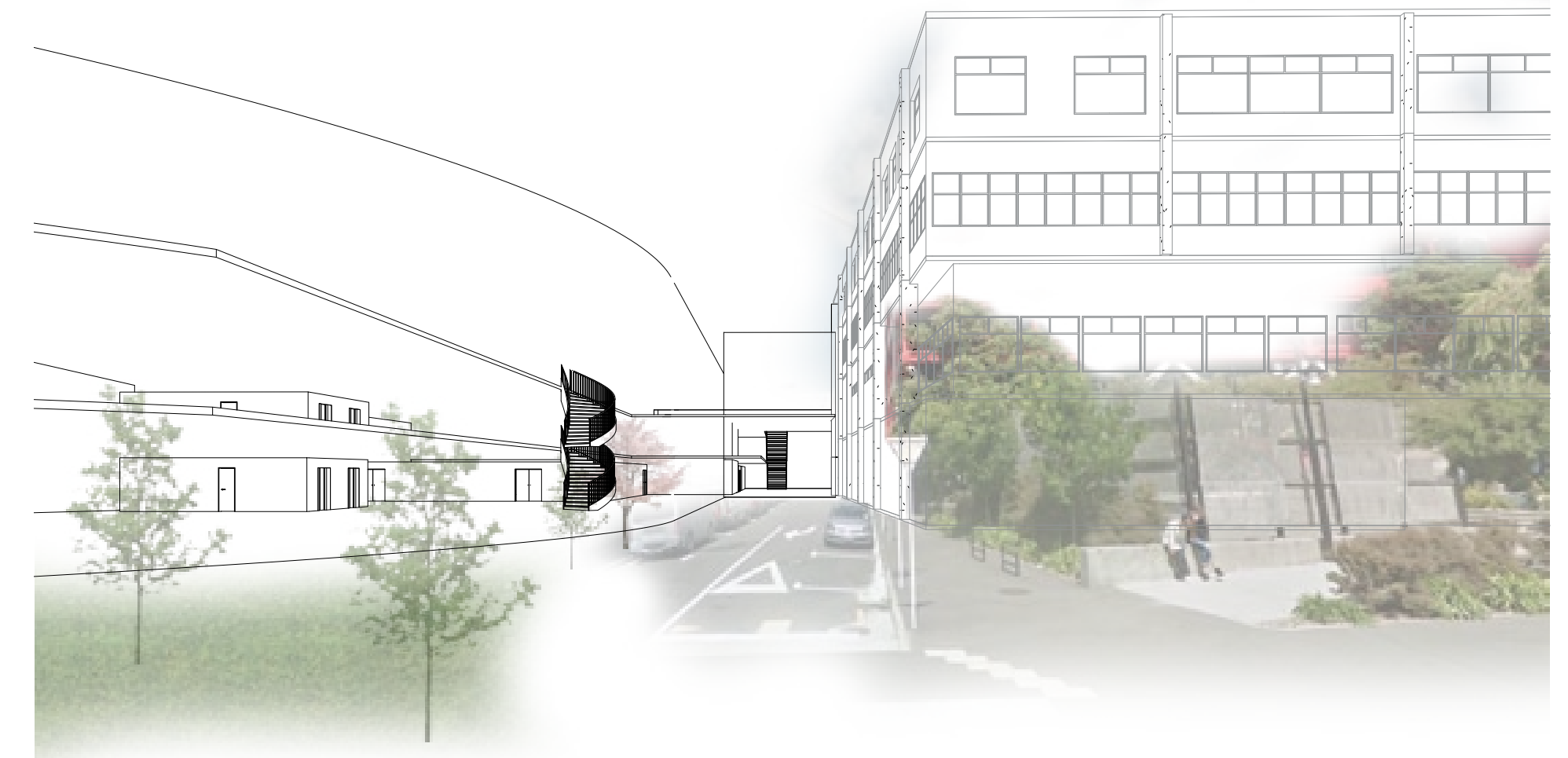

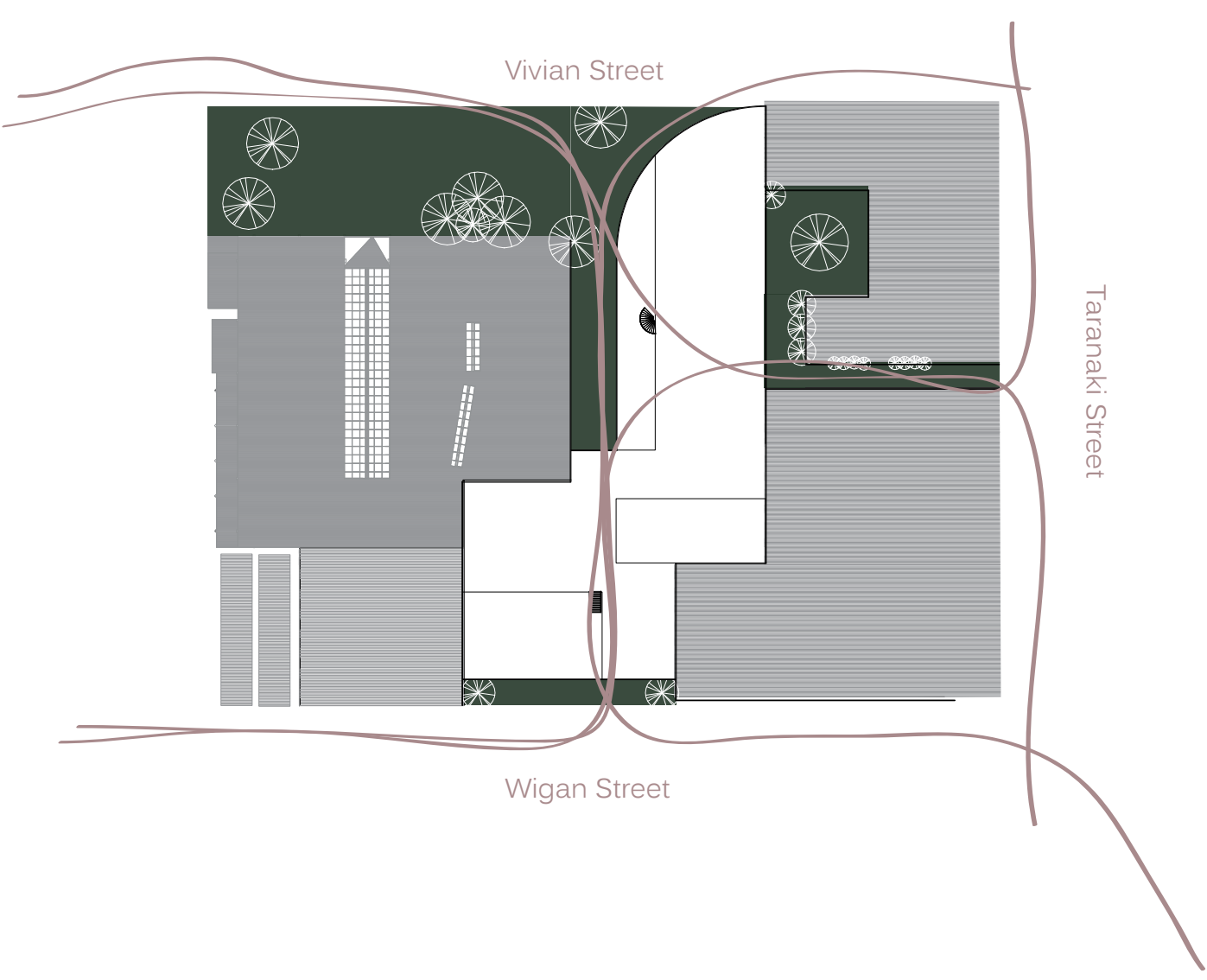

Fig 6.01. (Opposite page) Initial perspective down Knigges Ave from Vivian Street. Curvature of facade enticing people into intervention. Fig 6.02. (Above) Diagram of pedestrian movement off Taranaki Wigan and Vivian Streets and through Cobblestone Park and the Ecologies Design Lab. 


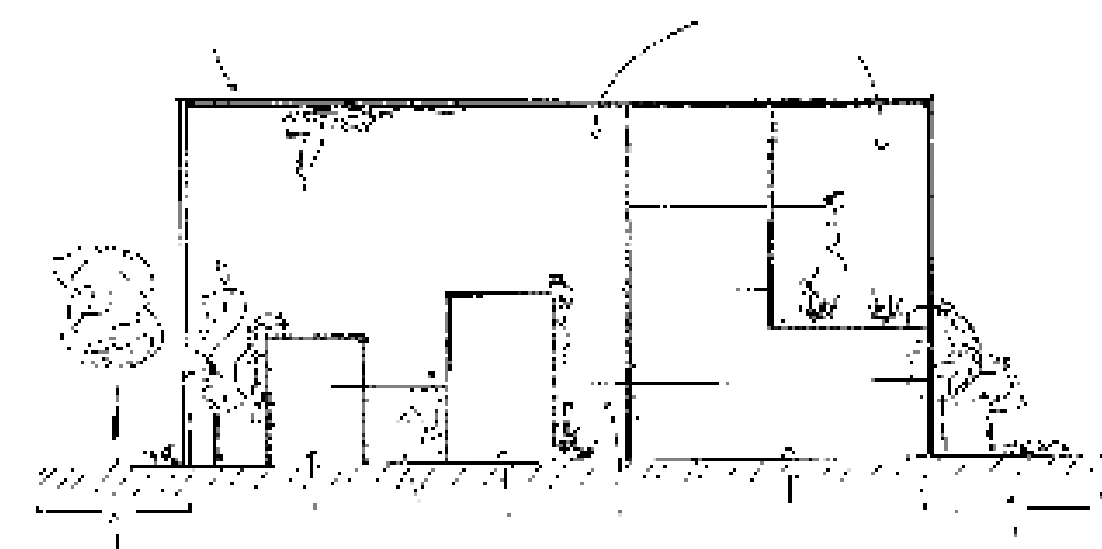

Fig 6.03. Sketch of section through design iteration showing what is

Design iteration two was about blurring the boundary between the interior and exterior; literally about bringing of Forestry and Nature Research in Wageningen, the Netherlands (fig. 6.4) where the laboratory and admin building was to be designed a functional, user-friendly research facility working in harmony with nature; that was also versatile and ecologically sound. With all workspaces in contact with indoor and outdoor gardens, appeal to an unmediated, primarily sensory isperience

Although the concept and depiction of spaces within the precedential lab are in accordance with the experience that is to be translated into the Ecologies Design Lab in Wellington, a further expression of blurring the line between interior and exterior is what was taken from his architectural casestudy. The whilst integrating unexpected architectural elements that still speak of biophilic design will further extend ideas taken from this precedent.

The intense inclusion of nature worked well for this design iteration however there was stil wa sense of rigid formation that halted this exploration. Designing dimensional cubes of space into the structure that

ultimately hindered the freedom of expression this project should encapsulate.

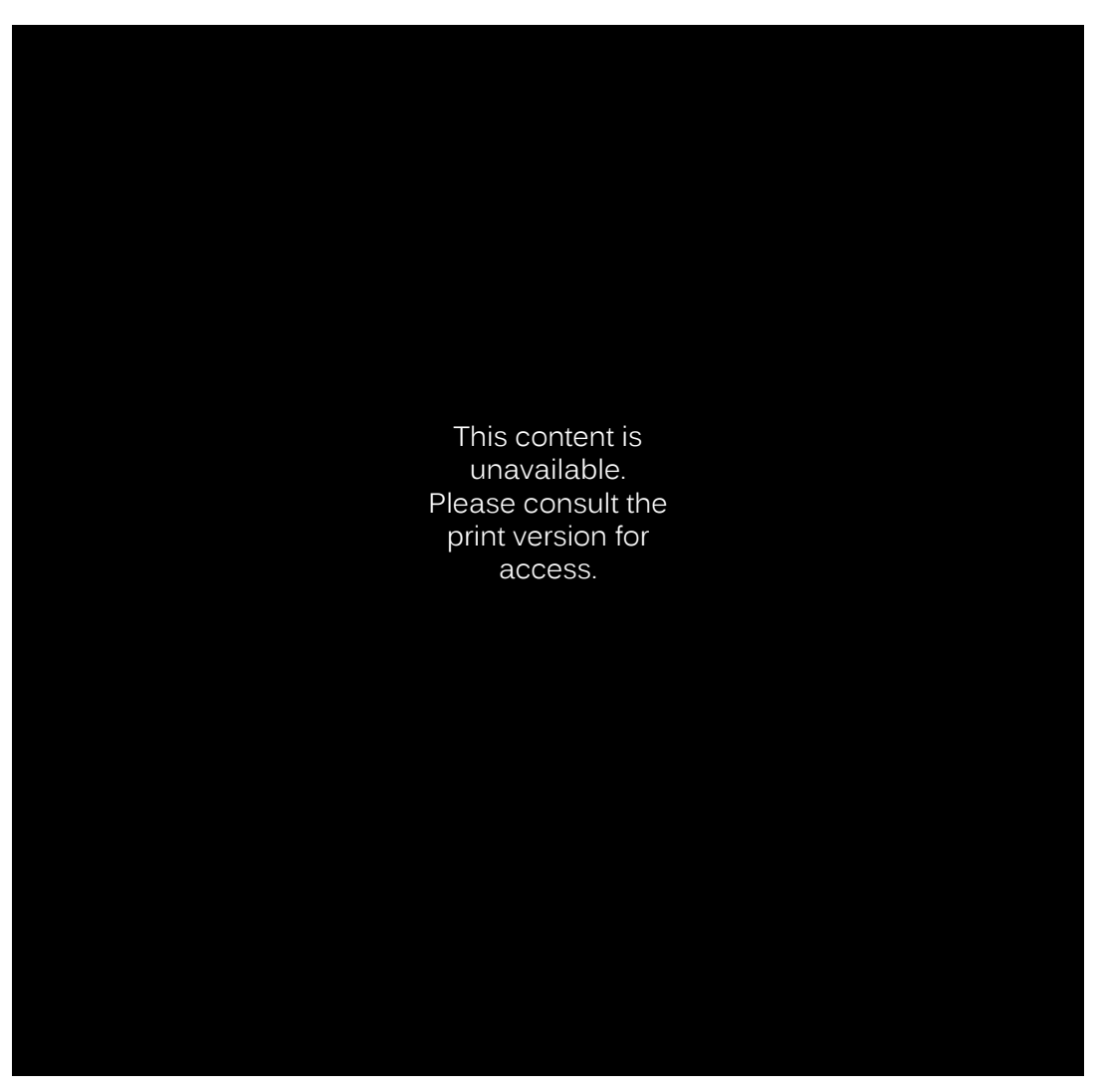

Fig 6.04. Image of Precedential Study Institute of Forestry and Nature Research in The Netherlands

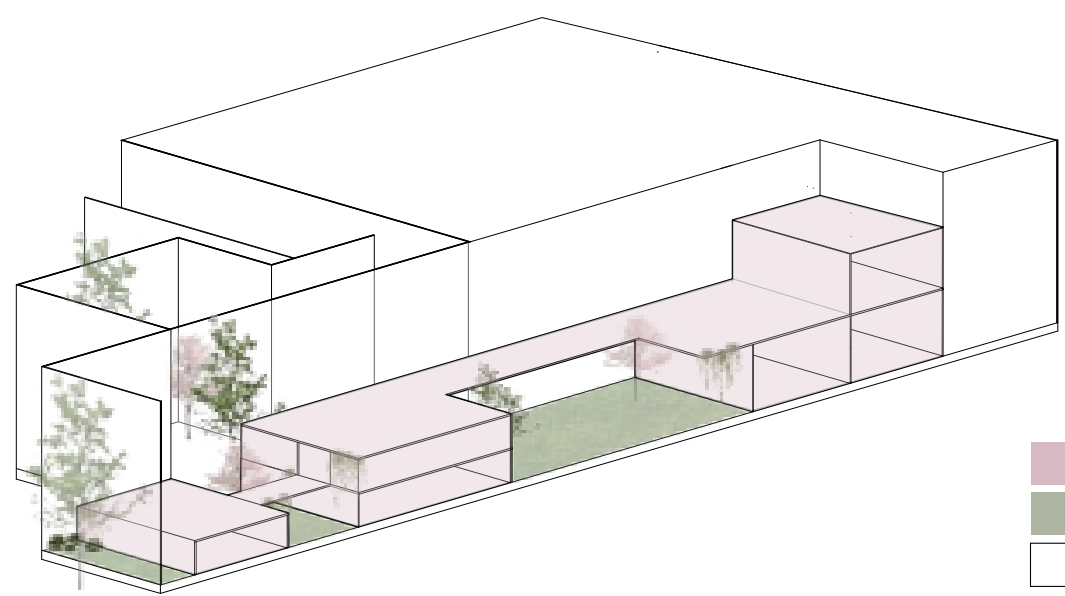


ecologies and wider ecosystems of urban interaction

included Lyons Architects New Academic Street for RMI (fig 6.6) and Geoffrey Bawa's gardens throughout S Lanka (fig 6.7).

Although the precedents (fig 6.06 and 6.07) vary in brief, scale, geography and medium, they have in common setting (Lyons New Academic Street) and people to the immediate ecosystems at play on an immediate site (Bawa's gardens). One of Lyons main aims for the New Academic Street is to open up the campus to the surrounding streetscape and creating light filled 2017) with the rooftop urban spaces (RMIT University, currently separating the vibrant Melbourne urban life to the busy students schedule; something obvious this thesis and their project have in common. Bawa's work was studied and utilised at a more intense scale as the positioning of sloped rooves collected storm water in an underlying pond feeding both natural cycles and sensory experiences on the site. As people experience e conts, they are more inclined to visualise, understand, care and hence protect whatever they are experiencing.
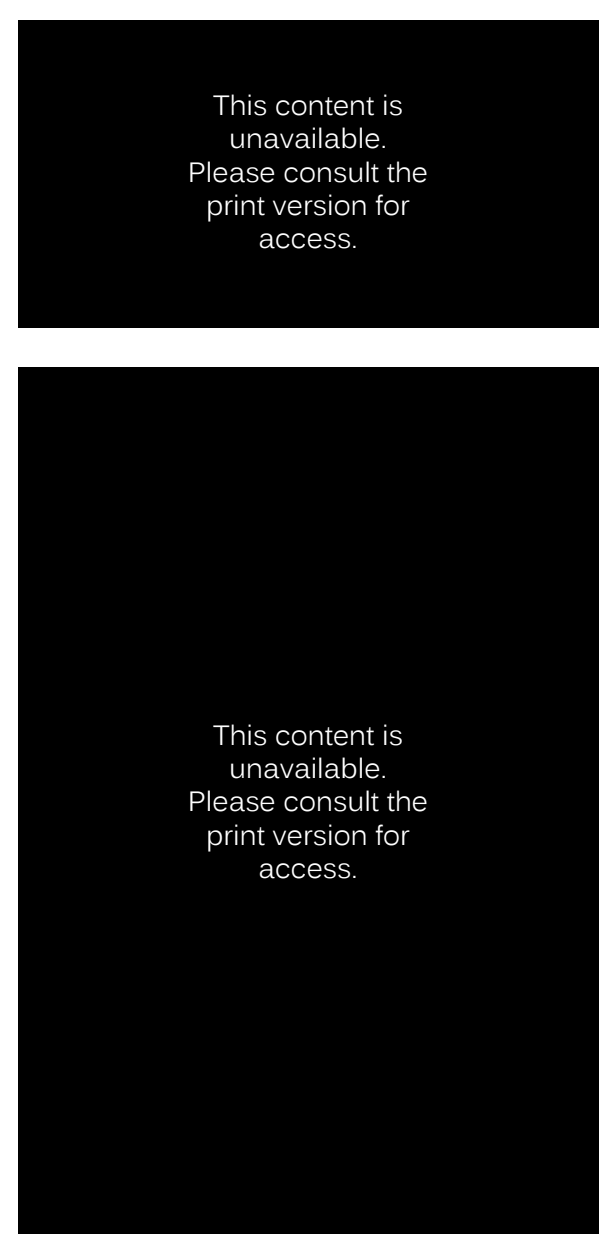

Fig 6.06. (Top) RMIT New Laneways project precedent

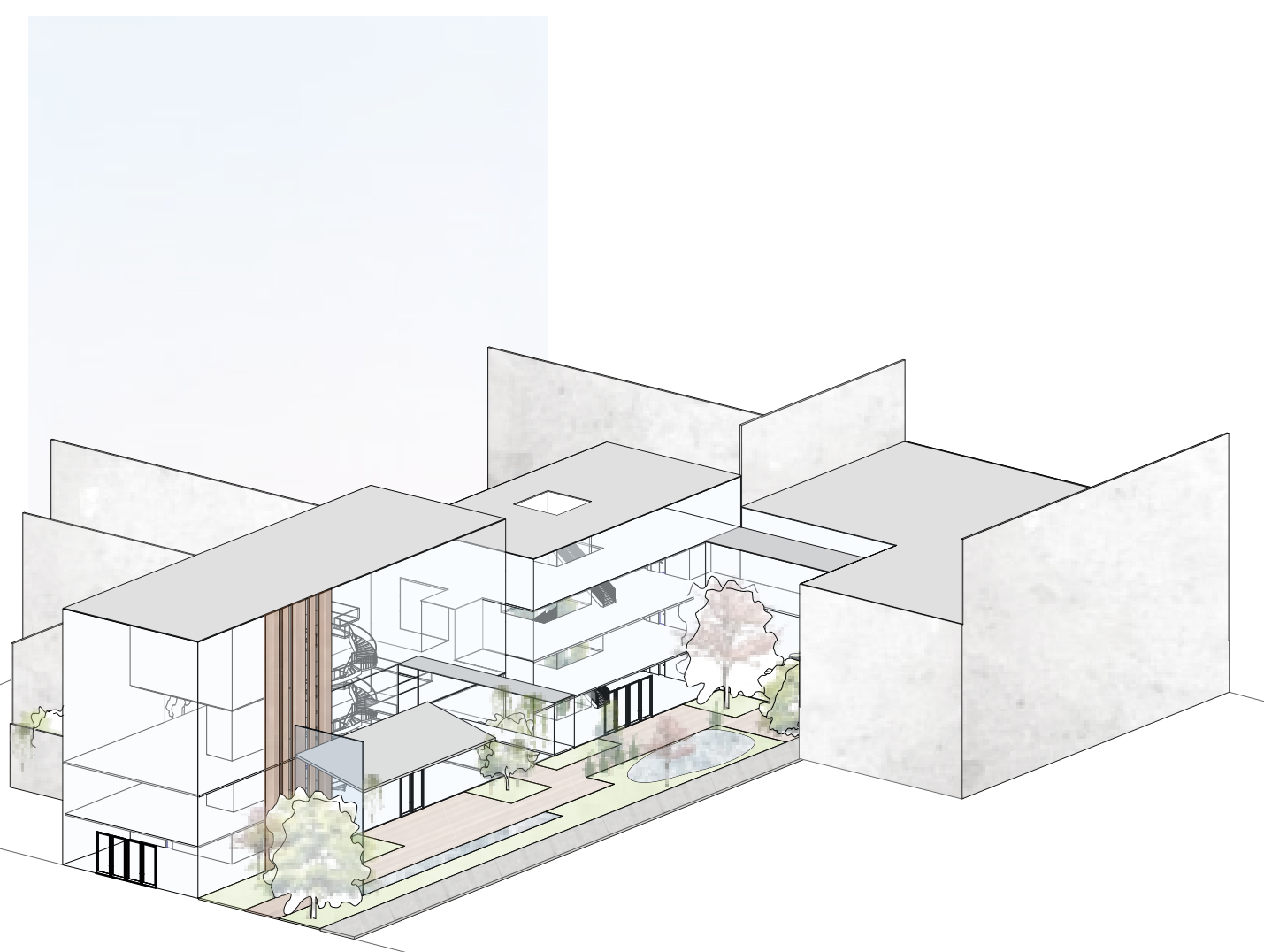




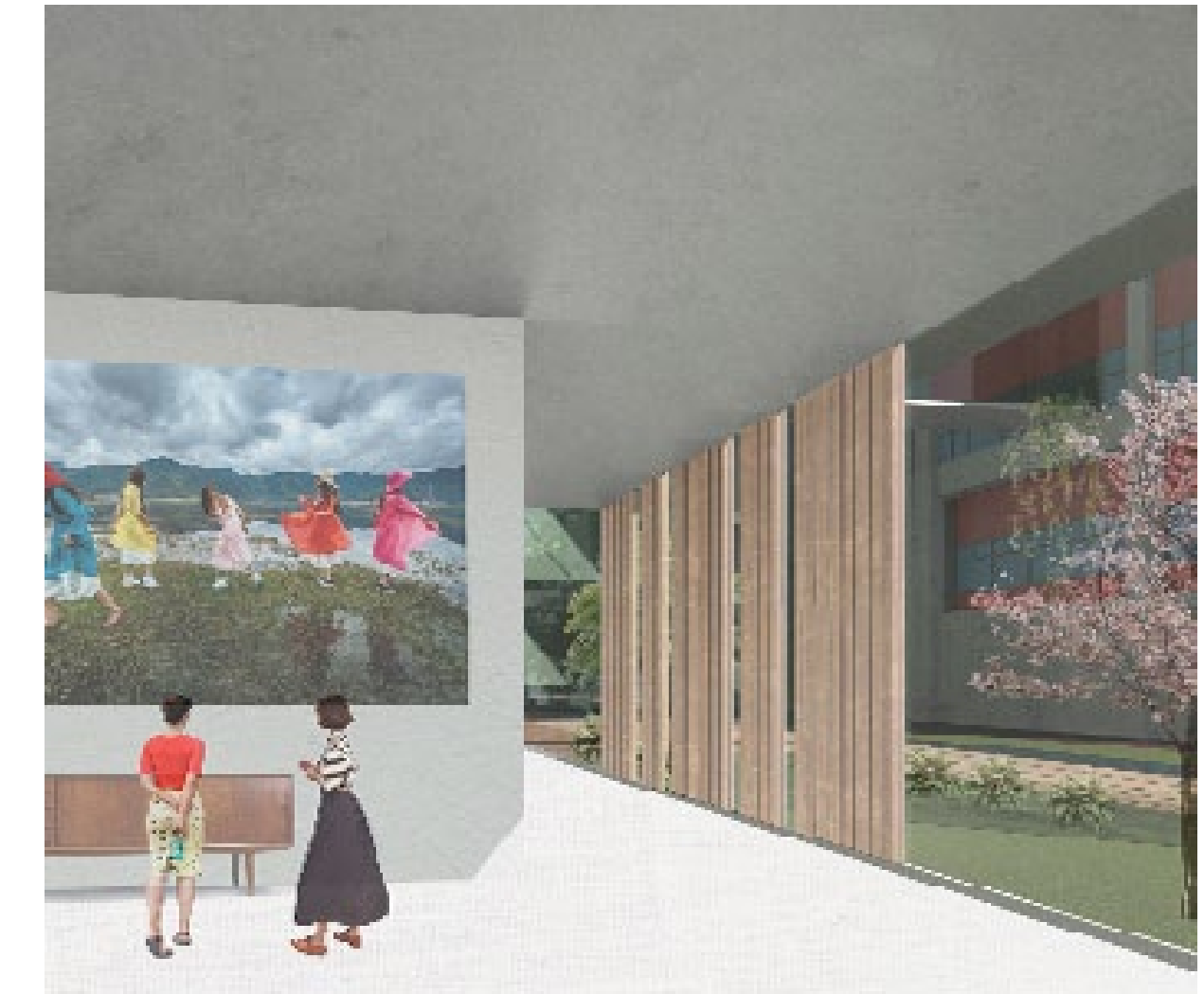

Fig 6.09. Entrance gallery showing compression of space evoking feeling of refuge

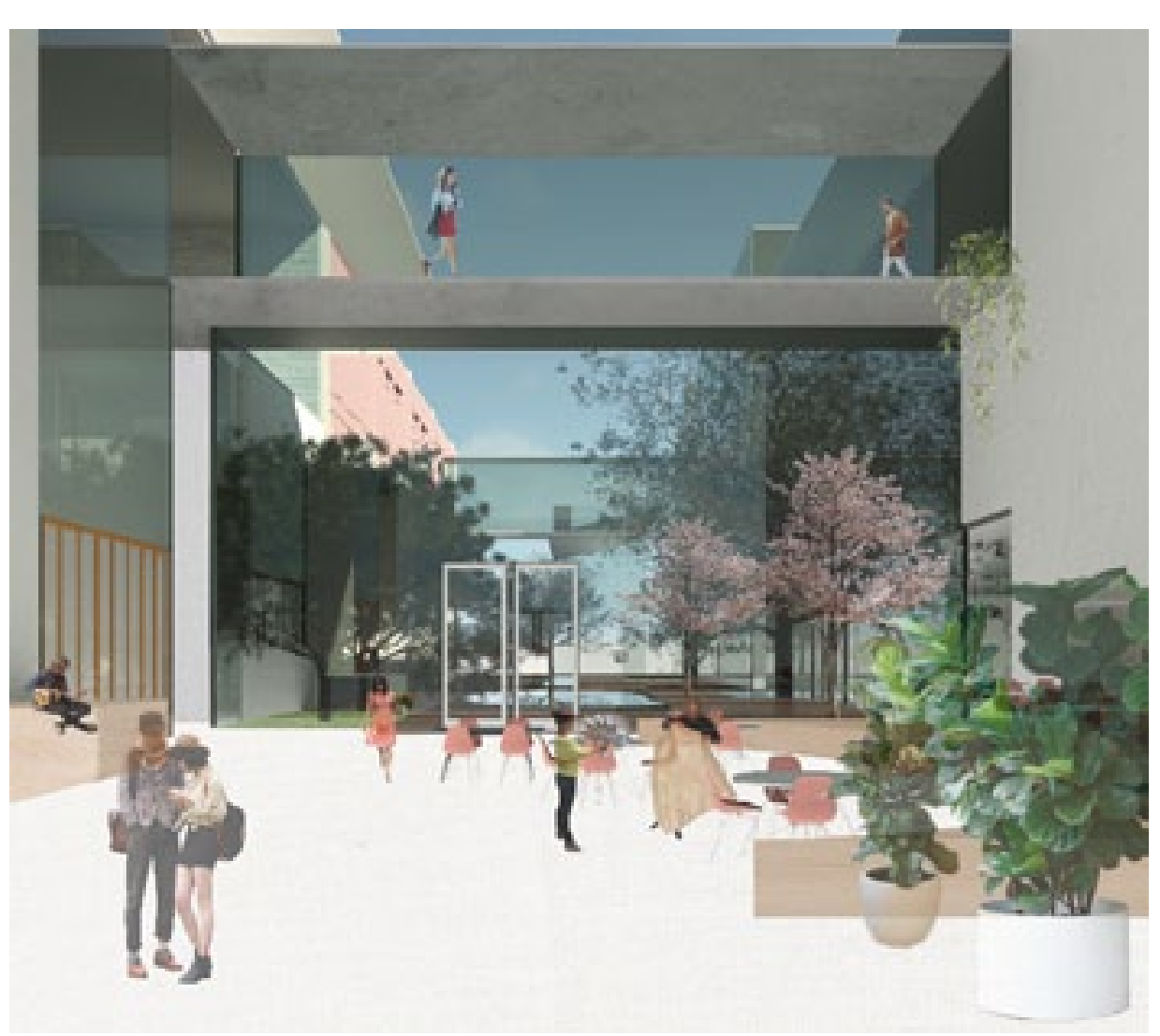

Fig 6.10. Dialogue space breakout area, scale evoking a humbling of human scale
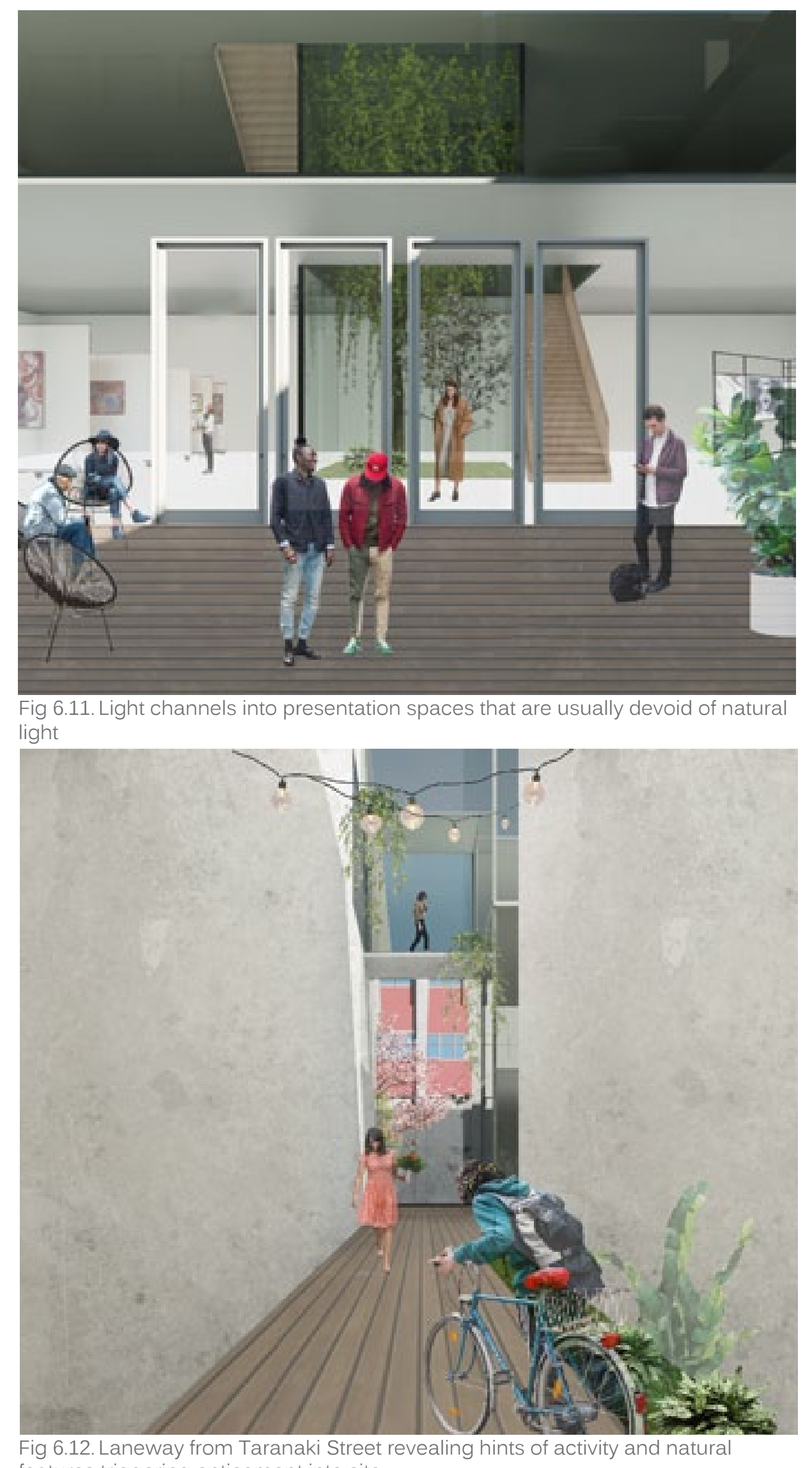

features triggering enticement into site 


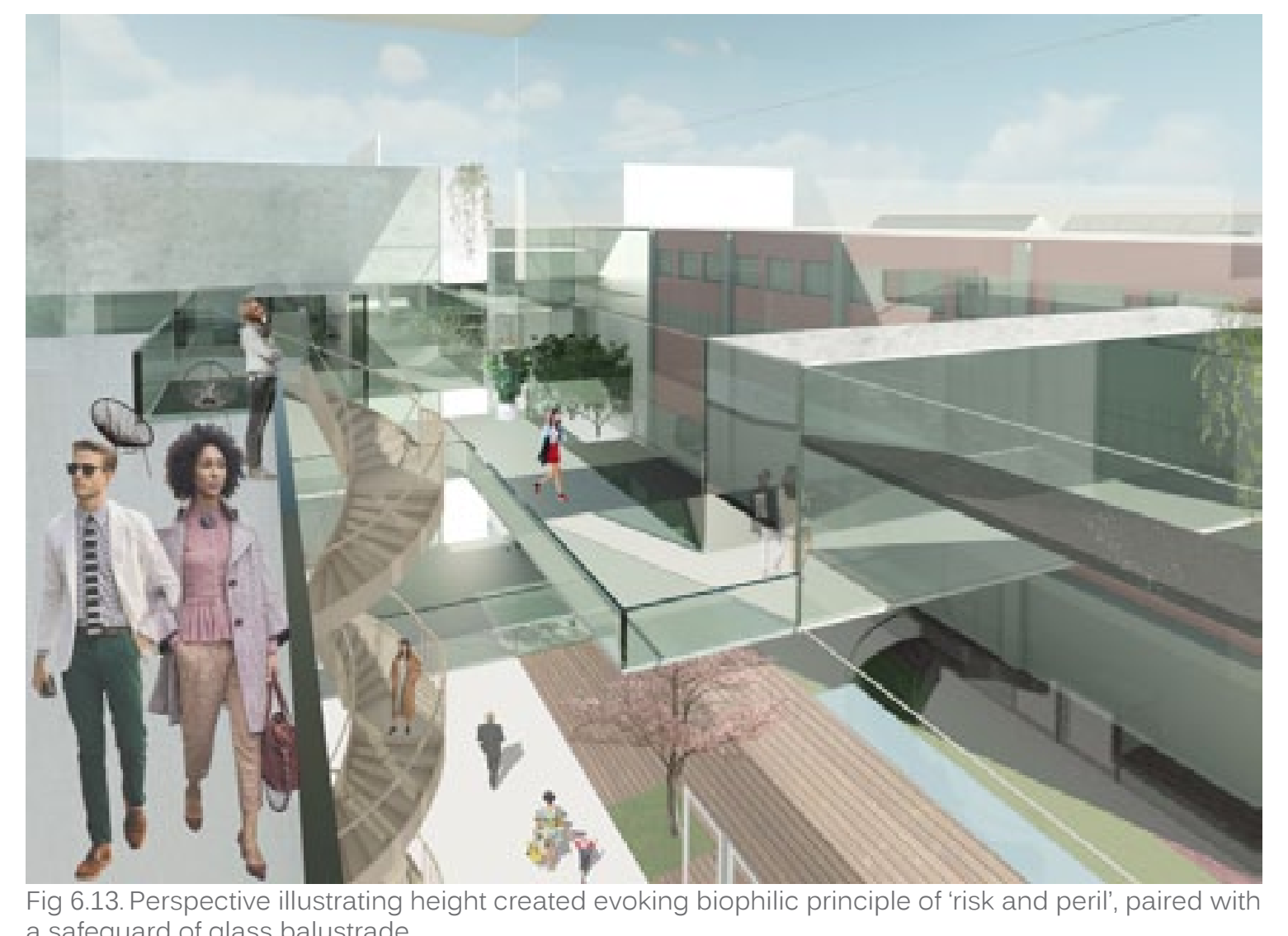

a safeguard of glass balustrade

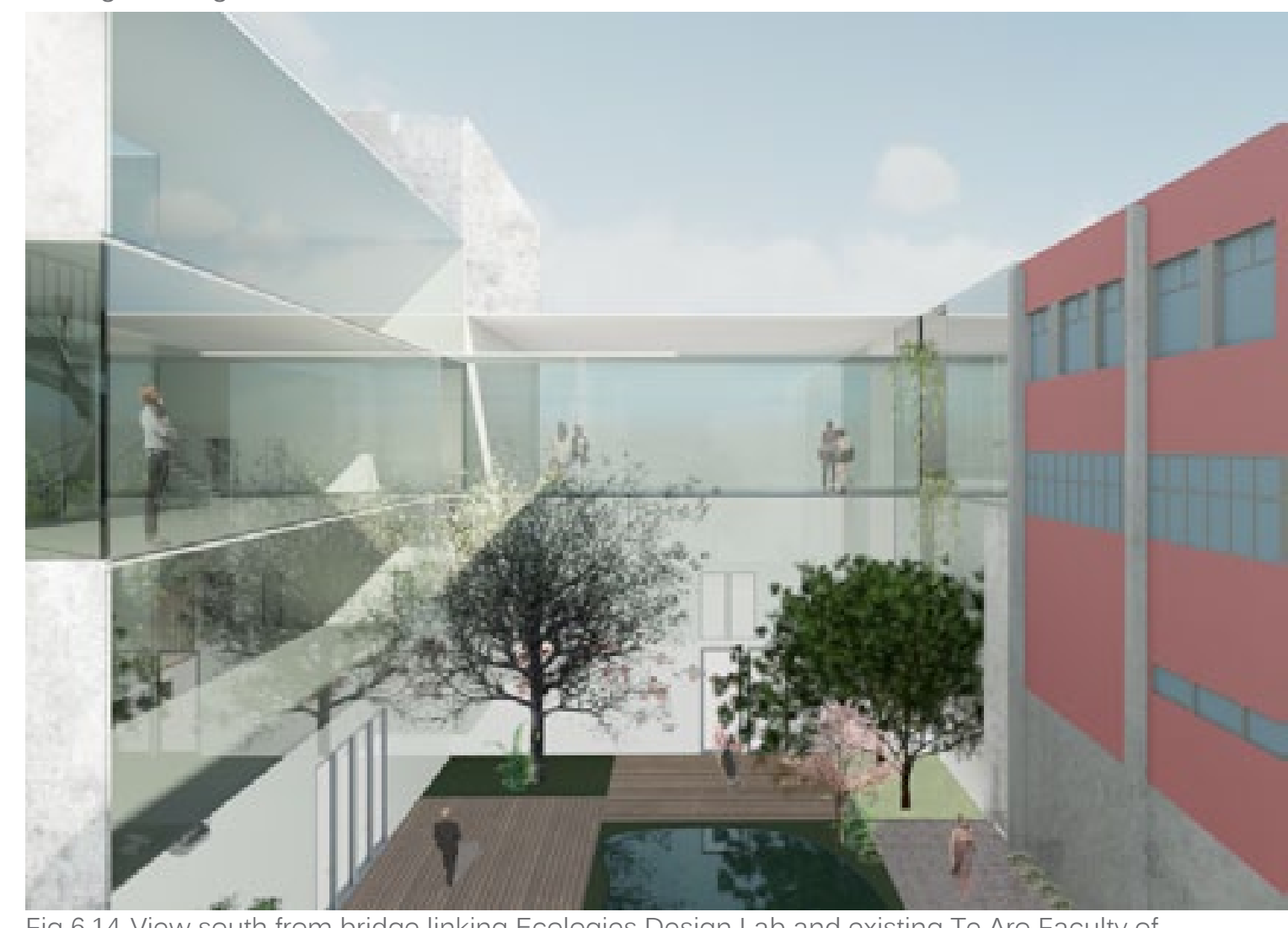

Fig 6.14. View south from bridge linking Ecolog
Architecture and Design through to Wigan St
The review of iteration three highlighted where the testing. Following the August review there was some confusion over whether the 10 characteristics of enticement (pre-refinement) were elements that had to be implemented into the design (as a checklist) if they were utilised as a set of tools used for critical assessment. As the intention for these characteristics was the latter, it was suggested that the list be

As conversation continued and started covering the wider ecosystem that this building is intended to address, the plan to connect smaller points of biophilic urban acupuncture around the city that lead to this large hub of biophilic research was likened to Martin Bryant's investigations on "Sweet Spots" (Bryant, 20is). It was agreed hat "Swe site in which however further testing and understanding of the organisations of these spaces needed to be done in order to articulate how the inside and outside work and how each laneway adds to enticement and hence how people are to inhabit this space between the existing urban fabric.

The need for these spaces to be able to express designing in elevation, sections and on when ecological meaning needed to be imprinted on each space to make moments of connection, not just in relation to tangible natural elements (like materials and visuals) but also in terms of further displaying the ecological process of nature that are present within this site and building. It he occupiers of his space natural processes are at work they are mose likely to connect and hence care about the effects this building is having on the systems within Wellington as a whole.
The final comments of this review were thoughts of the proposed building that was presen about structural members that were simply "tacked" on were voiced Designing from human perspective however has let this thesis unfold from an experiential point of view and resulted in perspectives that may not look structurally sound, but portray an ideal that would be reached by the end of this investigation. By experience through time, structure was secondant Post this review, more emphasis was placed on structure and materiality that fed back into the desired experiential journey 


\section{0}

Refinement + Reflection 
This next design phase was about opening up,

and thresholds. From the revised and concise list

of enticement characteristics, strong ecological

connections were made between element and element.

and element and human. Previously this thesis treated

the interior and the exterior as two different entities,

however they are one and the same as an experientia

journey. From the critical reflection of this, a succinct

architectural elements, inclusive of the structural ins all A code of materiality portrays the relationship of what is inside, outside, or transitional, creating a kind of spatial dance relating to biophilic principles that embody what it is to be full of poetry, beauty and wellness. The preceden of "The Nest We Grow" has driven the inspiration and articulation of incorporating ecological processes within the built form

Furthering this, the integral objects within this built form that stand as points in a journey through the urban fabric
act as points that biophilic impacts can ripple out from. The tectonics have come from this notion created on a small scale within the site, and ultimately interfere and create an echo throughout the city as peoples bodies move through and remember in a reoccuring manner the design language established within the Ecologies Going back to the idea of urban acupuncture, certain points in this design articulation have become integral as they represent strong links of dialogue, learning and discovery.

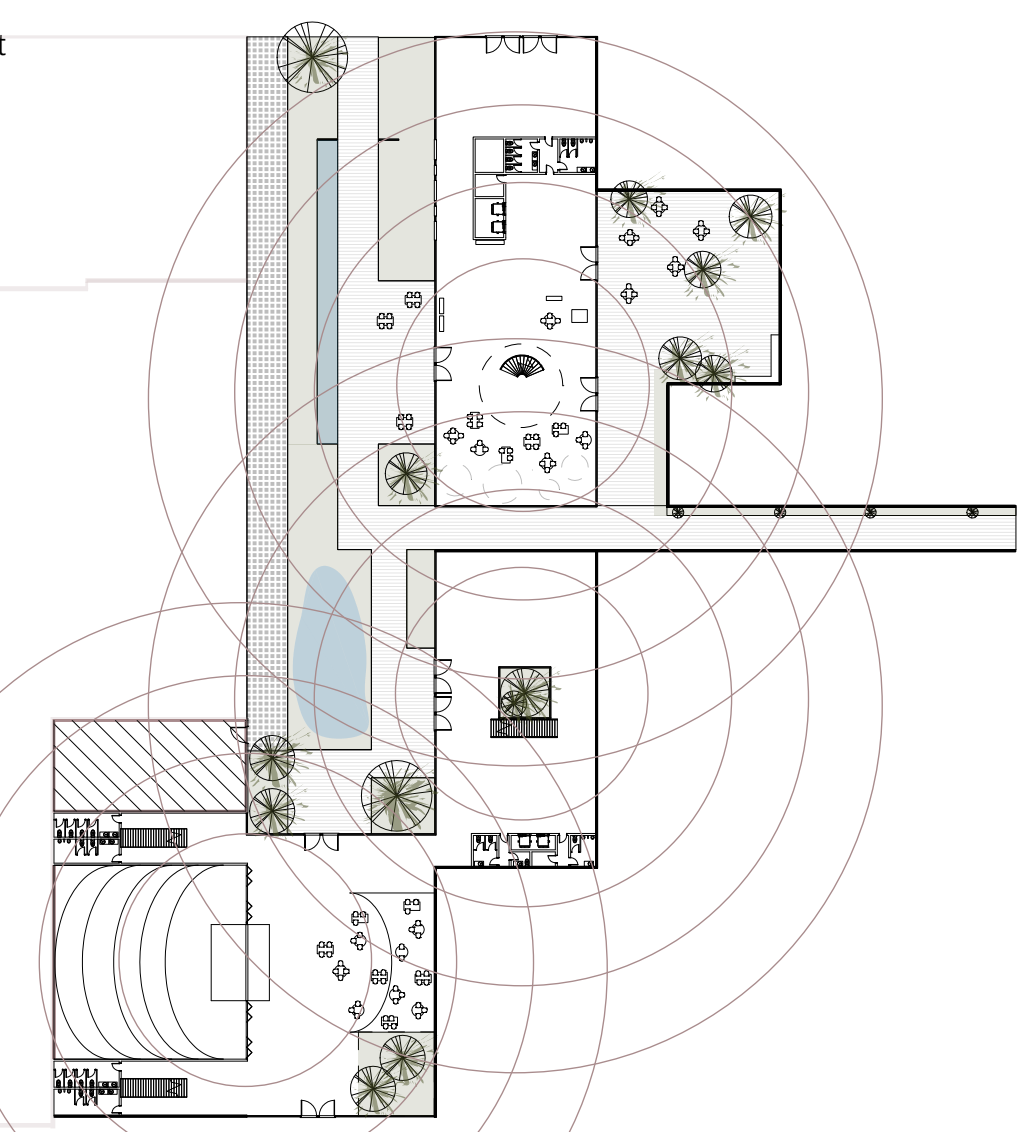

Fig 7.01. Diagram of design iteration 3 and ripples
Ig 7.02. A series of diagrams and figures from The Nest ecological processes are the drivers of design 
Having been derived from biophilic principles and holding in high regard the preservation of the natura environment, this building works predominantly with passive heating and cooling techniques, utilising the ample glazing making up the façade consideretion such as neighbouring buildings creating shadows across the building, and the strategic placement of openings, doors and windows to the exterior were used to ensure excess heating and cooling was not a problem within the interiors.

Thoughtful placement of elements such as concrete looring and walls ensure that the material language ensuring coolth in the warmer days and a slow rele of heat over night, and passive heating on the cooler days. Placement of openings in the façade encourages cross ventilation with minimal intervention needed by engineered mechanical systems. Despite needing mechanical aids throughout the large scale building, the balancing of exposed glazing and the dynamic that internal conditions can be enioyed at a median ( Atmospheric conditions are not static, they are changing over the course of an hour day and season. Through intense observation of the site and the

inclusion of passive systems within the structure, this building does not divorce those who occupy it from the exterior elements, but gently buffers the extremes that understand changes. For example people can see the rain on their windows and running down glass light

channels within interior spaces.

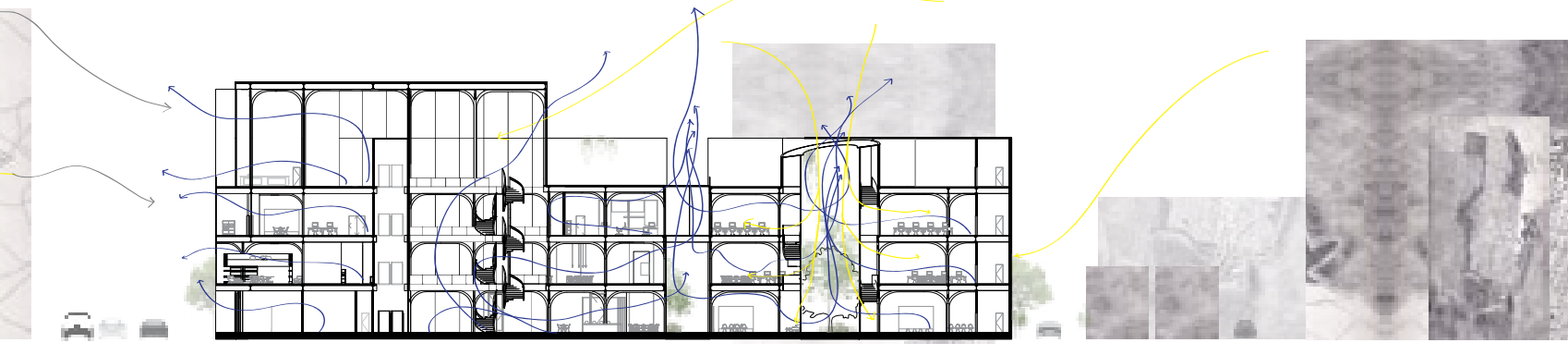

Natural sunlight

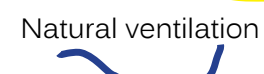

Natural shadowed by

neighbouring buildings

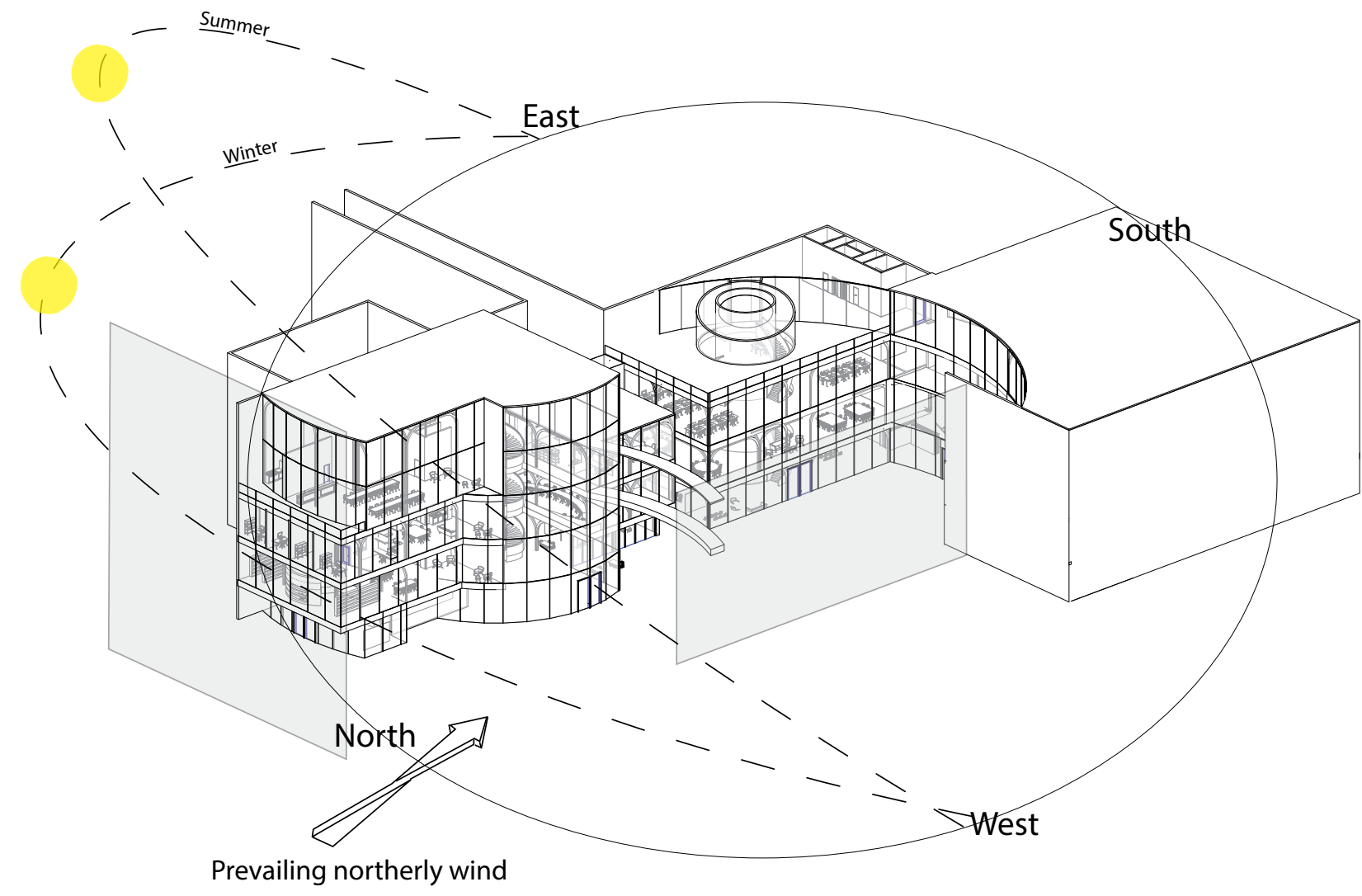

Fig 7.03. Section (opposite page) showing the inclusion Fig 704 Daylighting diagram (above) illustrating he

movement of the sun on site paired with the shadowing of neighbouring buildings. 

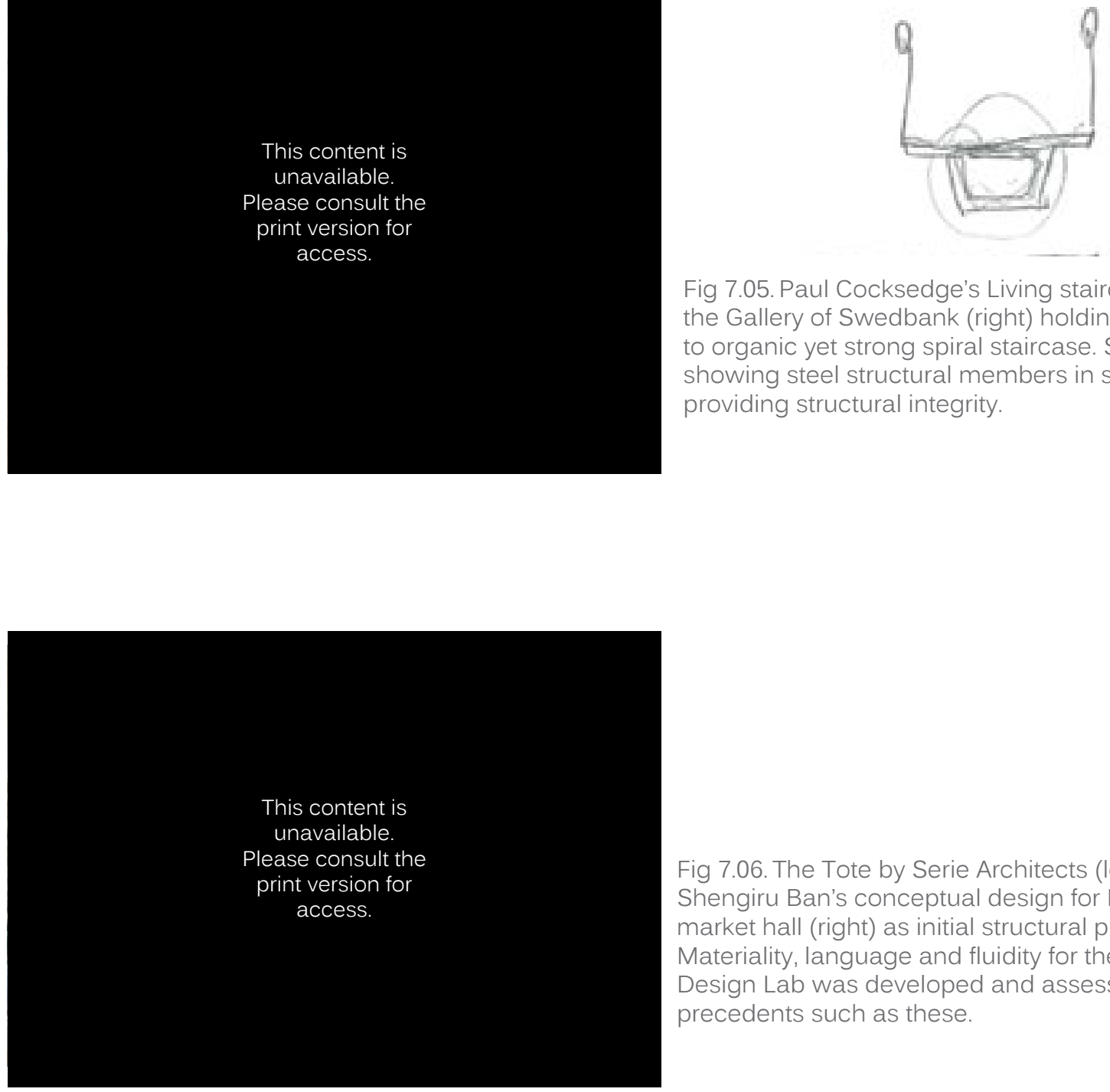

Both harmony and disruption were tested, as were

rigidness delight and curiosity, hence enticement

through the structural integrity of this building was found

Precedent was taken from architects such as Shigeru

Ban's existing and conceptual works, Niall McLaughlin Architects Bishop Edward King chapel and 'The Tote' by Serie Architect's.

Ultimately the structure in this building is designed to leave people in awe due to its scale and height, making human feel small, however at the same time instilling a reflects on the meaning that people are small in relation to the earth and time spent here on it is short, whether this be in nature or an urban setting. At the same time however impacts are being felt on global ecosystems and climal world they evolved in Therefore a realisation part of people as to what must be occur so that pople can come together and rectify the negative impacts they have created.

Fig 7.07. Niall McLaughlin Architect's Bishop Edward King chapel drawing on emotive and fluid moments. series of texplains that the structural integrity of a Series of tap

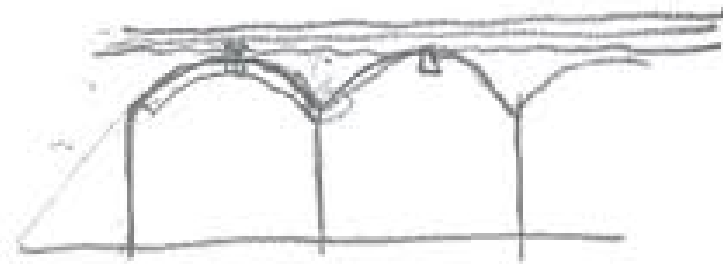

7.06. The Tote by Serie Architects (left) and . Deteriality (language and fluidity for the Ecologies Design Lab was developed and assessed against pedents such as these. 
8.0

Resolved Design 
The following chapter describes the experiential journey the question "How can architectural and urban design foster and celebrate connections between people and their surrounding ecosystems through biophilic design?

The images serve as perspectives portraying how one would experience the space and connect with the modelled, analysed, rendered and presented.
Fig 8.01. (Opposite page) First floor site map in the context of Wellington's urban fabric. into the and expesplon of ipples integrated differing ecologies and materials that evoke a connection for the natural world humans evolved in, and a part of. Showing gallery, atrium, presentation and dialogue public internal spaces.

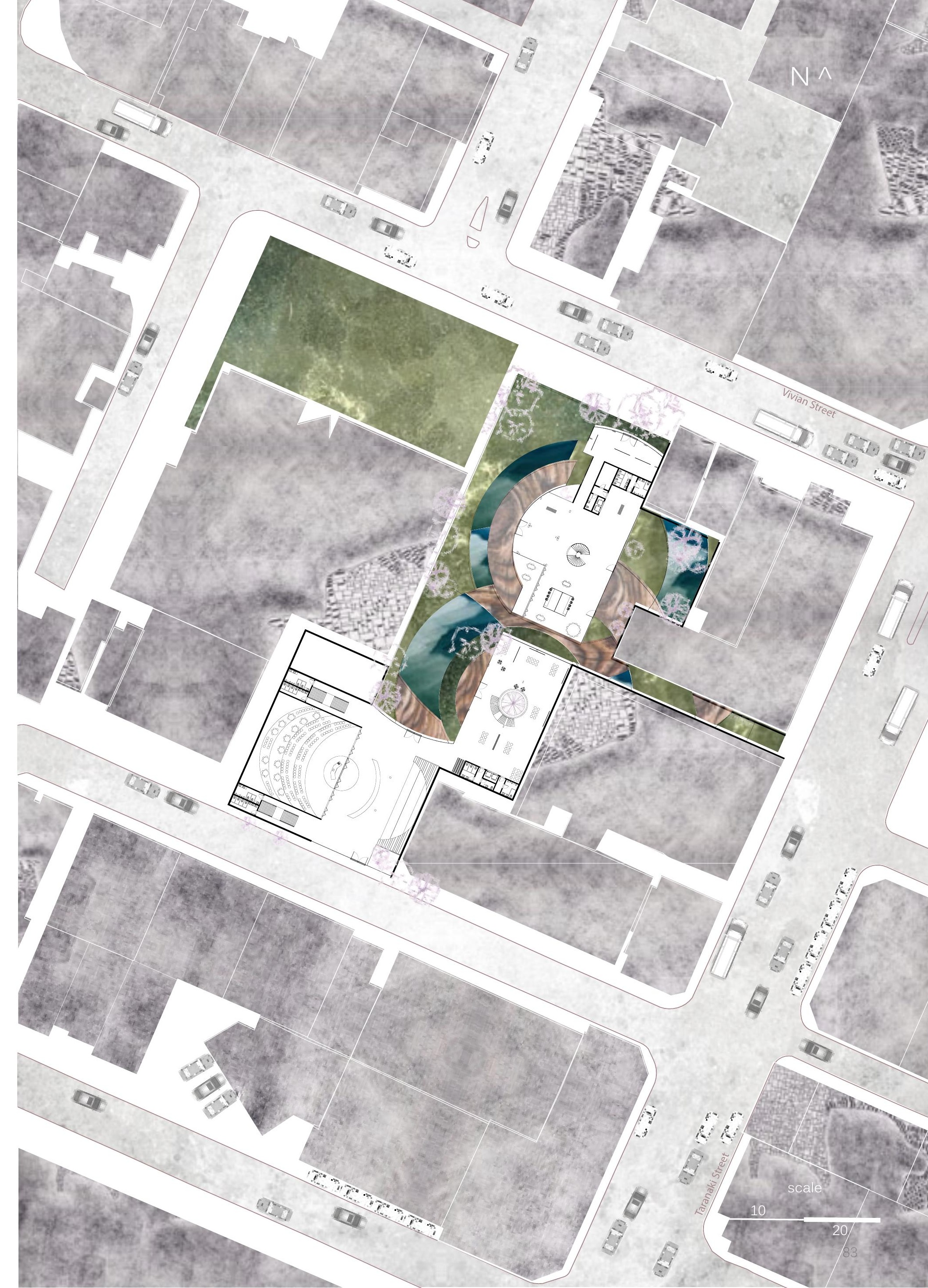




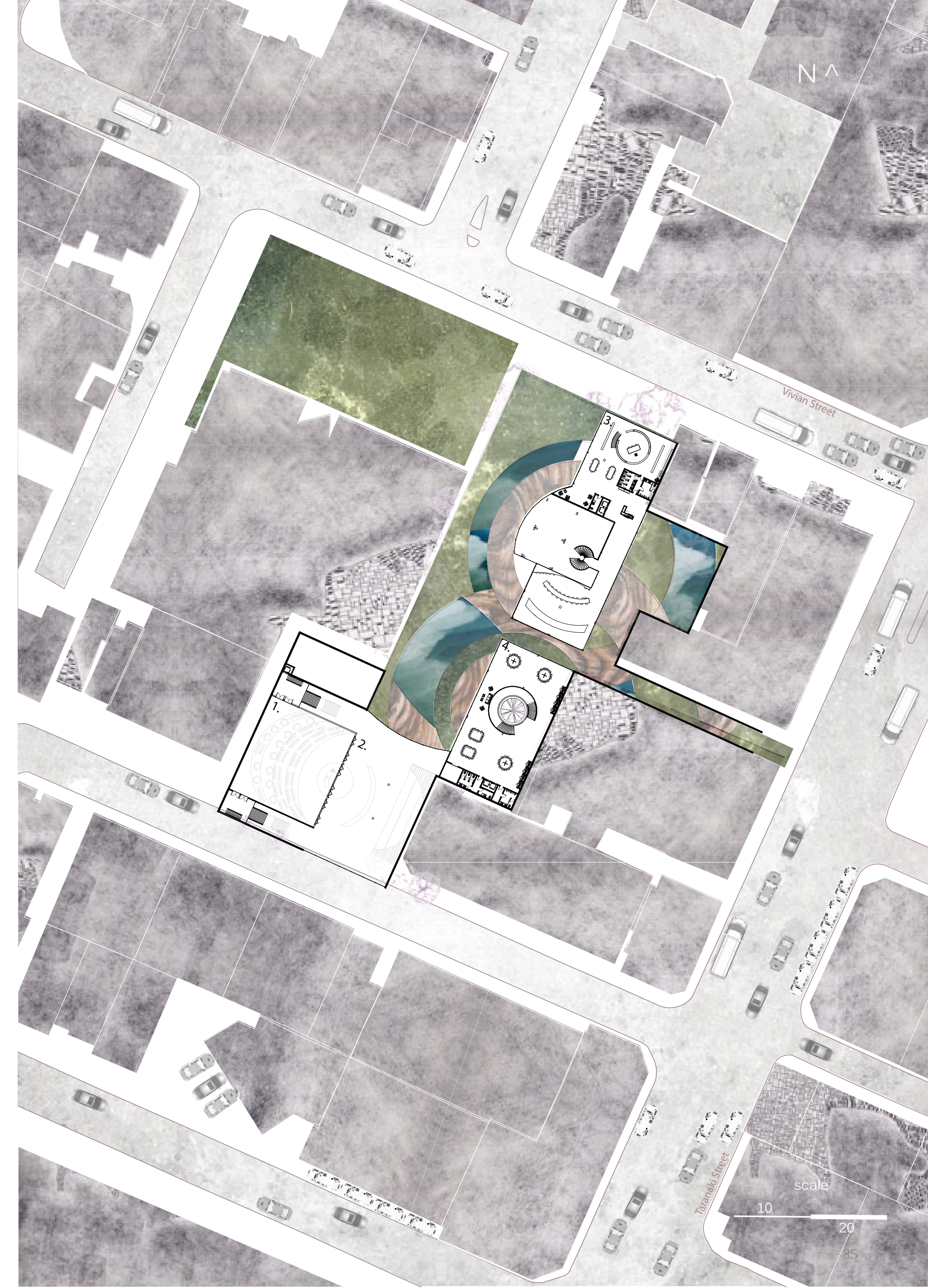




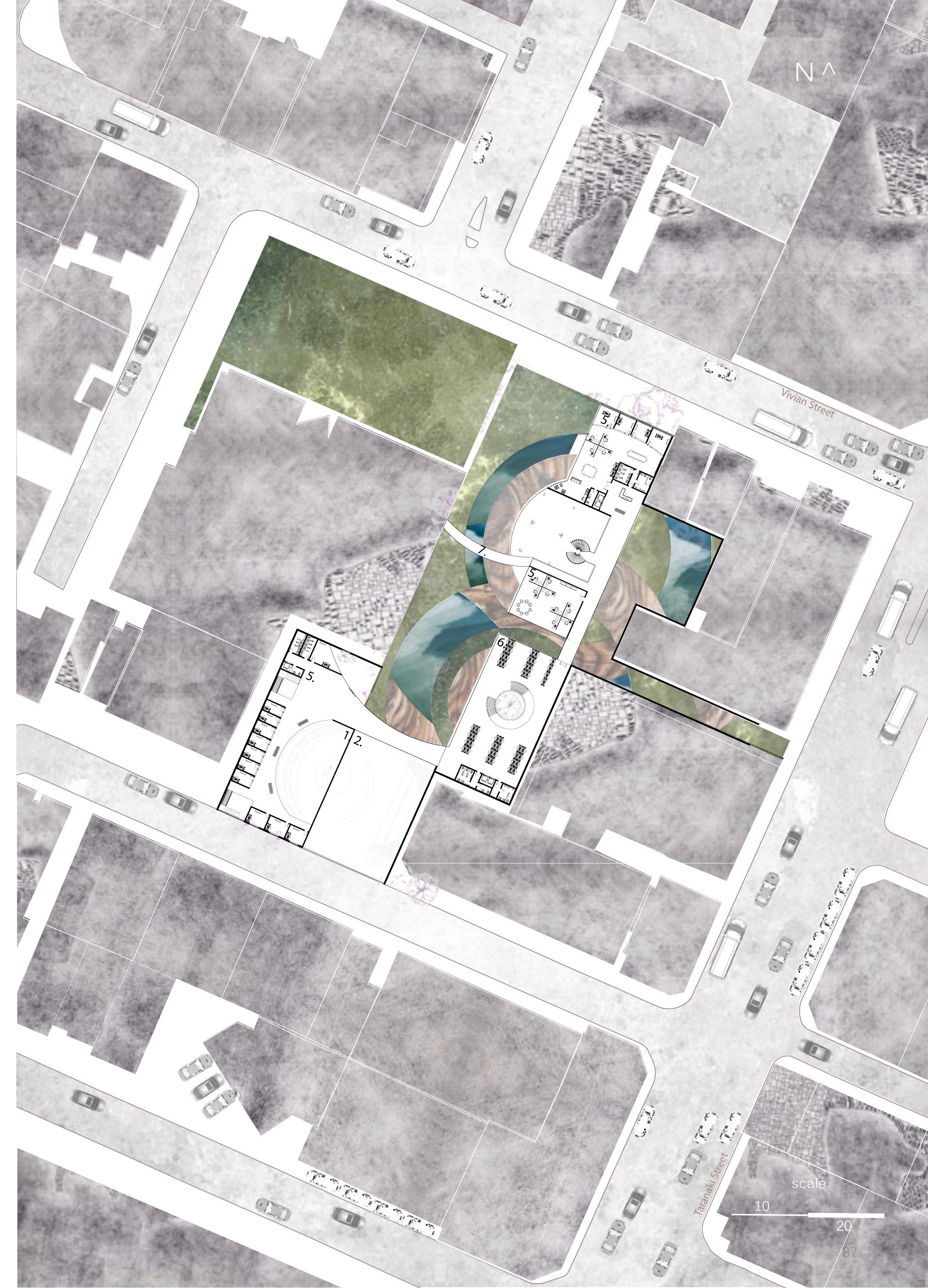




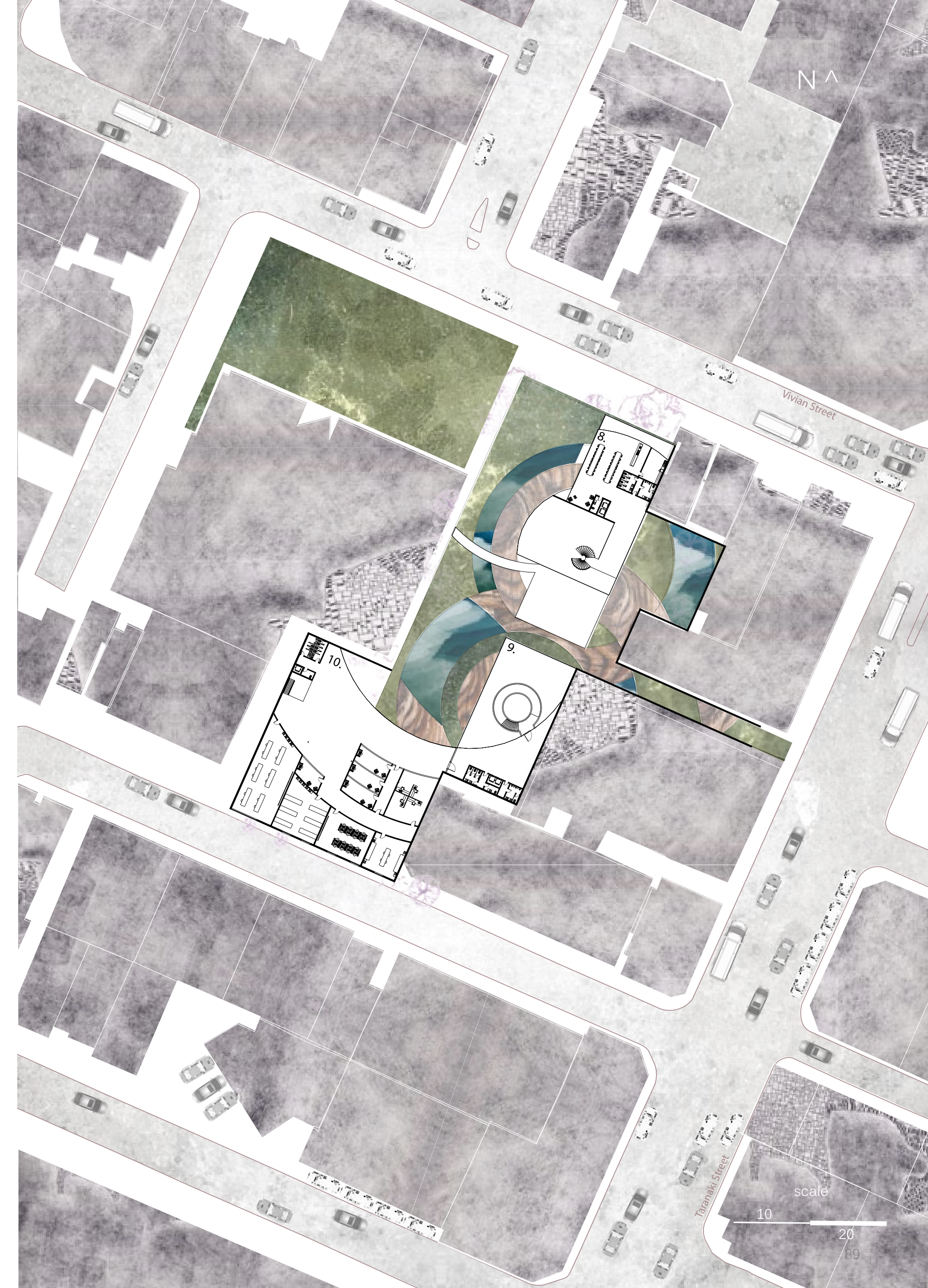




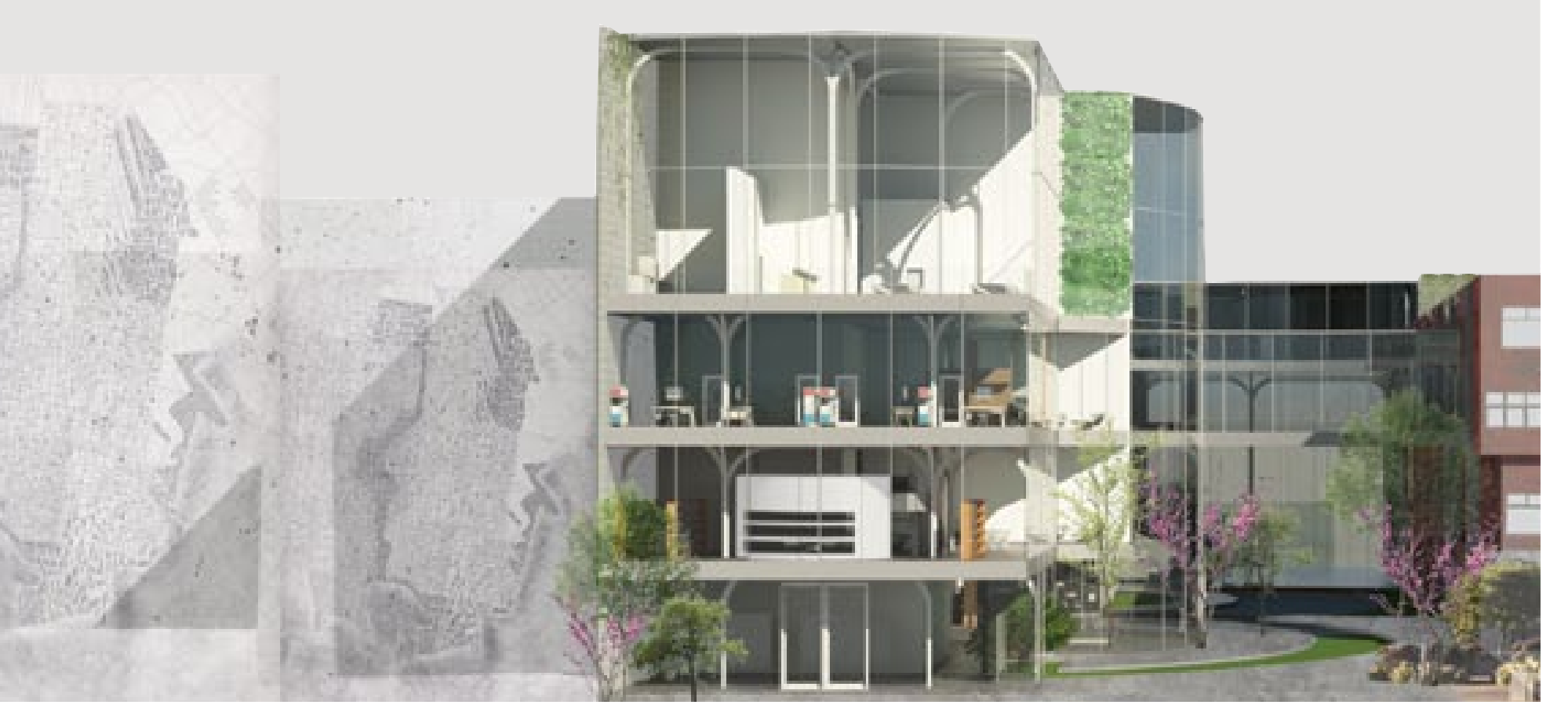

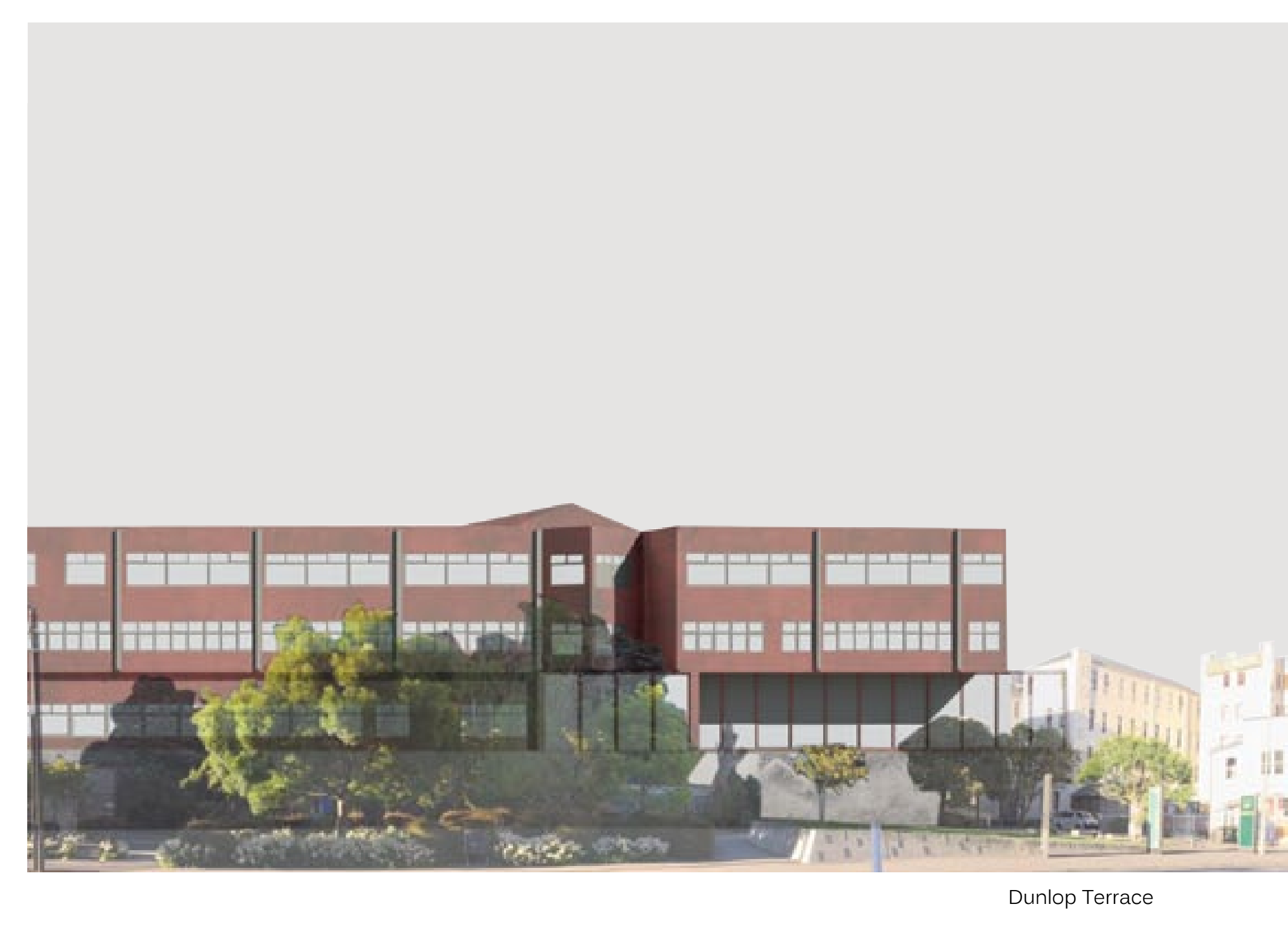

Fig 8.05. North Elevation showing the relationship

Design (left), and the Ecologies Design Lab (right). 

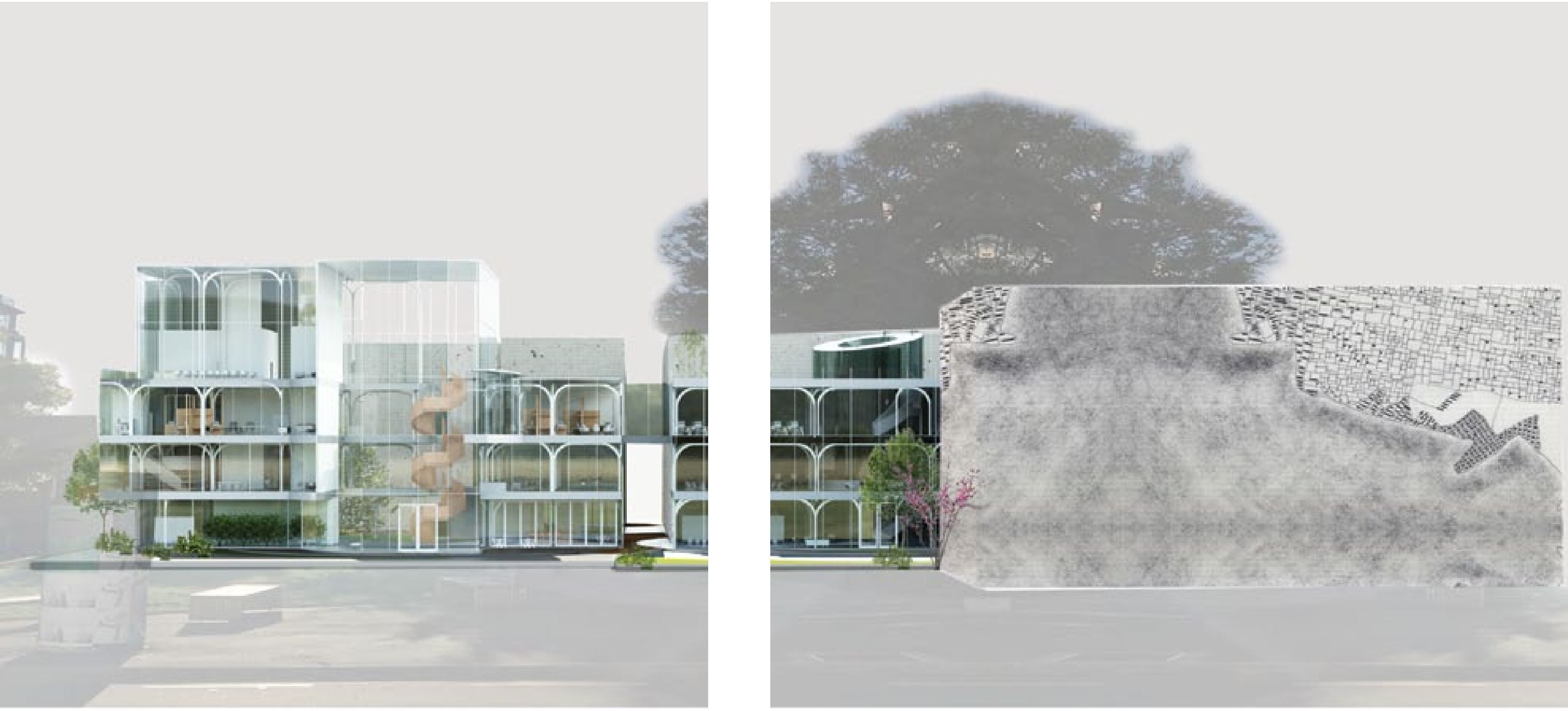

Fig 8.06. West Elevation showing the relationship

between Vivian Street and Wigan Streets to the Ecologies and Design.

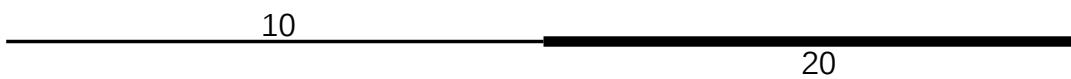



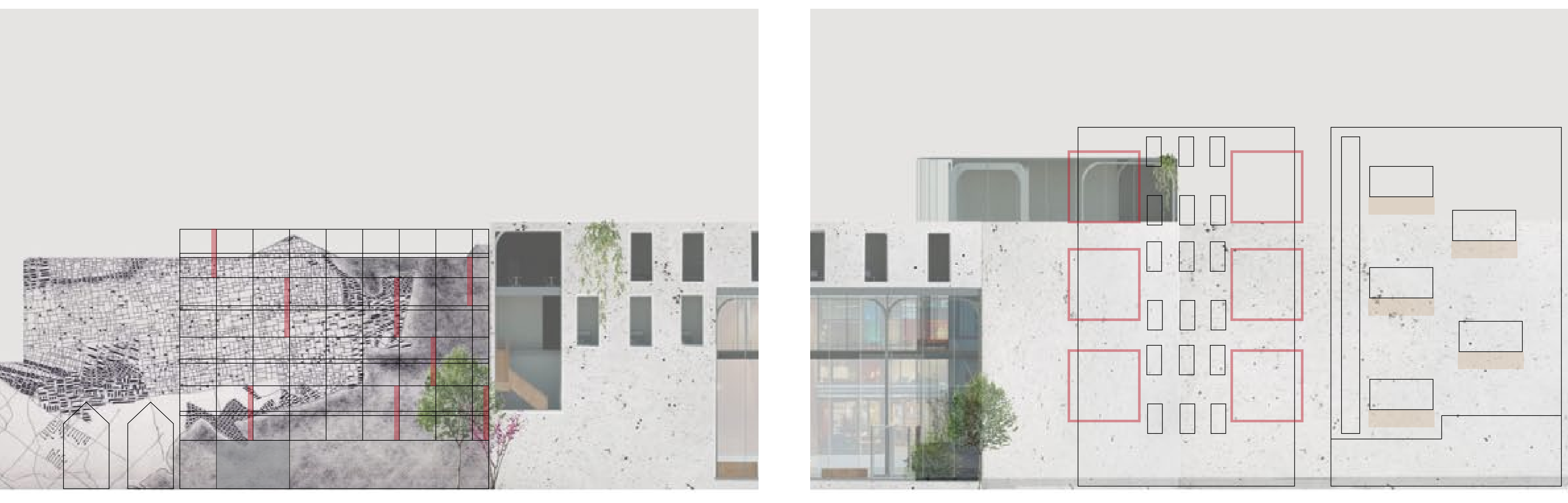

Fig 8.07. East Elevation showing the relationship between Victoria University Faculty of Architecture and Design

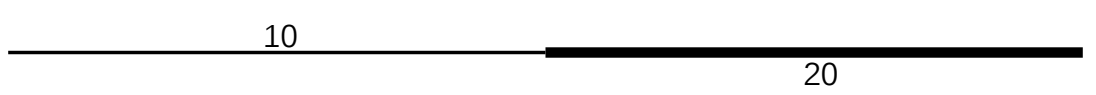



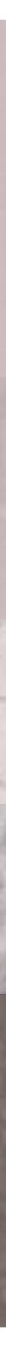

Fig 8.09. Short section through the dialogue space

showing the differing levels. Mezzanine spaces depicted

allow for a larger, informal audience, with the allowance

of the breakout space to be opened up to for when

a larger area of space is needed depending on the 

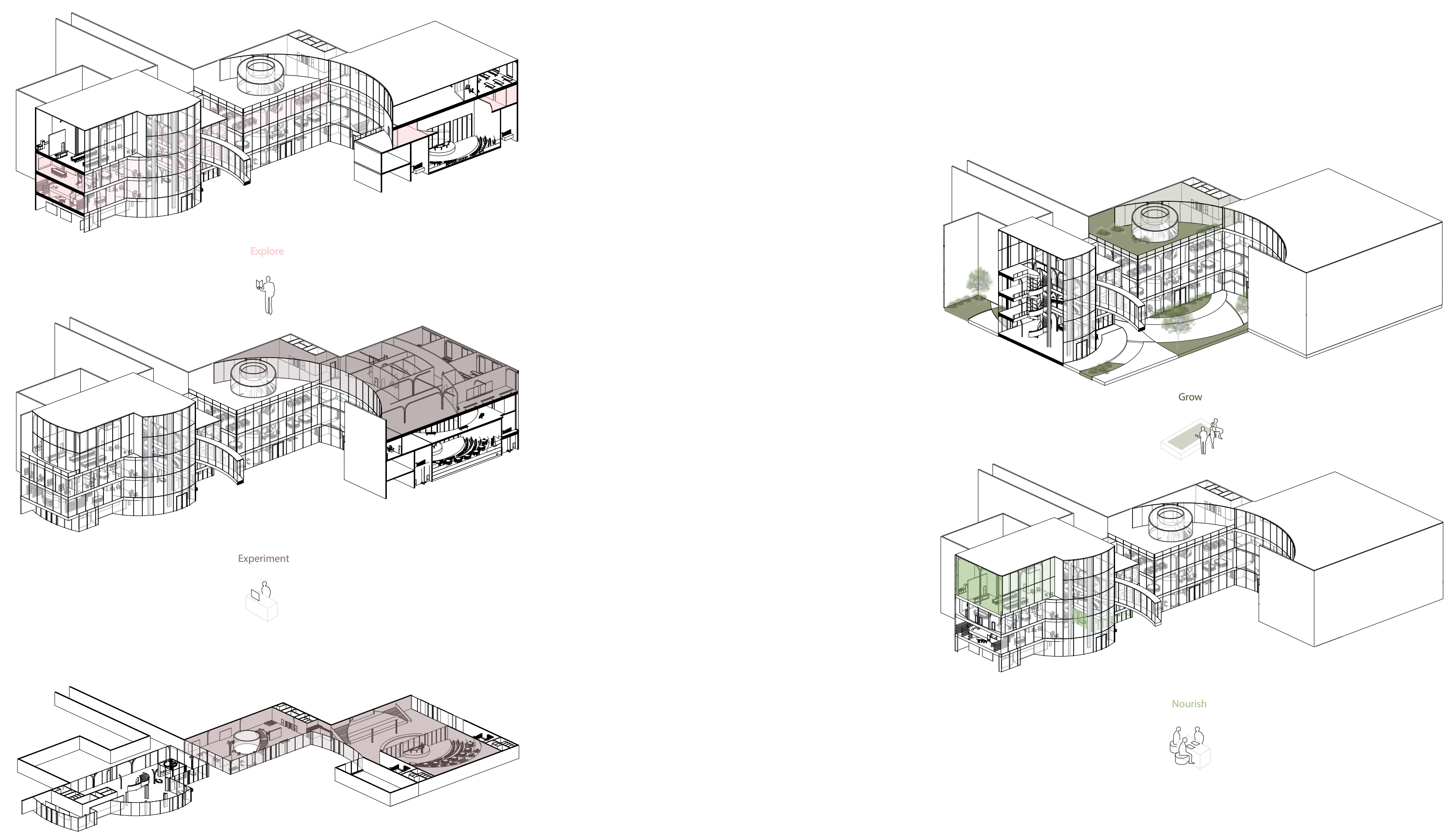

$$
\mathrm{Al}_{4} \text { Dialogue }
$$



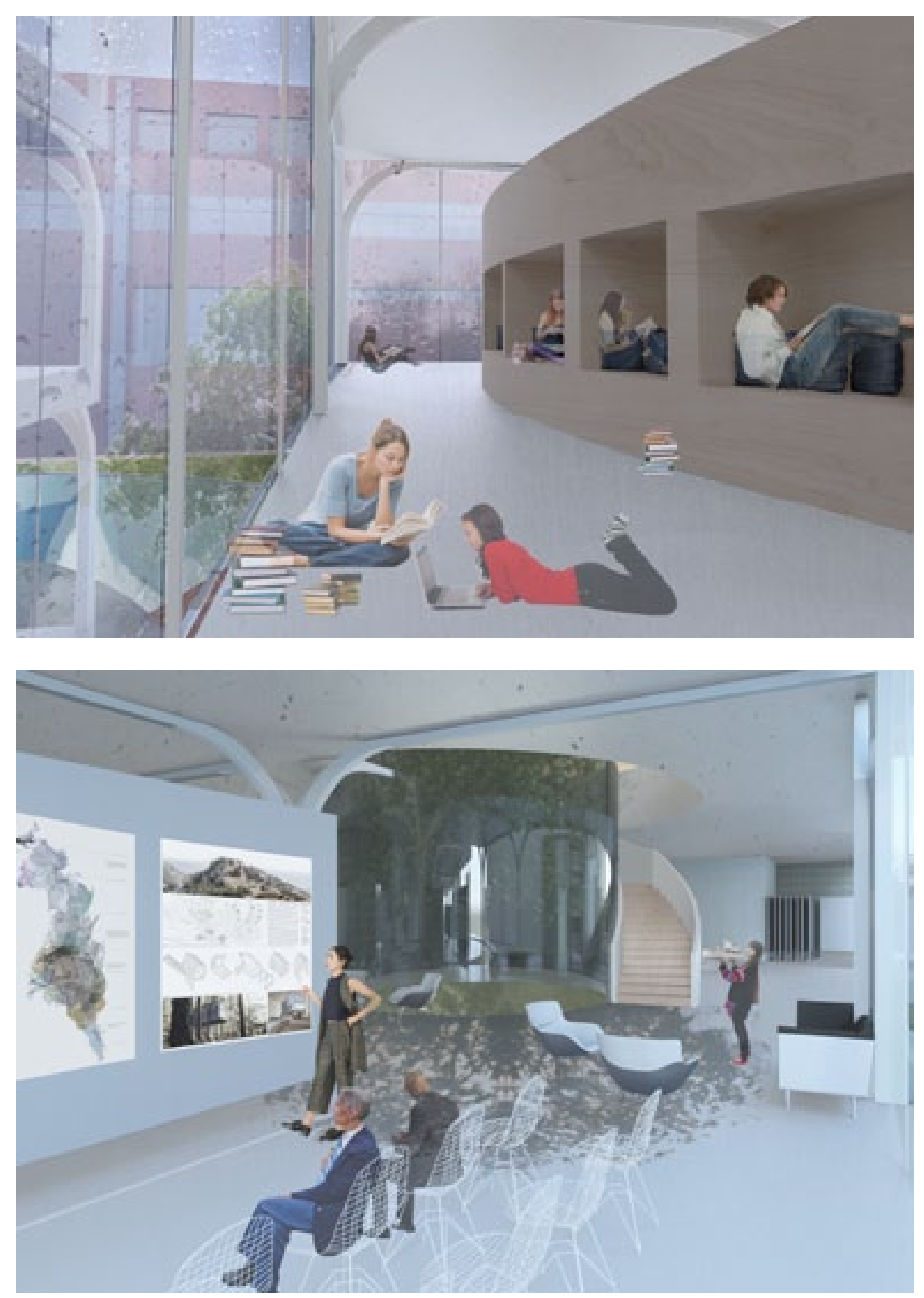

Fig 8.11. Image of the refuge spaces on a rainy afternoon. Referring to the nature of space, and creating spaces which students, professionals and the public can utilise
the spaces to research and study in in a comfortable manner.

Fig 8.12. Presentation spaces illustrate that some confines of any particular site can be used to introduce nature in a creative way. Although these spaces cannot receive an affluence of natural direct sunlight, light channels that are open to the sky are planted
with vegetation not only introduce sunlight but create

atmosphere through shadows and rain. The catchment of rainfall and the changing of lighting qualities allow the naturat systems. 


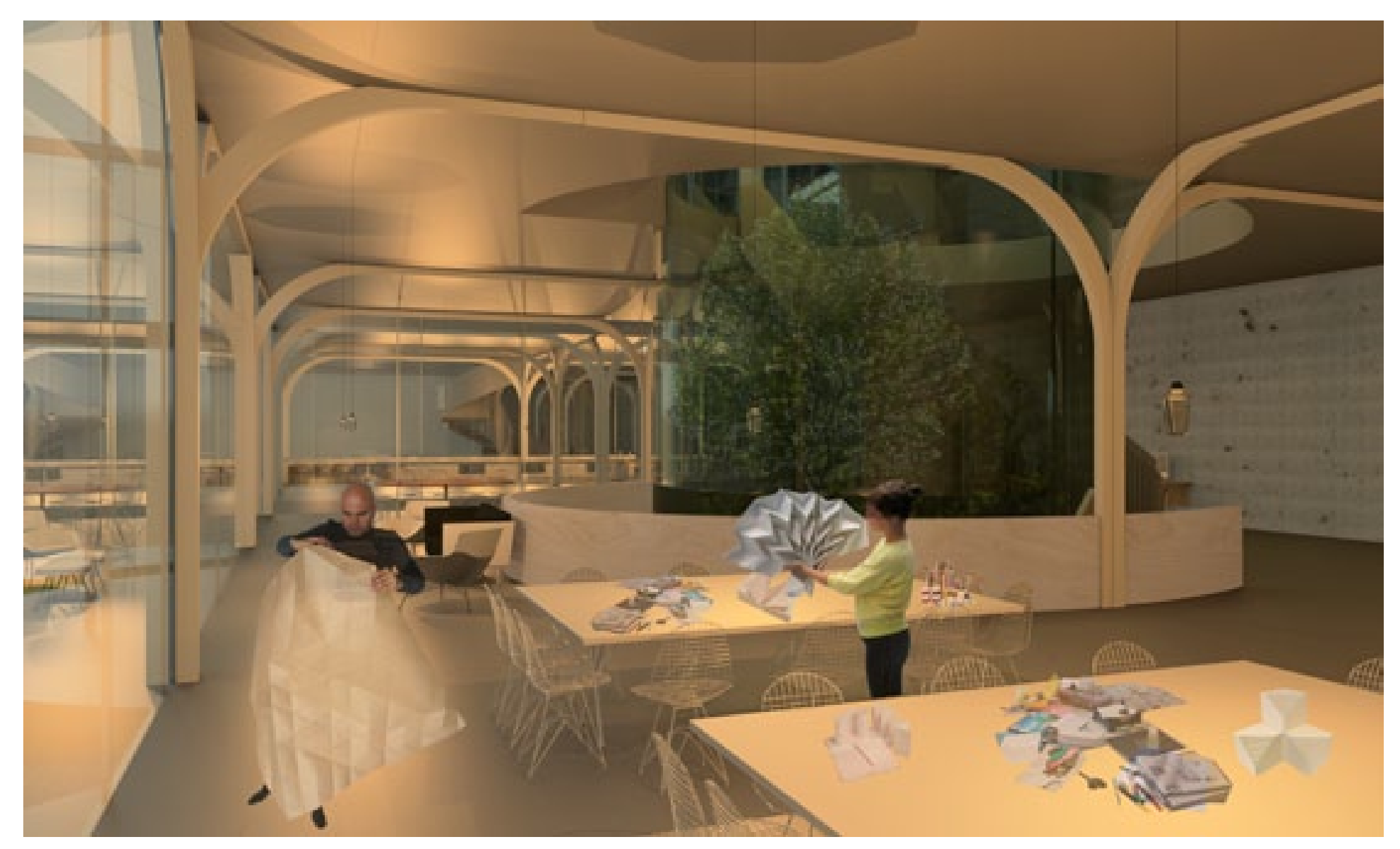

Fig 8.13. Studio spaces depicted in the night highlight

he fluidity of the structural members that work for both

lateral and gravitational loads. 


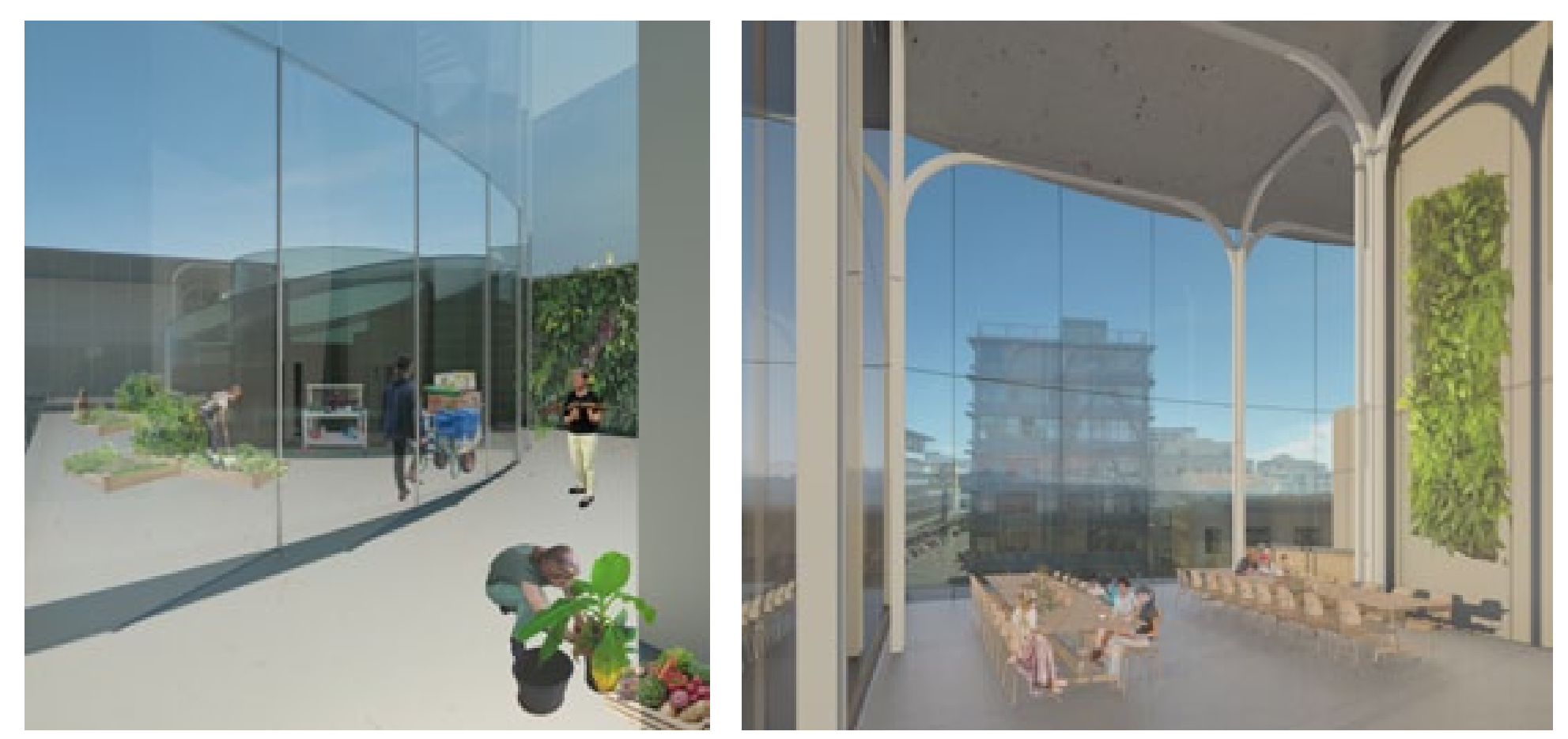

Fig 8.14. Rooftop gardening spaces illustrate the Ecologies Design Lab as a living testing mechanism. Not only is nature researched here, but grown and learnt from. double heighted structural members. As the structure instils a sense

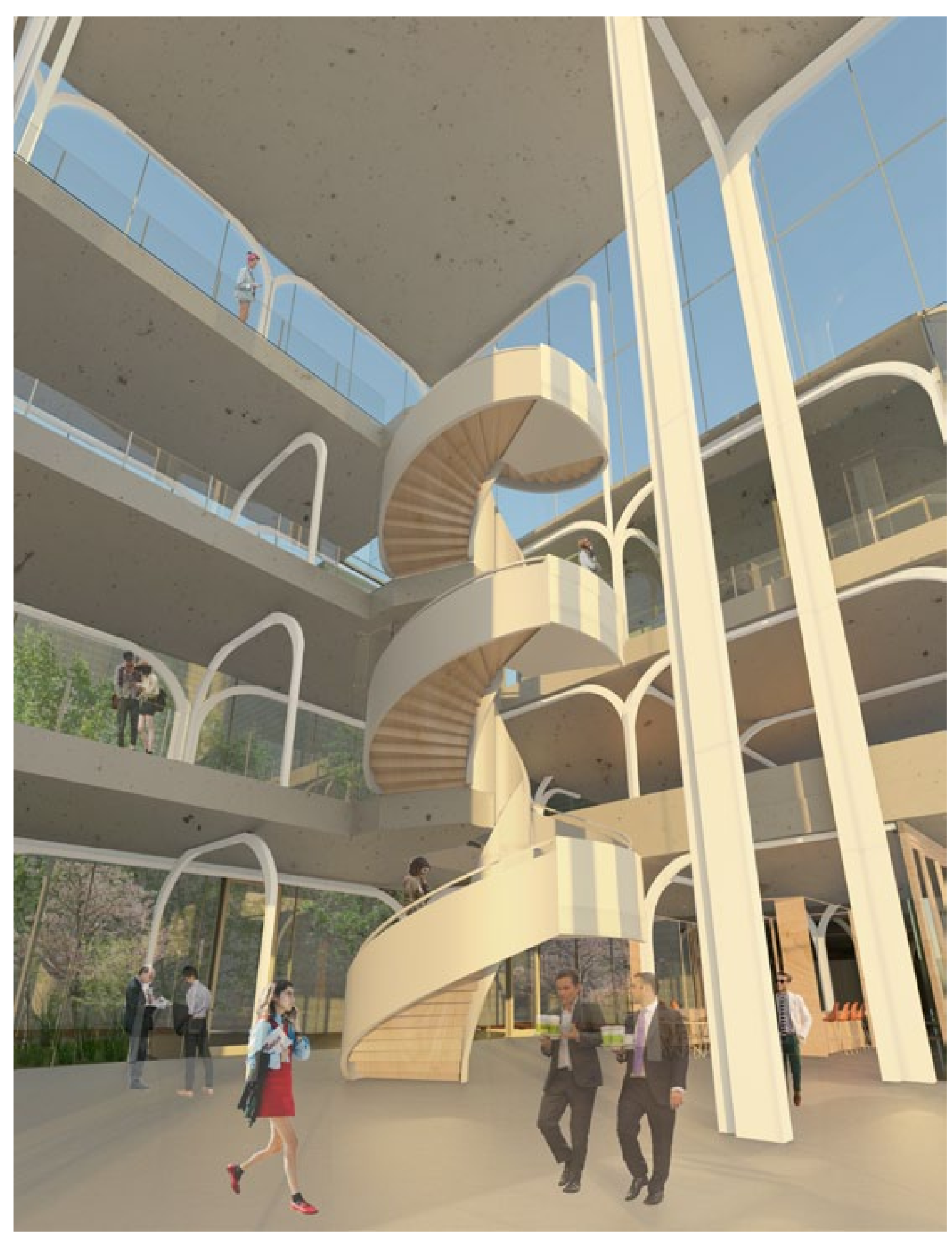

moring light filters into the make their way to work $A$ sense of prospect is created in the moment of pause by the scale of structural members public are invited to share food and dialogue over the long tables with produce they have all joined in growing and researching.

and the fluidity of the staircase. 


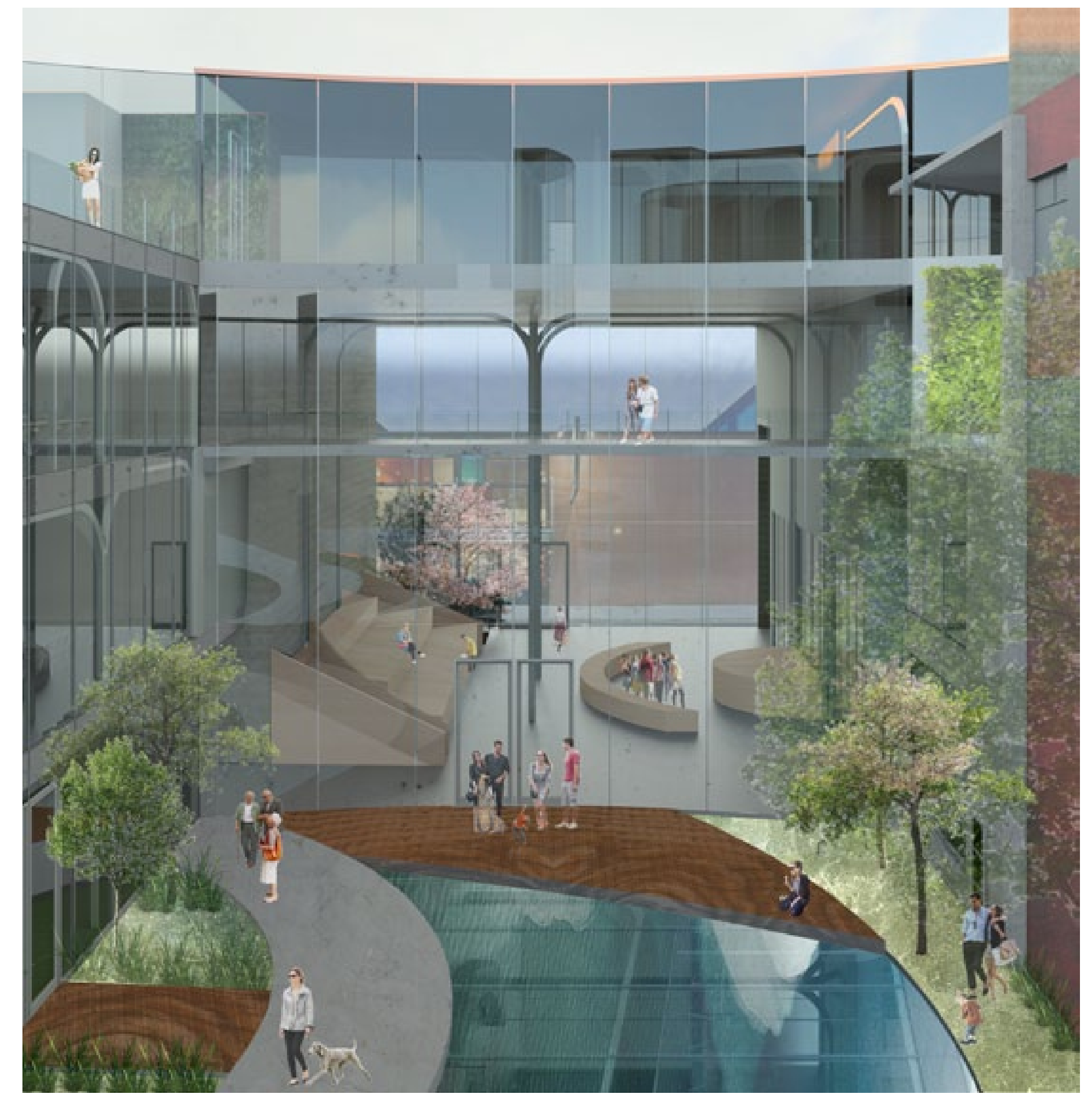

Fig 8.17. Perspective south facing through the Knigges

in Wellington. Holding boutique cinemas and lively

cocktail bars, enticing people through the space opens

opportunity to discover more than the immediate site

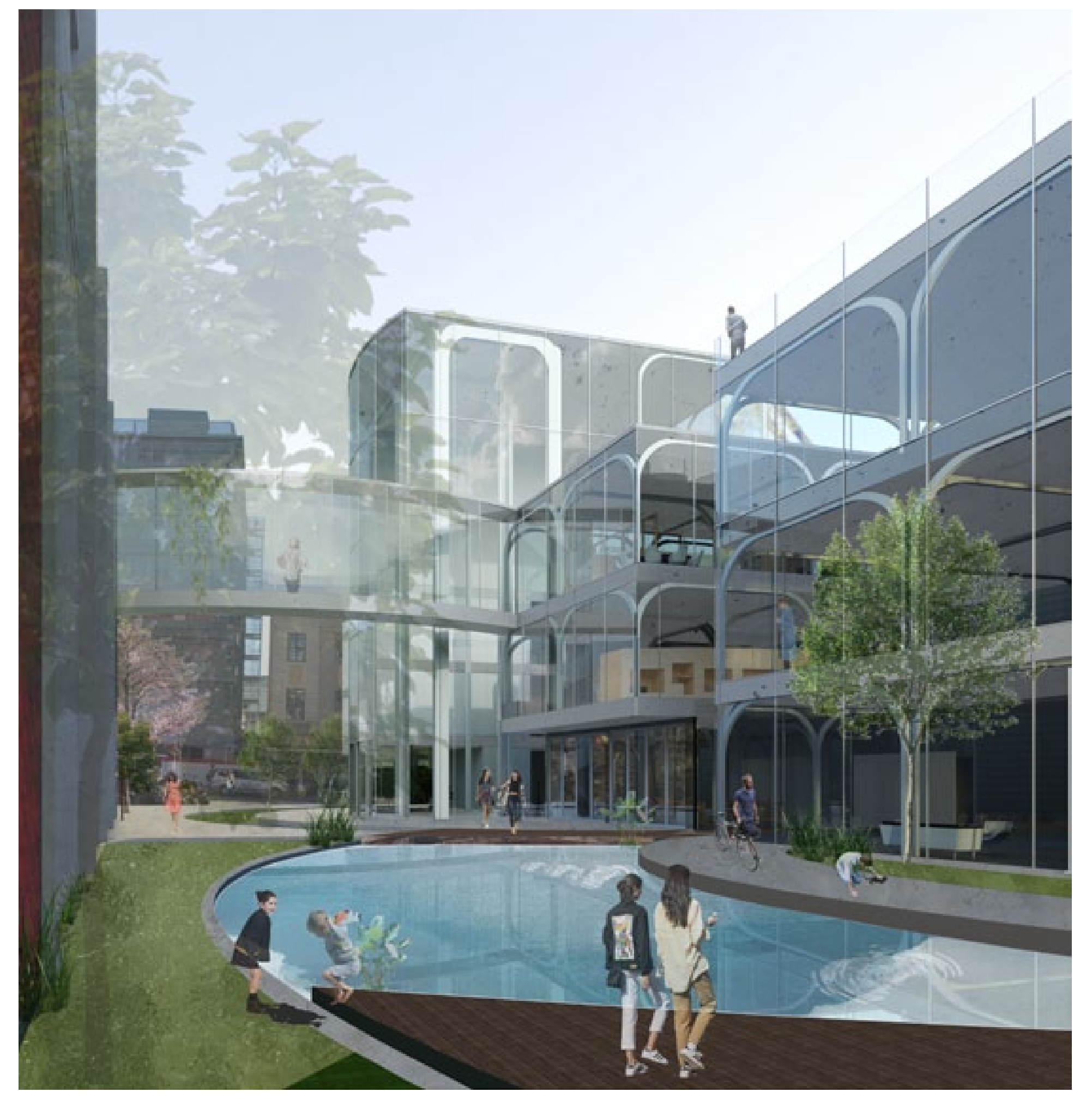

Fig 8.18. Perspective north facing through the Knigges

of people; students, professionals and public, through the

space. Presence of water, greenery and natural materials

relate strongly to nature in a space and are constructed

o instil an echo throughout the wider urban make-up. 


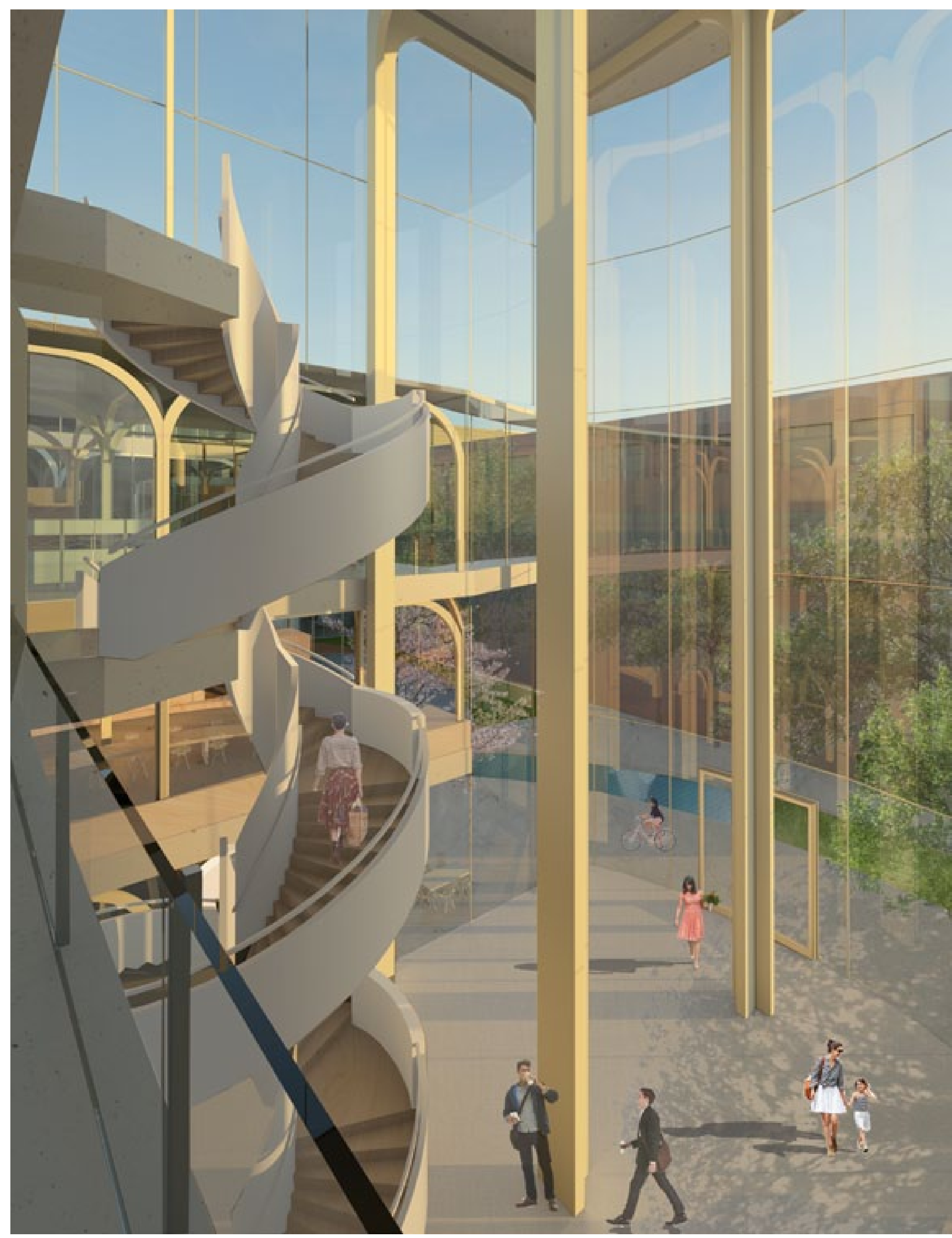


9.0

Findings 
9.1 Discussion

This thesis sets to investigate how design professions ure devoid urbanisation on humans, by designing solutions and cosystems that people evolved within and are a part of. This in turn mitigates and prevents some diseases of the mind, body and soul. As architects, the responsibility held in the treatment and execution of space is

increasingly important as the world's population rapidly of development has happened and is happening rapid rate. Observation of the latest generation of urba workers and dwellers shows the negative effects that separation from nature can have on one's holistic health. Architects and planners have worked in the past under the impression that a synthetic construction of urban environments aid in a positive manner the way in which people live, by protecting them from natural elements. They create road networks that get people places faster the allowance of mass production. What they have in fact done is divorce people from the natural systems human bodies are in accordance with, while leaving the natural environment in a degraded state.

This is why biophilia and biophilic design are important and were utilised as the founding plattorm for this thesis The Ecologies Design Lab is designed for people as

the development of buildings that respect mind-body

systems and highlights the importance of connecting the people with nature. What was found in this thesis was

that biophilic principles paired with the intent to entice

residents and visitors around and through the urban

created. This presumaof -s.avmeditings. The red wraetic cples $2 s$ has throperti some TjT*ts resg solutions 
9.2 Conclusion

By blurring the rigid barriers that define what an architect, do, the allowance for consideration of the human

experience opens up and becomes paramount. As this thesis has established for human holistic well-being to thrive, so too must the natural environment, as well as the connection between the two. A key moment in this thesis is the understanding that there is no differentiation between prioritising the urban dweller or the natural The contribution from this project then is the other. manifestation of the relationship designing with natural concepts (biophilia) holds with the feeling of enticement. People are not going to thrive holistically without nature, and nature will not thrive without the protection of humans from humans. People will not protect nature if they do not care about it or realise its worth, and they will not care about it if they are not enticed to experience its to experience and see, to see is to feel, to feel is to is care leads to protection, and to protect is to prosper in terms of well-being according to biophilic theory.

What was found in this design-led research process is that with the thoughtful placement of even the smalles of positive interventions, a healing echo can be felt throughout the urban environment that can ultimately clear that a shift in perception within the profession of architecture and urban design needs to be maade in order to rebuild the void that has evolved between the natural world and humans in cities, and hence how humans thrive in their local urban environments. Architects need to reconsider how they express and materialise concepts of structures, taking precedent from interior, landscape and urban designers and design profession it is helpful to understand where the each take founding concepts from in order to constuc a well thought and empathetic built environment The harmonious amalgamation in approaches to designing from each discipline then leads to the focusing of creating experiences through time, contrasting to objects in space, and hence anew realisation of how far architecture can aid the healthy progression of human well-being.
The combination of intelligent urban acupuncture and the implementation of unique spatial qualities will als connections and hence change it may seek to achieve. It is important to note for following developments, whether on a national or international scale, to recognise the great effects small interventions can have if implemented in the correct space in an urban setting. For an urban environment to be rejuvenated and thrive, a massive shin in development does not have to take place Paired with biophilic theories, cities around the world $c$ ensure a nurturing environment for their inhabitants, can matter the heritage, values or traditions they hold Health is a universal language, and although techniques and actual appropriateness may differ throughout the world, all theories are based on nature and natural processes.

It is important to foster urban settings that take care of their inhabitants, because humans are the only ones

currently experiencing. If people do not feel completely healthy themselves and do not experience the nurturing effects the natural world can have on them, it is highly unlikely they will feel compelled to take care of it and live in equilibrium with nature. This project shows that architects hold the power to start a positive chain inhabitants. To be open minded and inclusive of how other designers and architects work and draw inspiration from, means the thorough and empathetic output of consideration in the built environment of how humans and nature can prosper together.

Ultimately, if people succeed in this, architects will connect people to a more postive and holistically healing life in the a more positve and hing diseases and 
10.0

Bibliography 


\section{1 - Works Cited}

Affairs, U. N. D. o. E. a. S. (2015). World Population Prospects. Retrieved from http://www.un.org/ 1/development/desa/publications/world-population-prospects-2015-revision.html (Accessed

Alcock, I. (2014). Longitudinal Effects on Mental Health of Moving to Greener and Less Green

Barnaby Bennett, E. B., Irene Boles. (2012). Christchurch: The Transitional City Pt IV (Vol. 1, pp. 223). Freerange Press: Rainbow Print

Beatley, T. (2017). Biophilic Cities. Retrieved from http://biophiliccities.org/ (Accessed

Brown, S. (2010). Play: How it shapes the brain, opens the imagination and invigorates the soul. New York: Penguin.

Browning, W. Ryan, C. Smith, C. Clancy, J. (2014). 14 Patterns of Biophilic Design. Terrapin Brigh Green. New York. LLC.

Bryant, M. (2007). Modern Ecologies: Urban Ecology and Urban Design. Paper presented at the Smaller City Centres, Tauranga, New Zealand.

Bum-Jin Park, Y. T., Tamami Kasetani, Takeshi Morikawa, Takahida Kagawa. (2009). Physiological Effects of Forest Recreation in a Young Conifer Forest in Hinokage Town, Japan. Silva Fennica, 43(2), 291-301.

Caan, S. (2011). Rethinking Design and Interiors; Human Beings in the Built Environment: Laurence King Publishing.

Chambliss, K. M. (2013). Beholding Nature: Contemplation and Connectedness. (Liberal Arts), Prescott University, UMI Dissertation Publishing

Christian Martin, S. C. (2016). The extended Inclusion of Nature in Self Scale. Journal of Environmental Psychology, 14.

Clements-croome, D. (2006). Creating the productive workplace. New York: Taylor \& Francis.

Debord, G.E. (1958). Theory of the Dérive. Retrieved from http://library.nothingness.org/articles/ SI/en/display/314 (Accessed 13/05/2017)

Gallagher, W. (1993). The Power of Place: How Our Surroundings Shape Our Thoughts, Emotions, and Actions. New York, NY: Simon and Schuster, Inc.

Heerwagen, J., Kellert, S. R., Mador, M., \& Ebooks, C. (2008). Biophilic design : the theory, science, and practice of bringing buildings to life / edited by Stephen R. Kellert, Judith $\mathrm{H}$. Hoerwagen Martin L Mador. Hoboken, N.J. Hoboken, N J. : Wiley.

Kaplan, R. (1998). With People in Mind, Design and Management of Evertday Nature: Island
Kaplan S. (1995). Book review -- The Biophilia Hypothesis edited by Stephen R. Kellert and Edward O. Wilson (Vol. 27. pp. 801) Thousand Oaks: SAGE PUBLICATIONS, INC

Kaveh Samiei, T. (26 May 2013). Architecture and Urban Ecosystems: From Segregation to Integration. The Nature of Cities. Retrieved from https://www.thenatureofcities.com/2013/05/26/ architecture-and-urban-ecosystems-from-segregation-to-integration/ (Accessed (11/07/2017)

Kemp, M. (2006). Seen/unseen : art, science, and intuition from Leonardo to the Hubble telescope. Oxford; New York Oxford University Press.

Kenny Cupers, M. M. (2002). Spaces of Uncertainty: Müller und Busmann.

Lerner, J. (2014). Urban acupuncture / Jaime Lerner. In Ebscohost (Ed.): Washington, DC : Island Press.

Linda Steg, A. E. v. d. B., Judith de Groot. (2007). Health Benefits of Nature. Environmenta Psychology: An Introduction, 47-56. BPS Blackwell Textbooks

Louv, R. (2005). The Last Child in the Woods. USA: Workman Pubblishing Company

Madsen, M. V. (2009). Acupuncture treatment for pain: systematic review of randomised clinical trials with acupuncture, placebo acupuncture, and no acupuncture groups. BMJ 2009;338:a3115.

McEwan, A. (2011). Holistic Health Factors in the Workplace. Arizona State University, Arizona, USA

Melville, S. (2005). The lure of the object. New Haven: Williamstown, Mass. : Sterling and Francine Clark Art Institute; New Haven : Distributed by Yale University Press

Mies, P. v. (2013). Elements of Architecture. From form to place + tectonics (2 ed.). Oxford: Routledge. Taylor Francis Group.

Miessen, K. C. a. M. (2002). Spaces of Uncertainty. Retrieved from http://www.studiomiessen com/spaces-of-uncertainty-2/ (Accessed 06/07/2017)

Muller, B. (2009). Narrating Urban Acupuncture[s]. Vienna: University of Applied Arts Vienna.

Olmsted, F. L. (1865). Yosemite and the Mariposa Grove: A Preliminary Repot. Retrieved from Washington, D.C:

Pedersen Zari, M. (2017). Wellington Nature in the City Map. Retrieved from http://vuw.maps. arcgis.com/apps/MapJournal/index.html?appid=2d50a148a59748a99de1830a3122d950 (Accessed 16/03/2017)

Pedersen Zari, M. P. (2009). An architectural love of the living: Bio-inspired design in the pursuit of ecological regeneration and psychological well being. Sustainable Development and
Planning IV 293-302. 
Pedersen Zari, M. P. (2017). What makes a ciy 'biophilic'? Observastions and experiences from the Wellington Nature Map project. Paper presented at the Back to the Future; The next 50 years, Wellington, New Zealand.

Phillip White, S. B., Louise St, Pierre. (2009). Learning ecological design. Okala, 2nd Ed.

Psarra, S. (2008). Architecture and Narrative. The formation of space and cultural meaning. Abington, Oxford: Routledge.

Qian, C. S. S. (2011). "Urban Acupuncture" Strategy in the Urban Renewal. Paper presented at (

Salingaros, N. A. (2013). Unified architectural theory : form, language, complexity. Portland Oregon: Sustasis Foundation

Schultz, P. W. (2002). Inclusion with Nature: The Psychology Of Human-Nature Relations. Psychology of Sustainable Development.

Sola-Morales, M. d. (2008). A Matter of Things. Rotterdam: NAi Uitgevers.

Souter-Brown, G. (2014). Landscape and Urban Design for Health and Well-Being. Florence UNKNOWN: Taylor an

Souter-Brown, G. (2014). Landscape and Urban Design for Health and Well-Being.

Sternberg, E. M. (2009). Healing Spaces. USA: Harvard University Press.

Trancik, R. (1986). Finding lost space : theories of urban design. New York: Van Nostrand

University, R. (2017). New Academic Street. Retrieved from https://nas.rmit.edu.au/about/aboutnew-academic-street/ (Accessed 15/07/2017)

Xile, C. S. N. (4-10 Dec 2010). "Urban Acupuncture" Based on Digital Technology. Paper presented at the Information Science and Engineering (ICISE) Hangzhou, China. 
10.2 - Sources of Firgures

\section{$\mathrm{CH} 1.0$}

Fig 1.01

to nature

Source: Authors collection

Fig 1.02.

Digram of scope

ors collection

Fig 103

Collage of organic forms in humans, nature and built

Source: Accessed 01/07/2017 https://www.pexels.com/ search/plant/

Fig 1.04 .

Methodology diagram

\section{$\mathrm{CH} 2.0$}

Fig 2.01.

Source: Authors collection

Fig 2.02

Wellington situation analysis

Source: Authors collection

\section{Fig $2.03,2.04, \& 2.05$.}

Source: Authors collection adapted from http://vuw.

maps.arcgis.com/apps/MapJournal/index.html?appid=2

Accessed 20/03/2017

Fig 2.06 .

Map of Taranaki Street, Wellington

Source: Authors collection

Fig 2.07.

pathways through proposed site

Source: Authors collection

Fig 2.08.

Transect walk photographs/ situation analysis

Source: Authors collection
Fig 2.09

aranaki Street transect in relation to biophilic

Source: Authors collection

\section{$\mathrm{CH} 3.0$}

Fig 3.01, 3.02 \& 3.03 .

14 Patterns of biophilic design. Nature in Space, Natural

Analogues \& Nature of Space

Source. Authors collection adapted from Browning et al.

$\mathrm{CH} 4.0$

Fig 4.01

Initial Taranaki Street iteration

Source: Aurthors collection

Fig 4.02.

Initial Taranaki Street perspective

Source: Aurthors collection

Fig 4.03

in Wellington

Source: Aurthors collection

\section{$\mathrm{CH} 5.0$}

Fig 5.01

Biophilic nodes in Wellingto

Source: Authors collection

Fig 5.02 .

Spatial characteristics of enticement

Source: Aurthors collection adapted from.

https://es.paperblog.com/ar/delicias-kasuyosejima-y-los-apartamentos-okurayama-en-

https://www.moma.org/

https://arcspace.com/feature/the-new-york-timesbuilding/

Accessed 17/04/2017 
Fig 5.03

Spatial characteristics of enticement

Source: Aurthors collection adapted from
http://www.berliner-mauer-gedenkstaette.de/en/chapelof-reconciliation-216.html

https://www.flickr.com/photos/lichtschaffen/8545243459/ in/set-72157631860103134

http://www.bestinteriordesigners.eu/top-interior-

designers-kelly-wearstler/

\section{Accessed 17/04/2017}

Fig 5.04 .

Programme diagram

Athors collectio

Fig 5.05 .

Positioning image

Source: Authors collectio

Fig 5.06.

Programme inclusion diagram

Source: Authors collection

Fig 5.07 .

Disciplinary scheme

Source: Authors collection

\section{$\mathrm{CH} 6.0$}

Fig 6.01.

Source: Authors collection

Fig 6.02

Pedestrian movements and links diagram

Source: Authors collection

Fig 6.03 .

Design iteration 2 sketch

e: Authors collection

Fig 6.04

Precedent study Institute of Forestry and Nature Reseach in the Netherlands

Source: http://behnisch.com/work/projects/0022

Accessed 23/07/2017
Fig 6.05

iteration 2 sketch, interior vs. exterio

Source: Authors collection

Fig 6.06

Precedential study RMIT University

Source: Accessed 26/07/2017

https://nas.rmit.edu.au/new-precincts/arcades-and-

Fig 607.

Precedential study Bawa gardens

Source: Accessed 27/07/2017

http://www.geoffreybawa.com/lunuganga-country-

estate/virtual-garden-tour

Fig 6.08

Design iteration 3 perspective

Source: Authors collection

Fig 6.09

Design iteration 3 entrance gallery

Source: Authors collection

Fig 6.10 .
Design iteration 3 dialogue space

Source: Authors collectio

Fig 6.11.

Design iteration 3 studio space

Source: Authors collection

Fig 6.12

Design iteration 3 laneway

Source: Authors collection

Fig 6.13

iteration 3 instilment of risk and peril

Source: Authors collection

Fig 6.14

Design iteration 3 bridge perspective

Source: Authors collection 
Fig 7.01.

Ripples of well-being

Source: Aurthors collection

\section{Fig 7.02 .}

Precedential study "The Nest We Grow"

Source: Accessed 08/09/2017

https.//www.archdally.com/392660/nest-we-grow-

college-of-environmental-design-uc-berkeley-kengo-

Relating to climate and ecology section

Source: Authors collection

Fig 7.04

Perspective of sun analysis

Fig 7.05 .

Pource: Authors collection and accessed 11/10/2017

https.//www.archdaily.com/642612/living-staircase-paul-

https://www.archdaily.com/508936/swedbank-3xn

Fig 7.06

Precedential study on structural members

Source: Accessed 11/10/2017

https://www.archdaily.com/43090/the-tote-serie-

architects

https://www.designboom.com/architecture/shigeru-baneinventer-paris-proposal-sully-morland-02-29-2016/

Fig 7.07.

Precedential study on structural members

https://www.archdaily.com/611186/bishop-edward-king-

chapel-niall-mclaughlin-architects
Fig 8.01.

map Source: Authors collection

8.02.

Final design second floor plan

Source: Authors collection

Final design thrid floor plan

Source: Authors collection

8.04.

Final design fourth floor plan

Source: Authors collection

Source: Authors collection

8.06.

West elevation

Source: Authors collection

8.07.

Source: Authors collection

8.08.

ong section

Authors collection

8.09 .

Short section

Source: Authors collection

8.10.

ice: Authors collection

8.11.

Refuge spaces

Source: Authors collection

Presentation spaces

Source: Authors collection 
Fig 8.13 .

Studio spaces

Source: Authors collection

Fig 8.14 .

Rooftop gardens

Source: Authors collection

Fig 8.15 .

Shared nourishment spaces

Source: Authors collection

Fig 8.16.

Source: Authors collection

Fig 8.17 .

Knigges Avenue pedestrian walkway

rs collection

Fig 8.18 .

North facing Knigges Avenue pedestrian walkway

Source: Authors collection 

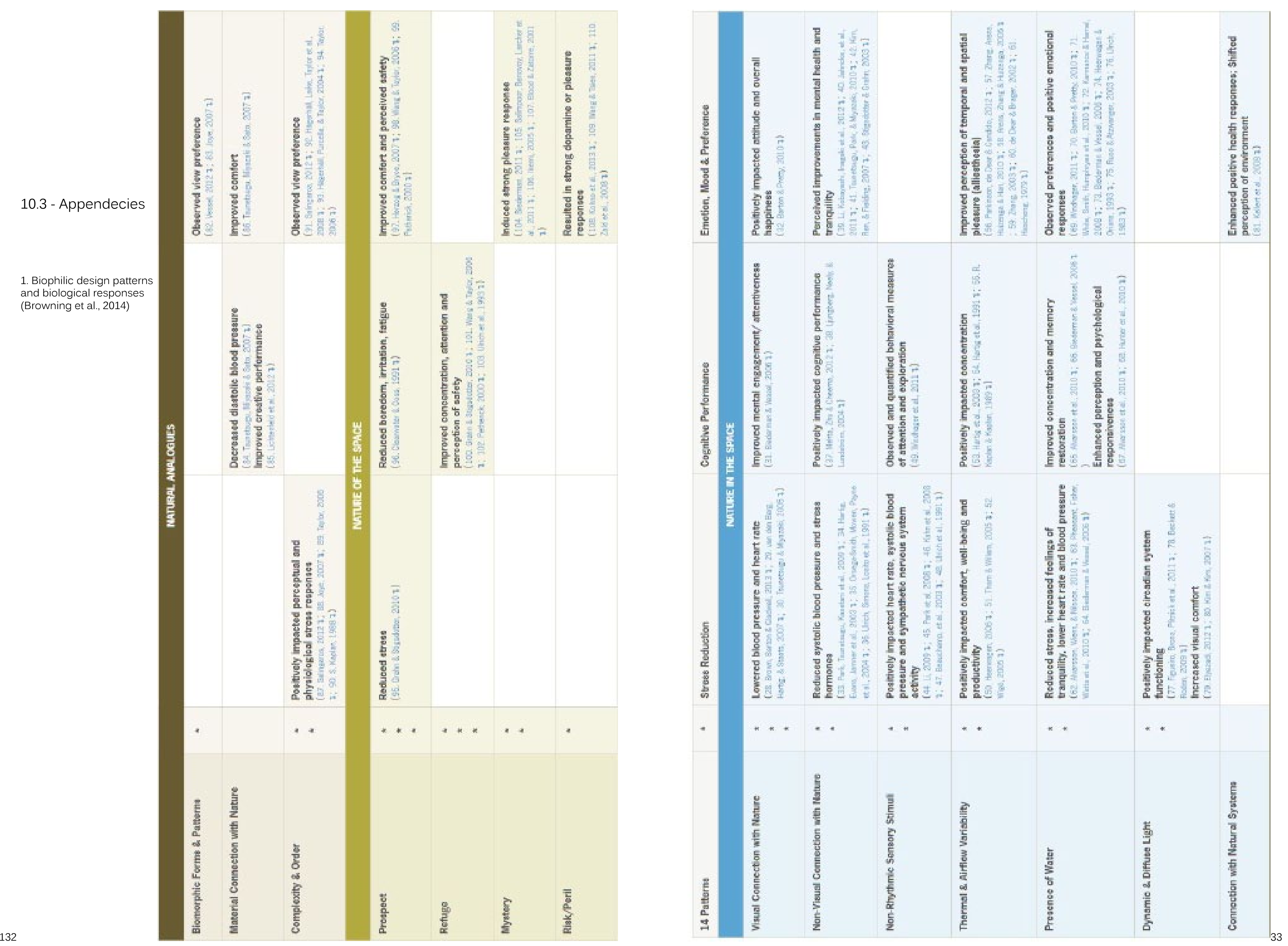
2. Additional four original spatial characteristics of enticement
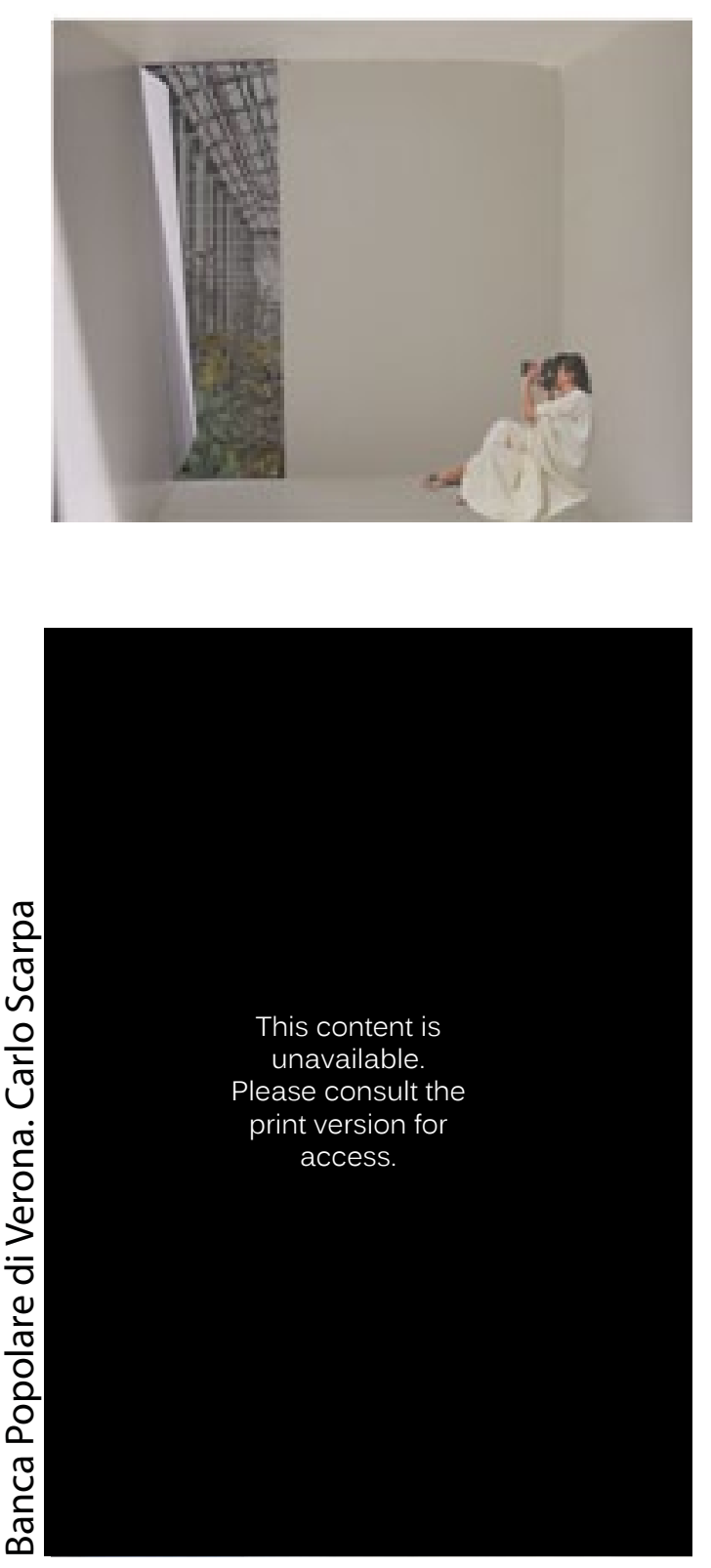

2. Extended Walls (Narrative). Relating to the continuation of space immediate existing space (Muller 2009).
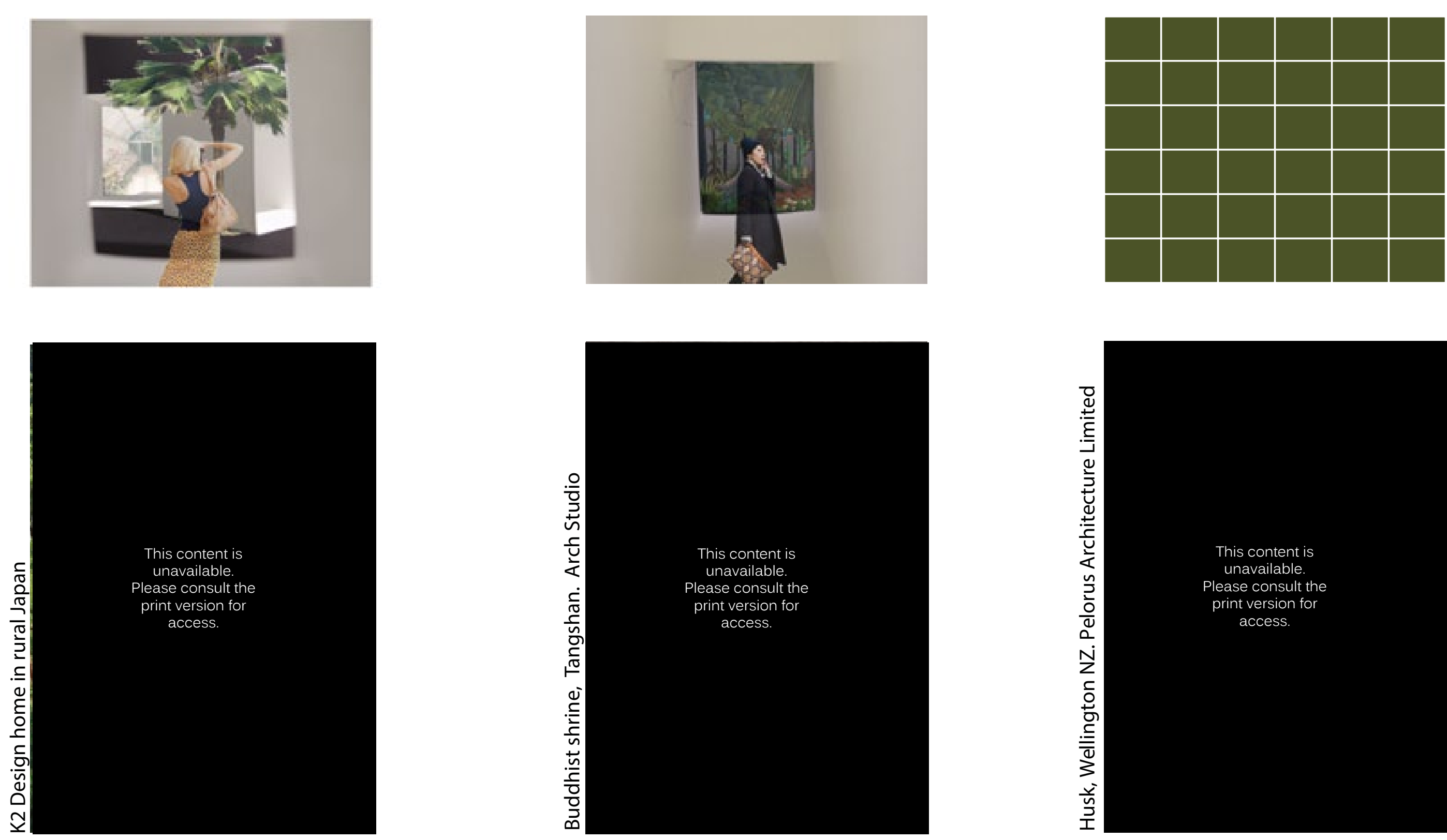

Anticipation (Biophilia). Creating architectural spaces that are able to be again relates to our subconscious need to uncover mystery as a sense of reward (Browning et al., 2014) protected by 3 or more sides of our being

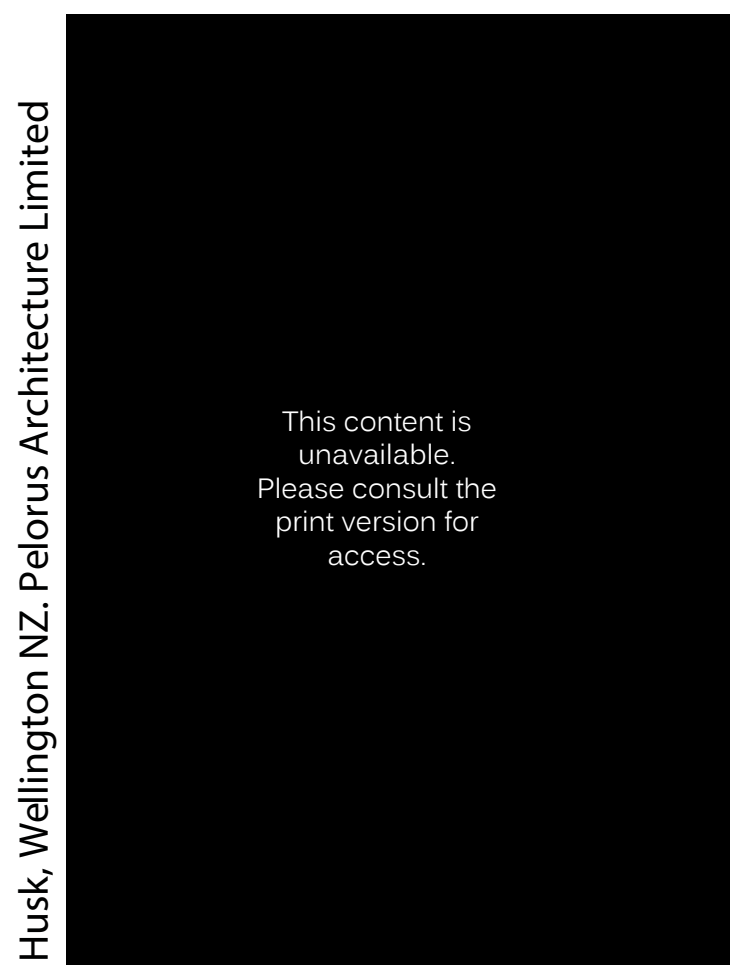

0. Scent (Biophilia). Relating to other senses in the body other than sight, is preferable to our non-visual connection with nature. Projections and presence of scents with positive correlations brings feeling of being balanced and fresh. The scents can be perceived as complex and variable however at the same time familiar and comfortable depending on the person experiencing them (Browning et al., 2014)
9. Lowered Ceiling (Biophilia). Compression of architectural spaces withdrawal meaning the subconscious reasoning that we are safe if we are closely Refuge spaces feel protective however no disengaging. (Browning et al., 2014) 

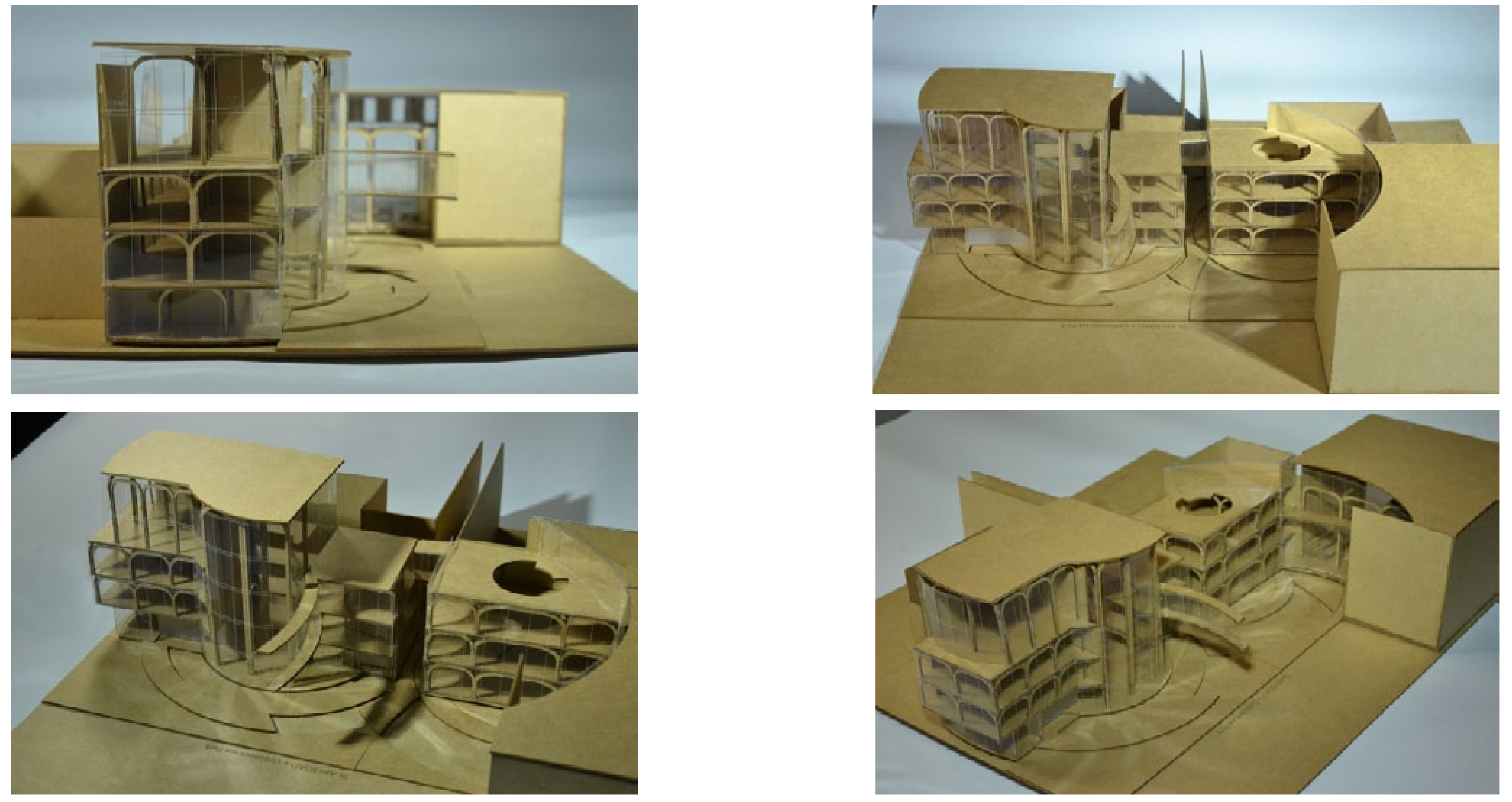

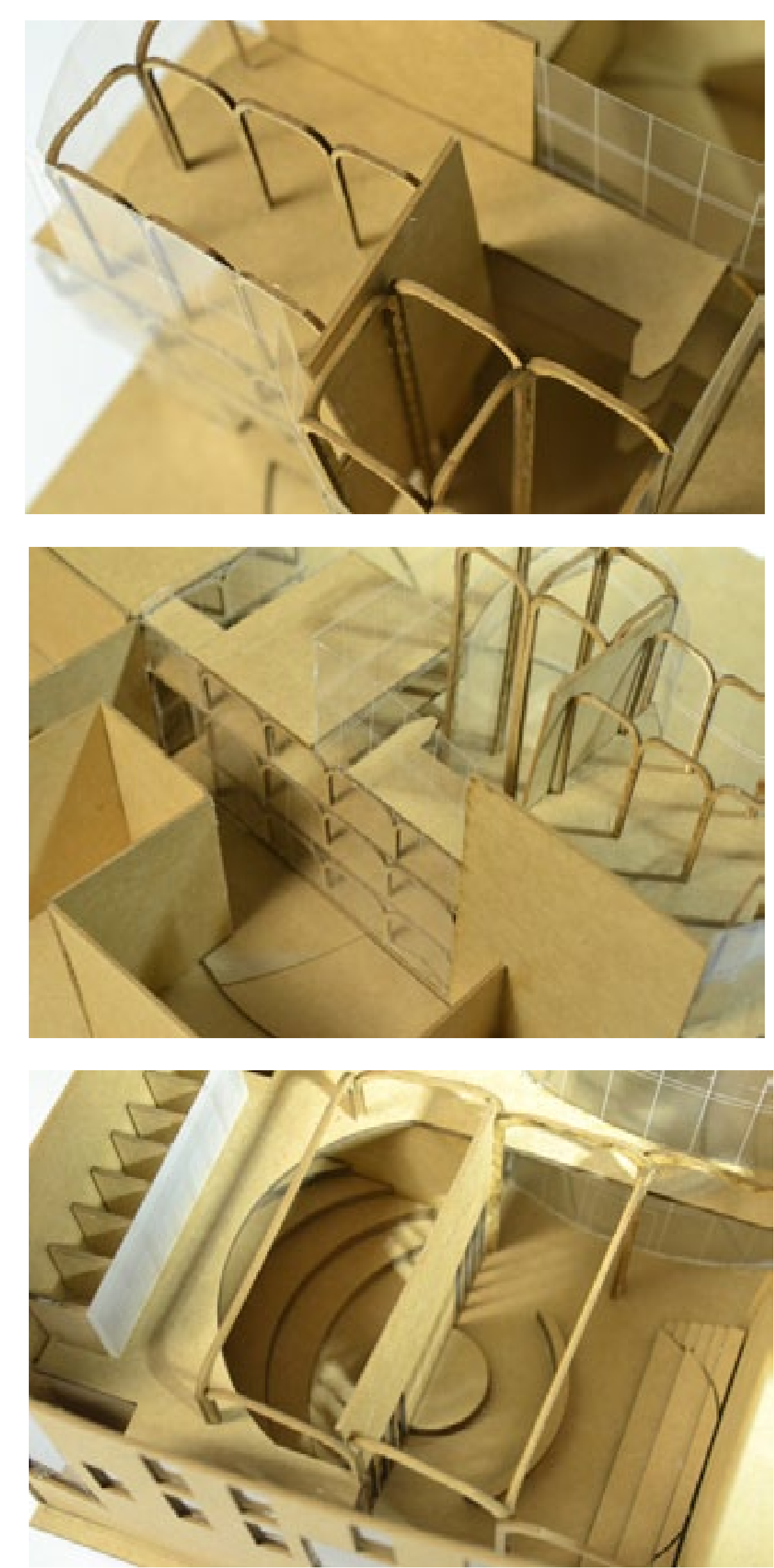
